\title{
La fortaleza de La Iruela (Jaén)
}

\author{
Vicente Salvatierra Cuenca
}

\begin{abstract}
RESUMEN
En el presente trabajo se analiza en profundidad la fortaleza de La Iruela (Jaén). Ubicada en las proximidades de Cazorla, la importancia de esta última localidad ha hecho que este interesante lugar pase casi desapercibido. No obstante, presenta algunas características y posibilidades de investigación arqueológi$\mathrm{ca}$, que lo convierten sin duda en un prototipo de las fortificaciones en pequeñas poblaciones que potenciaron los almohades, posiblemente en colaboración con las pujantes de comunidades campesinas.
\end{abstract}

PALABRAS CLAVE: Arqueología, almohade, fortificación, al-Andalus

\section{INTRODUCCIÓN}

El presente estudio es una primera aproximación a la fortaleza de La Iruela. Este trabajo se realizó como paso previo a la elaboración de una Ficha Técnica detallada que sirviera de base a un Plan Director de las Actuaciones: consolidación de las zonas en mayor peligro de derrumbe, excavación de las zonas principales, con recuperación del imponente aspecto que debió tener, restauración de lienzos, reconstrucción del complejo sistema de acceso, etc. Todo lo cual realzaría la fortaleza y permitiría profundizar en su puesta en valor, en una zona ya de alto interés turístico.

La fortaleza, en avanzado estado de ruina, ha sido objeto en el pasado de algunos intentos de puesta en valor que permiten en la actualidad acceder a ella, y recorrer algunas zonas. No obstante el estudio efectuado demuestra que

\begin{abstract}
This paper offers an in-depth analysis of the fortress of La Iruela (Jaén, Andalusia). Because of the greater importance of the nearby town of Cazorla, La Iruela has always gone almost unnoticed. However, the fortress is a good example of the type of fortification that the Almohads promoted in small towns, probably with the co-operation of the local peasant communities. For this reason, the fortress clearly constitutes an important archaeological site which deserves greater attention and research.
\end{abstract}

KEY WORDS: archaeology, Almohad, fortress, alAndalus

su interés es considerablemente mayor del que puede observarse hoy, o deducirse de los escasos estudios que se le han dedicado.

La complejidad de sus elementos defensivos -murallas, accesos, puertas en codo-, el interés de algunas de las piezas arquitectónicas que contiene, como la iglesia, y la aparente importancia del relleno arqueológico existente, apuntan todos a que se trata de una fortaleza relevante. La falta de estudios se debe sin duda al lugar que ocupa y sobre todo a que ha sido eclipsada por otros lugares de la zona, y por la mayor fama que rodea a Cazorla.

\section{SITUACIÓN}

La fortaleza de La Iruela es posiblemente el origen de la población del mismo nombre. Se ubica a un kilómetro al noreste de Cazorla, 
dentro del sistema montañoso compuesto por las sierras de Segura, Cazola y Quesada, situado al Este de la provincia de Jaén, relativamente próxima a las fuentes del río Guadalquivir. Ocupa las estribaciones inferiores del Cerro Escribano, extendiéndose por varias terrazas, y protegida en el lado Este por el arroyo que proporcionaba -y aún proporciona- agua abundante a la localidad, y cuya actividad erosiva generó un barranco y la gran peña que caracteriza hoy a la población, con precipicios de entre 40 y 80 m. (Fig. I; Lám. I).

\section{LA IRUELA EN LA EDAD MEDIA}

No conocemos el origen de esta población, aunque no puede descartarse que hubiera una pequeña aldea (qarya) ubicada en el propio promontorio rocoso surgida en época tardoantigua o a principios de la época islamica. Pero por el momento, los datos arqueológicos no permiten remontar la ocupación más allá del periodo almohade.

Por otro lado no aparece, que sepamos, citada en las fuentes árabes. Las primeras noticias escritas que poseemos sobre este lugar son de la época de la conquista, a partir de |23| cuando la ocupó Don Rodrigo Ximénez de Rada, arzobispo de Toledo. Juan de Mata Carriazo considera que es la localidad que aparece bajo los nombres de El Eruela, Areola, Theruela y Arcola, lugares que se citan en diplomas del obispado de Toledo durante el siglo XIII, y que posiblemente son las distintas interpretaciones escritas que los castellanos hicieron de su nombre árabe, que como hemos indicado es desconocido.

Según los elementos hoy visibles, la población presenta tres grandes fases. Entre finales del siglo XII y principios del XIII, los almohades levantarían el grueso de las fortificaciones de lo que hoy se considera el castillo (Fig. 2, RA). Aunque J. Eslava (1999) considera que puede haber una fase más antigua, "probablemente prebereber, que correspondería a los vestigios de grandes mampuestos observables en diversas partes", la cronología de los mismos no está clara.
Después de la conquista comenzaría la transformación de la ocupación del lugar. Los antiguos recintos almohades se convirtieron en el castillo señorial, y quizá se reforzarían algunos lienzos de su muralla, mientras que la población campesina se ubicaba al exterior de la fortaleza (Fig.2; RE, RI). Pero poco más debió hacerse, ya que muy pronto se inició una larga época de decadencia para La Iruela, cuando el 23 de noviembre de 1256 el infante Don Sancho de Castilla, arzobispo de Toledo, la entregue como aldea de Cazorla. Esta última se convertirá progresivamente en el centro político, económico y militar de la región, sobre todo cuando en 1333 pase a ser capital del Adelantamiento, y ello tuvo que repercutir en las posibilidades de desarrollo de todas las demás poblaciones del señorío, en especial de una tan próxima como La Iruela.

Esta última recuperará su "autonomía" en 1378, cuando el arzobispo Don Pedro Tenorio le otorgue el privilegio de villazgo, como conclusión de un largo enfrentamiento entre la localidad y Cazorla, que ha reconstruido $\mathrm{M}^{\mathrm{a}}$ del Mar García Guzmán (1985). De modo resumido, parece que durante la guerra entre Pedro I y Enrique || (|362-|369) Cazorla apoyó a Pedro I, en contra del propio arzobispo Gómez Manrique que apoyaba a Enrique; por ello el arzobispo separó de la jurisdicción de la capital a las aldeas que se le mantuvieron fieles, y concedió el privilegio de villazgo a La Iruela. Pero terminada la guerra el arzobispo derogó el privilegio. Ello ocasionará en los años siguientes diversos choques y litigios por la negativa de La Iruela a someterse de nuevo a Cazorla, llegando incluso al enfrentamiento físico cuando oficiales de Cazorla agredieron a los representantes de La Iruela, amenazándolos si no se sometían y destruyendo el documento que contenía el privilegio de villazgo. Todo ello acabó en un juicio ante el arzobispo Pedro Tenorio, que ante el conjunto de hechos falló a favor de La Iruela.

Es muy posible que sea a partir de ese momento, pudiendo ya disponer de sus propios recursos, cuando además de reparaciones en las murallas más antiguas, se levantó la hoy denominada Torre del Homenaje en la cima de 
la peña. Y sobre todo se amuralló la población, construyendo un recinto que se dotará de una puerta de acceso a todo el conjunto.

El siglo XVI será en La Iruela, al igual que en todo el Alto Guadalquivir, una época de gran pujanza. Se producirá entonces el primer ensanche urbano de la población, ensanche longitudinal hacia el Suroeste, siguiendo las curvas de nivel a lo largo de dos ejes, formados por las calles Corredera y San Antón, que confluyen en la plaza, hoy denominada de La Constitución. Ensanche que rompe con la estructura puntual, amurallada, que había caracterizado a la población durante la Edad Media.

En la confluencia de los nuevos ejes mencionados se levantó el edificio del Concejo, en cuya planta baja se alojaría el Pósito (VV.AA. 1991), formado por cinco naves paralelas, con fábrica de sillería tosca e irregular, que comunican con el exterior a través de vanos de medio punto adovelados. Estaban cubiertas con bóvedas de medio cañón, que según P. Galera (2000) presenta notables similitudes con el pósito de Baza, por lo que podría atribuirse con fundamento a Vandelvira. Las dos plantas superiores estaban realizadas con machones de ladrillo y paños rectangulares de mampostería separados por hiladas de ladrillo. La cubierta era una armadura de madera a tres aguas cubierta con teja árabe, conjunto que aproxima la parte superior de la construcción al mudéjar toledano. El edificio actual ha sido muy modificado, con cambios en la distribución de los huecos de las plantas superiores.

En la zona inicial de la ampliación mencionada se levantó la iglesia dedicada a Ntra. Sra. de la Concepción, una de las dos parroquias con las que contó la población. Madoz (1988) sólo menciona esta última. El antiguo templo de La Concepción sería sustituido en 1956 por la iglesia actual, un edificio de escaso valor artístico.

Por lo que se refiere a la segunda iglesia, hay que recordar que en 1534 Francisco de los Cobos, el poderoso secretario de Carlos V, consiguió hacerse con el señorío del Adelantamiento, que permaneció en su familia hasta que el arzobispado de Toledo lo recuperó de sus herederos en 1606. Durante este periodo se construiría la que Rus Puerta (1998) califica como Iglesia Mayor, situada al pie del castillo, que dividiría el recinto urbano bajomedieval, creando una amplia plaza de armas al pie del acceso a la fortaleza. Esta iglesia estuvo bajo la advocación de Sto. Domingo, lo que justifica $F^{\circ}$. Olivares (1987) en que Sto. Domingo de Silos era uno de los patronos de la población. El edificio quedó arruinado entre los siglos XVIII y XIX, y convertido en cementerio, adosándose a sus muros los nichos. En el siglo $X X$ se derrumba la techumbre y cesaría su función como cementerio.

La cronología y autoría de estas iglesias son elementos muy discutidos, por la falta de datos. Por un lado autores como Chueca Goitia (197I) o Pedro Galera (2000) han señalado en la Iglesia Mayor la existencia de algunos rasgos decorativos, o los elementos abarcantes de la parte superior de los muros extremos del Crucero, que relacionan esta iglesia con el estilo de Andrés de Vandelvira, arquitecto utilizado profusamente por $\mathrm{F}^{\circ}$ de Los Cobos, aunque con una ejecución más pobre y tosca, que sugiere la realización por parte de maestros locales, por lo que la construcción se habría iniciado después de 1534.

Sin embargo Luis Magaña (1954) recogió unos documentos según los cuales el cantero Rodrigo de Gibaja, ligado al arzobispado de Toledo, y encargado de diversas obras (la Colegiata de Baza, la iglesia de Puebla de Don Fadrique) en Granada, afirma que tenía a su cargo las obras de las parroquias de Sta. María en Quesada y de La Iruela, por lo que P. Galera (2000) apunta que este pudo ser en realidad el arquitecto de la iglesia y que la construcción pudo haberse iniciado antes de 1534. No habría que descartar que este maestro estuviese trabajando en la iglesia parroquial de la Concepción antes de 1534, mientras que Vandelvira proporcionó trazas para la de Sto. Domingo después de esa fecha por intervención directa de $F^{\circ}$ de los Cobos, aunque de la ejecución se encargaron otros canteros.

Pero en esa discusión se parte de que ambos templos serían del siglo XVI, algo que no está 
probado. Si la Iruela era villa a partir de mediados del siglo XIV, sin duda tenía población suficiente para disponer de una iglesia, y de esta nada sabemos. Quizá la iglesia de La Concepción fuera ese primer templo. Pero el problema es que como hemos señalado esta última iglesia se encuentra en la zona de ampliación del siglo XVI, fuera de las murallas, por lo que prácticamente hay que descartar que se trate de la fábrica medieval.

De hecho parece muy posible que esta se encontrase en el mismo emplazamiento que la iglesia mayor, al pie del castillo, y que precisamente de los Cobos edificase la nueva con el propósito de engrandecerla. La posición de una iglesia entre la alcazaba y la población es algo muy frecuente, y en parte heredado de los musulmanes, aunque no hay datos para suponer que en la Iruela hubiese una mezquita, ya que como hemos señalado la población en dicha época parece ser muy reducida, y limitada a la propia fortaleza.

\section{LA FORTALEZA}

Las fortificaciones de La Iruela se concentran en el extremo Oeste de la población actual, en un promontorio que gozaba ya de una buena defensa natural, tanto por los fuertes cortados de la roca existentes al Norte y Este, como por el barranco que lo separaba de las estribaciones del cerro Escribano. Pueden distinguirse restos correspondientes a tres recintos, a los que hay que agregar el que luego se desarrolló al Oeste y que abrazó la expansión de la población.

En época almohade (último tercio del siglo XII y primero del XIII) se organizaría lo que será el núcleo de la fortaleza (Fig. 3). Su cierre por el Oeste se hizo mediante un largo lienzo de tapial fabricado con muchas piedras de pequeño tamaño. Este lienzo (que denominaremos La Cortina) arranca en el extremo Norte, donde se apoya en la parte más elevada de la peña, bajando con numerosos quiebros hacia el Oeste, bordeando el precipicio. Prácticamente donde este último termina se creó una amplia terraza mediante el rebaje del terreno. En ese punto la muralla gira hacia el Sur, hasta la parte baja del promontorio, donde termina en una torre (Fig 3, 6) de la que arranca el muro perpendicular que cierra el Tercer Recinto (Fig. 3 , III), y del apenas quedan restos.

En la parte más elevada del afloramiento rocoso se levantó un primer recinto (I), al menos con dos niveles, que contaría con una pequeña torre. Su cronología no ha podido establecerse por ahora. Los castellanos levantaron sobre gran parte del mismo la que suele denominarse Torre del Homenaje, pero que no corresponde a esa tipología, sino que parece más bien una torre de vigilancia, por lo que la hemos denominado provisionalmente Torre del Picacho.

En el área donde La Cortina cambia de dirección, aprovechando la menor altura exterior, se encontraba el acceso a la fortaleza, protegida por un complejo sistema integrado por tres torres (Fig. 3, I a 3). De este sistema arrancaba también el lienzo que cerraba el recinto central (II). En este lienzo, se ubicaron al menos otras dos torres ( 4 y 5 ) de forma troncocónica muy característica. La comunicación entre los recintos II y III se realizaba por el extremo Este.

Aparentemente en época almohade no era sólo una fortaleza, sino que se trataría de un hisn semejante en muchos aspectos a otros como el de Los Guájares, en Granada (MALPICA et alii 1986; BERTRAND et alii 1990; GARCIA PORRAS 200I), de forma que en época islámica la población estaría asentada dentro del espacio amurallado.

Tras la conquista castellana al menos dos de los tres recintos de la fortaleza se convertirían en el castillo señorial, y la población campesina se asentaría al exterior de la fortaleza. Ese espacio sería amurallado en el siglo XIV creándose un cuarto recinto (IV) o Recinto Exterior (RE), que sería profundamente transformado en el siglo XVI, al segregar del mismo, mediante la construcción de la iglesia de Sto. Domingo, el que hemos denominado Recinto Interior (RI).

En las páginas siguientes abordamos la descripción de cada uno de los recintos y los elementos constructivos existentes en cada uno de ellos. 


\section{EL RECINTO EXTERIOR}

En el lateral Este de la calle que separa el extremo de la terraza donde está la fortaleza, del resto de la población, quedan restos de muros y tapias que pudieron formar parte del recinto que protegía la población por el Oeste, aunque en la actualidad están muy modificados (Fig.2). Están compuestos por la puerta de acceso a todo el conjunto, y dos fragmentos de lienzo situados al Sur de esta (Lám. 2), donde la calle traza una curva.

\section{EI Lienzo Sur}

El primer fragmento (Lam 3) es paralelo a la calle, y el segundo (Lám. 4) presenta un ángulo con respecto al primero, de forma que en principio trazan una curva con sentido esteOeste. Ambos están separados por vegetación, que impide determinar con exactitud si hay continuidad entre ellos. Están compuestos aparentemente por un zócalo de más de un metro de altura de mampostería, sobre el que se sitúa otro realizado en tapial, con piedras de cierto tamaño. Presentan numerosas huellas de reformas y arreglos.

\section{La Puerta}

El elemento más visible que puede corresponder en parte al recinto exterior es la propia puerta de entrada al mismo (Lams. 5 y 6). Esta puerta fue probablemente reorganizada en el siglo XVI, cuando se le dotó de cierta monumentalidad. Según informaciones orales, tuvo hasta hace unos años un arco de medio punto, que en la actualidad ha desaparecido. De los elementos que la embellecían sólo quedan hoy algunos grandes sillares en piedra gris que se han reaprovechado en la "restauración" de la misma, colocándolos en los dos laterales de la misma, posición que quizá ocuparon originalmente.

El camino que hoy conduce desde la Puerta del Recinto Exterior a la Torre Puerta del Recinto Interior, está probablemente muy modificado. Se han construido muros de mampostería que regularizan considerablemente el acceso. No obstante, la estructura quebrada del acceso, así como la pendiente existente, quizá sean en parte restos de la primitiva organización (lams. 7 y 8 ).

\section{El espacio interior}

El muro que flanquea el lado Norte del acceso de la Puerta posiblemente está sustituyendo a uno original semejante, ya que tras él el terreno baja aún hoy considerablemente, formando una terraza que tardaría bastante en ser ocupada. Sería este el límite de la población bajomedieval.

Pero el espacio ocupado por aquella aparece en la actualidad reducido y segmentado (Lám. 9). A continuación del muro Norte citado, en ese mismo lado, se encuentra una gran torre puerta y la iglesia de Sto. Domingo, edificios que redujeron notablemente el espacio de la población, no sólo por el terreno que ocupan, sino porque amputaron todo el sector Norte, que se constituyó en plaza de armas (RI). De forma que esas construcciones forman el límite Norte de la antigua aldea, que se extendía hacia el Sur, subiendo ligeramente por la pendiente. Hoy hay diversas casas, de muy distintas épocas y tipologías, alguna de las cuales presenta una indudable antigüedad, restos de lo que debían ser las construcciones populares de la zona.

Al Este de la iglesia, la inclinación del terreno se aprovechó para construir en la segunda mitad del siglo $X X$ un amplio anfiteatro, que baja hacia el barranco, y que sin duda afectó también a los restos arqueológicos que pudiesen quedar en la zona de la antigua aldea.

Al Norte del anfiteatro, entre él mismo y los restos de muros que cierran el Tercer Recinto, espacio en cierta forma prolongación del Recinto Interior, existen algunos otros muros, que en principio parecen corresponder a paratas y aterrazamientos realizados en diversos momentos, pero todos en época moderna o contemporánea. No obstante, alguno de ellos presenta al menos dos fases de construcción, como se observa por el cambio de material en altura, muy visible en algunos donde la diferencia aparece subrayada por el crecimiento vegetal 
entre las dos fases (Lám. 10). Esto puede hacer pensar que la inferior es mucho más antigua, y quizá convenga hacer un estudio más detenido. En cualquier caso es razonable pensar que en la zona debe existir un muro de cierre que completaría por este lado el recinto creado en época castellana.

\section{EL RECINTO INTERIOR}

Entre los muros de la fortaleza propiamente dichos y el muro exterior, una serie de elementos dibujan lo que hemos denominado Recinto Interior. Está compuesto por una plaza enmarcada al Sur por la Iglesia y la torre puerta (Lams. II y |2), el corte del terreno, que en algunos puntos tiene varias decenas de metros, al Norte y Oeste, y la fortaleza al Este, existiendo posiblemente una continuidad de la muralla entre esta y la iglesia, que cerraría el acceso de la población por ese lado.

Aunque la superficie de la plaza está regularizada, en el centro hay un afloramiento rocoso, en el que se construyó en época contemporánea un depósito de agua, hoy ya eliminado. Esta plaza se presenta hoy como un espacio totalmente despejado, lo que no es seguro que ocurriera siempre en el pasado. De hecho, algunos de los muros-parapeto que la rodean actualmente presentan restos que podrían corresponder aparentemente a varios momentos.

Lo existente en la plaza, a partir del dato de su ubicación entre la fortaleza y la iglesia, permite formular una serie de hipótesis respecto a su creación, modificaciones, funciones, etc.

Como hemos dicho la población islámica estaría situada dentro de las murallas, y este sería un espacio no ocupado. Después de la conquista la población pudo asentarse aquí. No obstante no habría que descartar totalmente que se crease muy pronto una plaza de armas, y quizá se levantó una primera iglesia bajomedieval, siguiendo el esquema de iglesia situada entre el recinto defensivo y la población, similar al que se produjo en localidades como Cazorla o Alcaudete.
Ello explicaría mejor las razones por las que situó en este lugar su notable construcción Francisco de los Cobos. La iglesia renacentista, cuyos restos presiden hoy este espacio, pese a su estilo, no sería en este sentido sino el final de la etapa medieval. Pero el hecho de que la puerta principal de la iglesia se abriese a la plaza, y que a esta se accediese a través de una torre-puerta, quizá estén indicando que se concibió simultáneamente como espacio político-ideológico. En cualquier caso el control de la aldea por parte de Francisco de los Cobos, la expansión de la localidad fuera de las murallas y la transformación social del siglo $\mathrm{XVI}$, lo convertirían muy pronto en un espacio marginal.

\section{La Torre-Puerta del Recinto}

El acceso a la plaza se realiza a través de una torre que servía además de campanario a la iglesia (Lams. 13 y |4). Este doble papel parece indicar la existencia de un único programa constructivo, uno de cuyos objetivos sería precisamente generar la plaza como un espacio cerrado, lo que parece reforzar el hipotético carácter ideológico de la misma. Aunque la torre tiene sus paredes rectas y aplomadas, su base es ligeramente más ancha, con una tendencia troncopiramidal, lo que le daría mayor solidez, algo necesario por la existencia de la puerta en su base. El cuerpo superior de la torre ha sido reconstruido recientemente, empleándose un tipo de mampostería que lo diferencia netamente del resto. No obstante la altura de la misma parece escasa, ya que no superaría el techo de la propia iglesia. Si esta es realmente la que tenía la original, habrá que pensar en que no se concluyó.

\section{La Iglesia de Santo Domingo}

Se sitúa entre la fortaleza y la población, según un esquema muy frecuente en la Baja Edad Media. En cualquier caso la iglesia que hoy existe es obra del siglo XVI. Es un edificio de gran tamaño que contrasta con el de la población en la que se ubica. Era un templo de tres naves, la central de doble anchura que las laterales y testero plano (Lam I5). El crucero está constituido por el tramo final 
de las naves. La ausencia de pilares, o huellas visibles de ellos, y la imposibilidad de estudiar los muros laterales, impiden determinar la longitud de los tramos de la naves, y por tanto conocer si el crucero resaltaba en planta. Por el momento, sólo aparece marcado por pilastras adosadas a los muros laterales que resaltan claramente de estos, y lo separan de las naves, y que se corresponden con contrafuertes al exterior, los únicos con que parece que contó el edificio.

En altura la iglesia presenta dos tipos de aparejo, separados por una cornisa. La división cabe relacionarla con el uso de materiales más ligeros y baratos en altura.

La iglesia fue empleada en época contemporánea como cementerio. Aunque a finales del siglo $X X$ este se retiró, quedan aún en sus muros abundantes restos de los nichos que se construyeron en ellos.

\section{LA CABECERA}

Se trata de una cabecera plana (Lám. 16). El conjunto está enmarcado por los espacios que alojan las escaleras de caracol para subir a las habitaciones de la planta superior. Por el exterior se refleja ligeramente la estructura tripartita interior que corresponde a las naves. Los sectores Sur y central son muy homogéneos, animado el último sólo por la abertura de un gran rosetón en altura. El lado Norte, por el contrario, muestra una notable complejidad; en la planta baja existió una antigua puerta, hoy tapiada, que estaba coronada por un elemento que sugiere cierto nivel de fortificación. Por otro lado la disposición de las piedras en el lateral izquierdo de esta puerta y las cajas de vigas existentes en el derecho y por encima, apuntan a que quizá existió otro cuerpo adelantado (Lám. 17).

Por encima parece que hubo dos habitaciones superpuestas. Una recibiría luz a través de un rosetón hoy tapiado. La situada encima la recibía a través de dos ventanas gemelas, una de ellas también tapiada.
Por el interior la estructura tripartita es mucho más acusada (Lam I8), con una capilla central, que al igual que la nave tiene una anchura doble que las laterales, que ha sido despojada de los elementos decorativos. En la coronación había un rosetón hoy tapiado (Lám. 19). La apariencia de las capillas laterales es desigual. La del lado Norte conserva sus elementos estructurales: profundidad, puerta que debe permitir acceder a la escalera de caracol para subir a las estancias superiores, así como restos de la decoración que la cubría, que aparece quemada (Lám. 20).

La capilla del lado Sur presenta, al igual que por el exterior, una estructura muy simple y homogénea, en ella se aprovechó la profundidad del muro para labrar unos nichos donde ubicar sepulturas (Lám. 2I). Teniendo en cuenta el material esta actuación posiblemente se realizó en los siglos XVIII o XIX.

\section{EL CRUCERO}

El crucero está marcado por las pilastras que separan ese espacio del resto del muro. Su anchura queda además resaltada por la estructura arquitectónica del conjunto visible en el lado Sur (Fig. 22). Se trata de la existencia de un elemento abarcante, un gran arco que engloba toda la anchura, y que en la planta inferior se divide en dos espacios, separados a su vez por otra pilastra, que apenas resalta del muro, con una hornacina en su parte superior.

El elemento abarcante fue utilizado por Andrés de Vandelvira, pero también pertenece a la tradición de Diego de Siloe, encontrándose en la catedral de Granada. Y la forma de iluminación, con tres huecos en el tímpano y la forma de estos, se relaciona igualmente con la tradición castellana alejándose de los modos vandelvirianos, siendo, entre otros, elementos que podrían atribuirse a la intervención hipotética de Rodrigo de Gibaja.

Los dos espacios inferiores, cubiertos con arcos, correspondían a sendas capillas, aunque en las mismas se ubicaron, aprovechando su profundidad, nichos del cementerio moderno, 
y no resulta por el momento posible hacer otras precisiones sobre las mismas, fuera de señalar que dicha profundidad parece ser bastante mayor que la de las capillas del frente opuesto.

El extremo del Crucero Norte está en la actualidad bastante deteriorado (Lám. 23). Sería similar al del lado opuesto, es decir, habría un elemento abarcante en la parte superior, que se divide en dos espacios en la inferior, que acogen sendas capillas. También la pilastra entre ambas está coronada por una hornacina. Las capillas, aunque están peor conservadas, sí presentan muchos más elementos originales. La de la izquierda (Oeste) ofrece en el fondo, y entre el arco y el friso, un aparejo de mampostería irregular, diferente al existente en el resto del edificio. En la misma además se abrió una puerta, con jambas y arco de yeso, que a su vez fue cegada, aunque en la actualidad esta nuevamente abierta. Es posible que todo el fondo de esta capilla sea un cierre original provisional, es decir, que se preparase el muro para construir en el futuro una capilla hacia el exterior que nunca llegó a levantarse. El resultado habría sido en ese caso semejante al de la capilla derecha.

El arco cobija aquí una puerta, que debía dar paso a una estancia hoy desaparecida, o que tal vez nunca se construyó, quizá el lugar donde iba a levantarse la sacristía. La portada conserva algunos de los elementos de la decoración dispuestos en dos pisos: en el inferior el arco de entrada, con nichos laterales (Lám. 24), y en el superior una gran metopa muy deteriorada (Lám. 25).

La decoración que presenta esta puerta en el frente que se abre a la iglesia, está ausente en lo que hoy es el exterior, donde sólo resalta su estructura abocinada (Lám. 26). Esto refuerza la idea de que era la puerta a una capilla, aunque el espacio en sí ha desaparecido o nunca fue construido. Provisionalmente nos inclinamos por esto último, ya que no hay señales de las rozas en las que encastrarían los muros de una habitación, y la coloración del muro que rodea la abertura es semejante en toda la extensión conservada, lo que no ocurriría si una parte hubiese estado protegida durante un tiempo más o menos prolongado de la acción de los elementos, frente a otras zonas expuestas a los mismos.

\section{LOS MUROS DE CIERRE LATERALES}

El lateral Sur de iglesia está oculto por el interior por los restos de los nichos del cementerio contemporáneo y una la extensa y frondosa enredadera que ha crecido sobre el mismo, todo lo cual impide por el momento realizar estudio alguno sobre el mismo (Lams 27 y 28). Entre los elementos ocultos hay una puerta, que es en parte visible por el exterior (Lám. 29). Esta puerta permitía acceder al templo desde el recinto exterior.

El muro del lado Norte a partir del crucero ha desaparecido en gran parte. Aunque se hizo una restauración para reponer parte de los elementos de la antigua puerta principal del templo (Lám. 30). La cara interior, que da al templo, está totalmente desnuda (Lám. 31).

\section{EL FRENTE OESTE Y EL CAMPANARIO}

El Oeste de la iglesia está ocupado en parte por la Torre-Campanario, cuyo tramo inferior, al exterior, contiene la Puerta por la que se accede a la plaza. A sus plantas superiores se accedía desde la iglesia. El tramo bajo la torre se salva mediante una escalera de caracol adosada a la misma (Lám. 32). Después se prosigue por un escalera ubicada en el interior.

El resto del muro Oeste presenta un fuerte deterioro, quizá como consecuencia de la mayor debilidad del muro, no por la presencia en la parte alta de una ventana/saetera, sino más bien porque parece que en un momento dado esta trató de ampliarse, y quizá incluso se intentó abrir una puerta (Lám. 3I).

\section{LA CRIPTA}

A la altura de la pilastra que marca el inicio del crucero, y en las proximidades de la misma, se abre la entrada a una cripta, que data posiblemente de la época de uso de la iglesia (Lám. 33). La misma no ha sido examinada. 


\section{LA FORTALEZA}

La fortaleza se articula internamente en varios recintos, construidos en diferentes épocas. Uno de los rasgos distintivos de esta fortaleza es la imagen de su frente Oeste. En esa imagen destaca la torre ubicada en la parte superior del picacho más elevado, y aunque aparentemente se alinea con el frente Oeste, en realidad se encuentra bastante alejada del mismo. El frente Oeste propiamente dicho es lo que hemos denominado La Cortina.

\section{La Cortina}

El frente Oeste, que cierra la fortaleza, es uno de los rasgos notables y distintivos de este lugar, y donde se acumulan varios elementos de entidad. Pueden diferenciarse tres torres (Fig. 3, I, II y VI) y los lienzos que las unen (Lams. 34 y 35).

La disposición natural de las rocas del cerro es muy irregular, debido al plegamiento de las mismas. Este problema se salvó en la muralla de cierre mediante la construcción de un gran basamento de mampostería regular, que rellena y regulariza el espacio. Sobre ese base se disponen los cajones de tapial. Es aún preciso realizar un análisis detenido del tapial de cada zona. En principio parecen haberse utilizado dos técnicas. Una empleando un tapial de gran dureza, con piedras de pequeño tamaño, presente en los lienzos de muralla, y en algunas zonas de las torres. Sin embargo, en estas se recurrió de forma generalizada a rellenar los cajones con piedras de mediano tamaño dispuestas en hiladas regulares, unidas por argamasa, echando después la mezcla de arena y cal, que proporcionó el recubrimiento externo, que en la actualidad se ha perdido en muchos puntos.

Los frentes de las torres I y VI están situados en el mismo plano que los respectivos lienzos de la muralla vecinos a las mismas, y la torre II tampoco resalta excesivamente con respecto al lienzo Sur. Esto no puede atribuirse exclusivamente a la topografía de la zona, ni puede achacarse a una hipotética impericia en el planteamiento defensivo. Por el contrario responde a una concepción sumamente imaginativa que aprovecha al máximo las posibilidades del lugar.

Las torres I y || y la torre III, situada en el interior del recinto, conforman un sistema estrechamente relacionado, que defendía la puerta de acceso a la fortaleza. (Fig. 3)

\section{LA TORRE I (Lams. 36-38)}

Se asienta en un largo y estrecho espolón, cuyo lado Norte está limitado por un precipicio (Lám. 37). El parapeto hoy visible al Norte es reciente, aunque posiblemente se apoya sobre estructuras antiguas. En consecuencia esta torre forma el extremo Norte de la línea de fortificación. El espolón constituye en cierta forma un alcazarejo, independiente del resto de la fortificación. La pared Este de la torre no existe y quizá nunca existió, funcionando todo el espacio como entrada. Tuvo un segundo piso, cuyo sistema de acceso ha desaparecido, aunque al mismo quizá pertenezcan los confusos restos que hay en el interior (Lám. 38). La función del espolón en el que se asienta la torre era al mismo tiempo la protección del patio de acceso a la fortaleza situado al Sur entre las Torres II y III.

\section{LA TORRE II (Lams 39-40)}

Es la de mayor porte y forma parte del complejo sistema de acceso al interior de la fortaleza. Está muy deteriorada faltando buena parte de las caras Norte y Este. En lo que queda se advierte una notable variación en la coloración, que puede deberse a su mayor exposición a los elementos, al diferente grado de deterioro o al tipo de material utilizado en cada tramo en altura, más ligeros a medida que se subía, o de reparaciones realizadas ya en época medieval.

Tenía al menos dos plantas. La inferior con la entrada, y una segunda a la que se accedería desde el adarve. Desde esa sala se subiría a la terraza, almenada. A la entrada se llega en la actualidad mediante una escalera adosada al muro Oeste, que terminaba en el lien- 
zo Norte de la torre. La escalera quizá sea una construcción tardía, aunque para aclararlo es necesario un estudio detallado de los mampuestos y el análisis físico-químico de la argamasa utilizada.

La desaparición de los lados Norte y Este de la torre produce la errónea impresión de que el acceso era un gran espacio libre, aunque en realidad era una puerta en codo. En el lado Norte aún quedan restos que permiten establecer que había una gran puerta con arco de acceso. Posiblemente en el lado Este había otro, que daba paso al recinto central o Segundo Recinto (R2) que constituía el centro de la fortificación. En la actualidad la desaparición de buena parte del lienzo Este de la torre ha permitido construir una escalera que lleva también al recinto inferior, que hemos denominado Tercer Recinto (R3), creando una cierta confusión acerca del funcionamiento de la fortaleza en la época de su uso como tal (Lam $4 \mathrm{I}$ ). Desde el Este se aprecia con gran claridad que la torre apoya sobre un zócalo de mampostería que impediría que la humedad del suelo se trasladase a la parte superior.

A la salida de la Torre II hacia el $2^{\circ}$ Recinto había un patio a cielo abierto que resulta hoy difícil de distinguir. Está empedrado como si fuese un camino (Lám. 42), controlado por la Torre I (Norte) y el alcazarejo de acceso a la misma (Lám. 43), mientras que ha desaparecido la parte superior del lienzo que lo cerraba por el lado Sur, que sólo puede apreciarse hoy desde el Recinto inferior (R3) que muestra varias alteraciones y reformas (Lám. 44). Igualmente falta el cierre que suponía la Torre III, y a la que se accedía desde él mismo.

\section{LA TORRE III}

No forma parte de la Cortina propiamente dicha, pero si del complejo acceso original de la fortaleza, por lo que nos referimos a ella aquí. Era una torre-puerta de paso recto, de la que hoy sólo queda parte del paramento Sur (Lám. 45). Ignoramos si por encima del cuerpo al que pertenece este y que contenía el paso, había otro, o solamente una terraza. En el lado Norte, frente al lienzo de la torre, formando parte también del alcazarejo subsiste un grueso machón de mampostería, que debió tener también relación con la torre (Lám. 37). A falta de un estudio detenido, su altura es el único argumento para suponer que la torre tuvo un segundo cuerpo. Cuerpo o terraza, a ellos se accedería desde el alcazarejo, y desde ellos se controlaría también el patio, convirtiendo este en una auténtica trampa para cualquier hipotético atacante.

\section{LA TORRE VI}

La "Cortina" termina en la actualidad por el Sur en una torre de tendencia troncocónica, semejante a otras de la misma fortaleza, aunque notablemente delgada y estilizada (Lams. I y 47). Hace años fue objeto de una desafortunada "restauración", o más bien de un recubrimiento exterior, es de suponer que para detener el deterioro de la misma, cuando ya este estaba muy avanzado. Pero no se corrigió la deformación de la parte superior, que le da en la actualidad un extraño aspecto. Además, esa actuación ha ocultado la roza del lado Este donde encastraría el lienzo que cerraba el recinto por el lado Sur, y quizá otra en la cara Sur que lo prolongaba hacia ese lado, aunque de este no hay ningún indicio.

La posición del cimiento de mampostería de la torre respecto del "camino" que hoy existe por encima, indica la existencia de al menos I metro de potencia arqueológica en esta zona, sin contar el desnivel que existe entre dicho "camino" y la base de la muralla que separa este Recinto del Segundo (Lám. 47).

Por lo que se refiere a su estructura interna esta sólo puede observarse hoy desde la zona de acceso junto a la torre II (Lám. 48), que muestra que la torre era hueca. Esto junto a la posición de las saeteras existentes en sus tres frentes, indica que debía haber al menos una cámara por debajo del nivel del adarve. El acceso a la misma es otra incógnita a aclarar, ya que pudo existir una puerta en la parte inferior, o llegarse a ella desde arriba. Originalmente la torre era más alta. Le falta al menos una terraza que estaría al nivel del adarve, desde el que se accedería a ella. Aunque tam- 
bién es posible que falte un cuerpo entero, con cámara, al nivel del mencionado adarve, y la terraza por encima, siendo por tanto más semejante a las otras dos torres. El adarve está bastante dañado, pero la propia vegetación existente sobre el mismo indica que posiblemente se ha producido una acumulación de tierra vegetal que protege el suelo original.

\section{La muralla entre los Recintos II y III}

Es el muro Sur del Recinto, Lo consideramos ligado especialmente al II Recinto porque las torres del mismo tienen todas su entrada desde este. El muro presenta por ese sector discontinuidades, con segmentos desaparecidos, arruinados y otros "restaurados" de forma deficiente, siendo por otro lado muy difícil obtener una panorámica completa del mismo. Sin embargo, es desde este Recinto desde donde se accede a todos los elementos integrados en el mismo: adarve, aljibe, torres IV y V.

Por el contrario, el muro tiene una apariencia más relevante vista desde el III Recinto o desde el exterior, debido a la pendiente existente (Lám. 49). Se aprecian tres sectores: el primero al Oeste, que corresponde a la zona donde el lienzo ha desaparecido visto desde el interior. Existen una serie de refuerzos que subrayan las modificaciones sufridas por el acceso a la fortaleza. El sector intermedio, con un lienzo muy nítido que se asienta sobre la roca, correspondiente en el R2 a la zona con adarve y al aljibe. Y el Este, donde se sitúan las torres y estaba la puerta de comunicación entre los dos recintos.

Como en otras fortalezas existen en esta diversos elementos y detalles defensivos que hasta cierto punto reflejan el armamento de la época. Los más interesantes quizá sean las saeteras para ballesta, de las que aún quedan algunas (Lám. 50 y $5 \mathrm{I}$ ). Notablemente estrechas y de poca altura, permitían al ballestero, situado de rodillas sobre el adarve y protegido por el antemuro, apuntar su arma, una de las más mortíferas de la época. Posiblemente se realizaron introduciendo en el "cajón" una estructura o molde de madera con la forma, de manera que cuando se rellenaba el cajón con la masa, quedaba el hueco, lo que explica que no se aprecie ruptura en el propio tapial, lo que sí sucedería si se hubiese "tallado" posteriormente. Otro elemento destacado son las almenas, realizadas en tapial y que coronaban todos los lienzos y torres.

\section{El Segundo Recinto}

Por motivos prácticos iniciamos la descripción siguiendo a partir de la zona de acceso, por el que hemos denominado II Recinto, después analizaremos el I y el III.

El II Recinto constituyó el núcleo de la fortaleza, donde se concentran la mayor parte de los elementos construidos detectados hasta el momento. Igualmente era la zona mejor protegida, que posiblemente actuó como alcazaba. No obstante, este aspecto funcional debería ser investigado en profundidad. Esto es posible gracias a que conserva un importante relleno arqueológico.

\section{EL TRAMO JUNTO AL ACCESO}

El sector más próximo a la torre-puerta es posiblemente el sector más afectado por el deterioro, habiendo desaparecido todo el lien$z o$ en altura, $y$ donde simplemente se ha construido un muro a modo de parapeto por motivos de seguridad (Lám. 52).

A continuación hay un tramo algo mejor conservado incluyendo el adarve. No obstante, la rasante actual de la zona está prácticamente a menos de Im. por debajo del mismo, lo que parece implicar la existencia de un relleno arqueológico notable.

\section{EL ALJIBE}

Hasta ahora sólo se conoce un aljibe en esta fortaleza. Está ubicado al final del sistema de acceso y muy próximo a la Torre IV, adosado a la muralla y su parte superior quedaba ligeramente por debajo del aljibe (Lám. 53). Se trata de una obra realizada en tapial de gran calidad, con mucha cal. Es de mediano tamaño, con 8'40 × 2'00 metros. Hoy está casi completamente lleno de tierra, lo que impide cono- 
cer su profundidad, y esta resulta casi imposible de calcular. Por el desnivel existente en el extremo Este puede rebasar como mínimo los tres metros, pero si tenemos en cuenta que está casi al nivel del adarve, y hay que pensar que este a su vez estaba varios metros por encima del nivel del suelo, podemos estar ante una obra de gran envergadura. En el borde adosado a la muralla se advierte el arranque de la bóveda de medio cañón que lo cubría. Estaba realizada con argamasa y piedras de mediano tamaño. Es posible que el exterior de la misma fuese plano y actuase como una ampliación hacia el interior, del adarve.

Por el lado Este se aprecia claramente la caída del terreno desde el aljibe hasta la Torre IV (Lám. 54), y que sigue bajando hacia el Este. Pero esta pendiente no existía originalmente, el examen arqueológico del extremo Este, sugiere que en realidad el suelo original está varios metros por debajo del actual, no sólo a la altura del aljibe, sino también a la de la Torre, lo que confirmaría que el aljibe es una estructura de gran relevancia.

En la pared Oeste del aljibe se observan en la parte superior una serie de agujeros, que quizá correspondan a cajas de vigas. Aunque pueden ser las huellas de las maderas empleadas en la construcción del propio aljibe, el hecho de que sea lo único que no aparece revocado con una gruesa capa de argamasa antigua, quizá implique que eran las cajas de las vigas del techo de un edificio que habría estado adosado al aljibe, o de una amplia estructura de madera que habría hecho las funciones de adarve, que en esta zona falta. Pero en este último caso habría estado encastrado en la propia muralla, de lo que no parece haber huellas. Por tanto, es probable que se trate de un edificio que, al igual que el aljibe, tuvo la función de adarve, y que al igual que este, se adosó a la muralla, pero sin afectarla. Si ello es cierto, parte de la estructura puede estar aún enterrada.

\section{LAS TORRES IV Y V}

Al Este del aljibe, pero separadas del mismo por un tramo hoy vacío, se encuentran, muy cerca una de otra, dos torres, ambas bastante deterioradas (Lám. 55). A causa del relleno del
II Recinto al que hemos aludido y por el desnivel existente entre los dos recintos, las torres IV y $\vee$ presentan en su parte posterior un desarrollo considerablemente mayor que en el frente, con el fin de apoyarse en la roca. Aunque por el distinto grado de conservación resulta imposible afirmarlo, da la impresión de que se trata de dos torres gemelas, y su ubicación en el extremo, controlando al mismo tiempo la puerta de acceso al recinto inferior, obligan a plantearse la posibilidad de que existiese en este punto un pequeño reducto o alcazaba. De ser así, buena parte del mismo debe encontrarse aún enterrado.

\section{LA TORRE IV}

Es la mejor conservada. Tiene una acusada forma troncocónica, semejante a la Torre VI, apreciable especialmente desde el exterior, y con claros paralelos en las de las Eras de Sta. Catalina en Orcera. Es una obra de tapial de buena calidad, que ha sido reparada en varios puntos en época moderna con mampostería. Tenía al menos dos pisos, el superior con una saetera en la cara Sur, y la inferior con una en la Sur y otra en la Oeste, aunque estas están muy deterioradas y anormalmente próximas al suelo (Lams. 56, 57, y 58). Por otro lado la puerta de la torre es una construcción posterior, ya que está rompiendo los cajones de tapial. Estos dos elementos, unidos a la inclinación del terreno exterior ya comentado, sugiere que el suelo original estaba más abajo, y que del mismo modo quizá la puerta original estaba -o comenzaba- más abajo.

La parte inferior de la torre, vista desde el exterior, puede ser al menos en parte maciza. Pero teniendo en cuenta el desnivel de la parte interior del II Recinto, y la propia estructura de la torre, no habría que descartar que exista una cámara ciega, que sirviese como lugar de almacenaje, y a la que se accedería desde la I planta de la torre.

El tapial no se apoya directamente sobre la roca, sino que existe un zócalo de mampostería que resalta ligeramente, sin llegar a constituir una zarpa. Posiblemente su función fue crear una plataforma que salvase las irregulari- 
dades de la roca, al tiempo que preservaba al tapial de la humedad.

La torre fue construida con 14 cajones de tapial (al exterior), y un coronamiento almenado, lo que da una altura desde este lado de más de II metros, que contrasta con la imagen del interior, donde hoy apenas son visibles cinco metros. La recuperación de la rasante original supondría el realce considerable de esta torre por su parte más visible e interesante.

\section{LA TORRE $V$}

Esta ha desaparecido totalmente en su frente Norte y en gran parte de los laterales situados por encima de la rasante actual del $2^{\circ}$ Recinto, hasta el punto de que apenas puede reconocerse como tal torre, reducida casi a un muñón (Lám. 59). No obstante la torre sería muy semejante a la anterior, ya que por el exterior muestra la existencia de 13 cajones superpuestos, aunque sólo 6 sobresalen de la actual rasante del II Recinto (Lám. 60). Esta diferencia entre interior y exterior, la posición del suelo actual en relación al primer cajón del tapial del fondo indica que, al igual que en el caso de la anterior, probablemente buena parte de la primera planta se encuentra enterrada.

El deterioro de esta torre prosigue en la actualidad, con pérdida progresiva de la masa de los cajones de tapial de la pared Sur, cuya parte superior también amenaza con derrumbarse, siendo indudablemente uno de los elementos sobre los que resulta más urgente intervenir para su preservación. La ruina de esta Torre se ve complicada además por la hiedra trepadora que ha surgido en la misma. Un auténtico "árbol" que recubre toda la parte superior de la torre por el exterior. Paradójicamente, aunque las raíces producen la destrucción de la torre, también contribuyen a mantener la unión del conjunto, por lo que no debería eliminarse hasta que se empiece la restauración.

\section{LOS CIERRES ESTE Y SURESTE}

El Recinto termina por el Este en un precipicio de más de $40 \mathrm{~m}$. de caída, en la parte superior emerge la roca, y no quedan restos de estructuras. La parte superior fue reforzada con un parapeto y cierres de mampostería en las zonas con grietas que hipotéticamente podrían permitir un asalto (Lám. 6I).

El extremo del lienzo que separa los recintos II y III, una vez sobrepasadas las torres, concentra una serie de problemas, cuya resolución es de gran interés para la historia de la fortaleza, y que además revalorizará notablemente esta construcción.

En primer lugar, visto el extremo por la parte superior parece como si existiera la base de otra torre (Lám. 62). Pero el mismo extremo visto desde el frente Este (Lám. 63) se advierte que en realidad hay un paño de mampostería que se adosa por el interior al muro principal, y que es ese engrosamiento lo que da la falsa impresión de torre en la parte superior. Por otra parte, la perfección del corte vertical de los cajones en el extremo del muro, y el hecho de estar enfoscado, sugiere que se trata de una jamba, por lo que a continuación existía un hueco, y por su tamaño, este sólo puede ser una puerta. Es decir, ese final de muro sería una de las jambas de la puerta al recinto inferior. El muro adosado quizá habría tapiado dicha puerta en un segundo momento.

Sin aparente relación con estas transformaciones está la reparación existente en el muro que se advierte al exterior del mismo (Lám. 64). Se trata de un "parche" que sella una importante rotura deliberada. Una posibilidad es que en ese punto se abriese una puerta hacia el interior, cuando aún subsistía la rasante original, y que luego se tapió. Otra posibilidad es que se rompiese en fecha más reciente, intentando acceder a un hipotético "tesoro", fenómeno desgraciadamente frecuente en muchas fortalezas, y que el parche sea una "restauración" reciente.

Por otro lado, este muro está también afectado por el florecimiento en su esquina de un "árbol" enredadera, que está deteriorándola seriamente, sin que, al contrario de lo que ocurre en la Torre $\mathrm{VI}$, en este caso parezca contribuir a la cohesión del muro. El desnivel actual entre los Recintos II y III se salva mediante una 
escalera moderna, adosada en su parte superior al muro de cierre de la fortaleza, también moderno.

El desnivel entre los recintos II y III parece haberse generado por la acumulación de sedimentos arqueológicos en el II Recinto a los que ya nos hemos referido. Aún aceptando que la parte inferior del muro, donde la mampostería es más visible, corresponda a la cimentación del mismo, y por tanto a niveles no arqueológicos o estériles, existiría una colmatación no inferior a los 2 metros de potencia, que se extendería por buena parte del Segundo Recinto. Su excavación cambiaría considerablemente el ya interesante aspecto de esta fortaleza, aumentándolo, sin descartar la aparición de nuevas estructuras de ocupación.

\section{EI Primer Recinto}

Hemos denominado Recinto I a la elevación existente dentro del II Recinto, dominada por la Torre situada en la parte más elevada de la peña. En este recinto pueden distinguirse por un lado un conjunto de muros que quizá formaron el primitivo alcázar almohade, y por otro la torre y algunas estructuras adosadas, que hay que fechar ya en época castellana.

\section{EL ALCAZAR ALMOHADE}

Lo que hoy queda de este hipotético alcázar son los restos de varios espacios situados al lado y por delante de la Torre castellana, destruidos por esta, y un largo recinto rectangular, que quizá servía de acceso a la cima de la peña.

De los primeros el único que presenta cierta claridad es el situado inmediatamente a los pies de la Torre castellana. Se trata de un espacio de tendencia cuadrada, donde pudo haber una habitación (Lám. 65). Por su posición puede hablarse de torre, aunque el escaso grosor de sus muros indica que no tendría más de una planta. Desde el exterior (Lám. 66), se observa que el muro que corresponde a ese espacio tiene una altura relativamente escasa, por lo que la potencia arqueológica difícilmente superará el metro. No obstante la vegetación que lo cubre indica que existe al menos un nivel de tierra. Un sondeo arqueológico deberá verificar la existencia o no de niveles arqueológicos.

El segundo espacio que consideramos parte del alcázar se encuentra al Este del anterior (Lams. 67 a 70). Presenta una planta de tendencia rectangular, bastante estrecha. Se aprovechó un escalón en la roca, para delimitar un espacio cuyo uso no está determinado. El muro presenta dos tipos de tapial. El de la base es extraordinariamente abundante en piedras, hasta el punto de que parece casi una mampostería, muy semejante al de la torres de la cortina. A partir de cierta altura se utilizó un tapial de mucha mayor calidad, con abundante cal y menos piedras y de menor tamaño. De este tipo quedan menos restos, alguno de ellos en precario equilibrio por la erosión del muro que le sirve de base. La diferencia de composición en el material utilizado no tiene necesariamente que deberse, en este caso, a diferencias cronológicas, sino a que el segundo tapial tendría menor peso y por ello se utilizó en altura.

\section{LA TORRE DEL PICACHO}

En el punto más elevado de la peña se alza una Torre (Lám. 7I), adaptada a la estrecha plataforma. A ella se llega en la actualidad mediante una larga escalera que facilita el acceso (Lám. 72).

Es una torre de mampostería, con sillares encadenados reforzando las esquinas. Se trata de una pequeña torre de 6'40 $\times$ 5'00 metros de lado y una altura aproximada de 7'00 metros (Eslava 1999). Tan escasa altura explica el aspecto achaparrado de la torre, y por otro lado hace que no encaje en la categoría de Torre del Homenaje. Aunque algunos autores han sugerido que pudo tener dos plantas, hay que notar que carece de saeteras, arpilleras u otro tipo de hueco que iluminasen e hiciesen operativa para la defensa una hipotética cámara superior, por lo que posiblemente esta no existió. Tenía cubierta con bóveda de cañón apuntada, en la que se abre la trampilla para llegar a la terraza (Lám. 73). Por el grosor de los muros, el espacio interior sólo tenía 3'60 × 2'20 metros. Posi- 
blemente la mayor parte del interior contenía la escalera para llegar a la terraza. En algunos puntos se conservan mechinales, que debieron sostener la escalera, o quizá un piso intermedio de madera, a modo de descansillo y donde se guardaría el combustible para una hipotética hoguera de señales.

En conjunto, más que a una torre del homenaje se parece más a los modelos conocidos de torre atalaya o torre vigía, a lo que posiblemente estaba destinada, sin descartar una complementaria función simbólica.

En el lado Este de la torre existió un pequeño recinto, quizá reaprovechando estructuras almohades. Hoy apenas queda nada de este, pero en tiempos hubo unos muros que cerraban las aberturas naturales de la roca y dificultaban la aproximación a la puerta de la torre.

Hoy se accede al interior de la torre por un hueco abierto en el lado Oeste. Pero se trata de una ruptura reciente, como puede advertirse por su posición, y la falta de regularidad de sus laterales. La puerta original se sitúa en la cara Este, es baja y estrecha, cerrada con arco de medio punto (Lám. 74). Su deterioro impide determinar si tuvo marco de sillares, aunque el deterioro quizá se deba precisamente a su sustracción. Para llegar a ella era preciso rodear la torre por el Norte, por un estrecho y difícil reborde, ya que la peña al Sur presenta un corte casi liso, y luego entrar en el recinto por el Este.

\section{EI Tercer Recinto}

El Tercer Recinto es en la actualidad el espacio más desarticulado de la fortaleza, debido a la desaparición casi completa del muro de cierre Sur, así como de las estructuras que pudieran haber existido en el interior (Lám. 49). El recinto se presenta hoy como una pendiente dividida en dos zonas por un camino que permite recorrerlo. En algunos puntos de esa pendiente, sobre todo en la parte superior, aflora la roca, pero esa misma circunstancia indica que existió un aterrazamiento antiguo, que es el que ha dado lugar a la for- mación de la pendiente, por lo que no hay duda de que la zona tiene amplias posibilidades arqueológicas.

A la muralla que cerraría el Tercer Recinto (Muro Sur) pueden tribuirse varios fragmentos de muro. Aunque no tienen el mismo aspecto, por la diferencia de conservación y quizá debido a diversas reparaciones. El de mayor entidad (Lams. 75, 76) está situado bajo las torres IV y $V$. Es muy delgado para lo que suele ser normal en una muralla. No se descarta por tanto que fuese una cerca, que cerraría lo que inicialmente sería un albacar, pero que quizá luego fue reaprovechada. Tampoco puede descartarse por completo que en realidad este fragmento no formase parte de la muralla, sino que perteneciese a una vivienda $u$ otro edificio situado en el interior del Recinto.

Otros restos atribuibles a esa misma cerca tiene aún menos entidad. Entre ellos destaca un muro que se adosa a la cimentación de la torre VI (Lám. 77). Este muro es posiblemente reciente, colocado precisamente para contener la ladera, pero por su posición es posible que se apoye sobre el muro original. Como señalamos al hablar de la torre, el enfoscado que hoy la recubre impide determinar donde encastraba exactamente el lienzo Sur.

Cabe por último referirse al muro existente bajo un aterrazamiento moderno, que constituye uno de los "miradores" que se han colocado en esta zona (Lám. 78). El lugar, una "lengua" que se abre desde la base del Recinto II, ampliando la superficie, con cortados a ambos lados, implica que el muro describiría una curva, para adaptarse al terreno. En el nivel actual de observación, no podemos descartar que ese cimiento sea también un muro de aterrazamiento más antiguo, pero su potencia, el material utilizado y su disposición bajo el "mirador", hacen pensar más bien en que formase parte de la muralla.

\section{LA CASA}

Al pie del lienzo de separación entre los Recintos II y III, en su sector central, sobresale la roca de la vertical del mencionado lienzo, 
como si se tratase de una zarpa de cimentación. Esta roca fue recortada en un sector, obteniendo una pared plana. En los laterales de la misma, donde en apariencia no existía continuidad con las vecinas, se colocaron dos muros (Lams. 79, 80). Podría interpretarse todo esto como un intento de regularizar la zona, teniendo los muros la función de dar solidez al cimiento en que se apoya la muralla.

Pero el rebaje de la roca sólo se ha efectuado en un sector, y los muros no soportan en ningún caso la muralla. Por ello, creemos que hipotéticamente pudieron formar los lados de una habitación. No se prolongan en la actualidad más allá de la roca, porque el terreno delante de este conjunto ha sido rebajado por debajo de la hipotética línea de cimentación, por lo que tampoco existen posibilidades de encontrar niveles "in situ" relacionados directamente con ese conjunto.

\section{CONCLUSIÓN}

El análisis detenido de la fortaleza de La Iruela muestra que se trata de un pequeño conjunto, con múltiples elementos de gran interés, que en cierta medida resume los avances y organización a que se había llegado en la fortificación a mediados del siglo XIII.

No obstante, es también evidente por lo expuesto, que aún quedan muchos aspectos por aclarar. Frente a una visión inicial, de que se trata de una ruina que no podía dar mucho más de sí, resulta evidente que conserva una potente estratigrafía, y esconde muchos elementos a cerca de la organización para la vida diaria, más allá del mero aspecto defensivo.

El paso siguiente sería efectuar un detallado plano topográfico del lugar, así como unir excavaciones y arqueología de la arquitectura, para aclarar muchos de los problemas cronológicos que subsisten. 


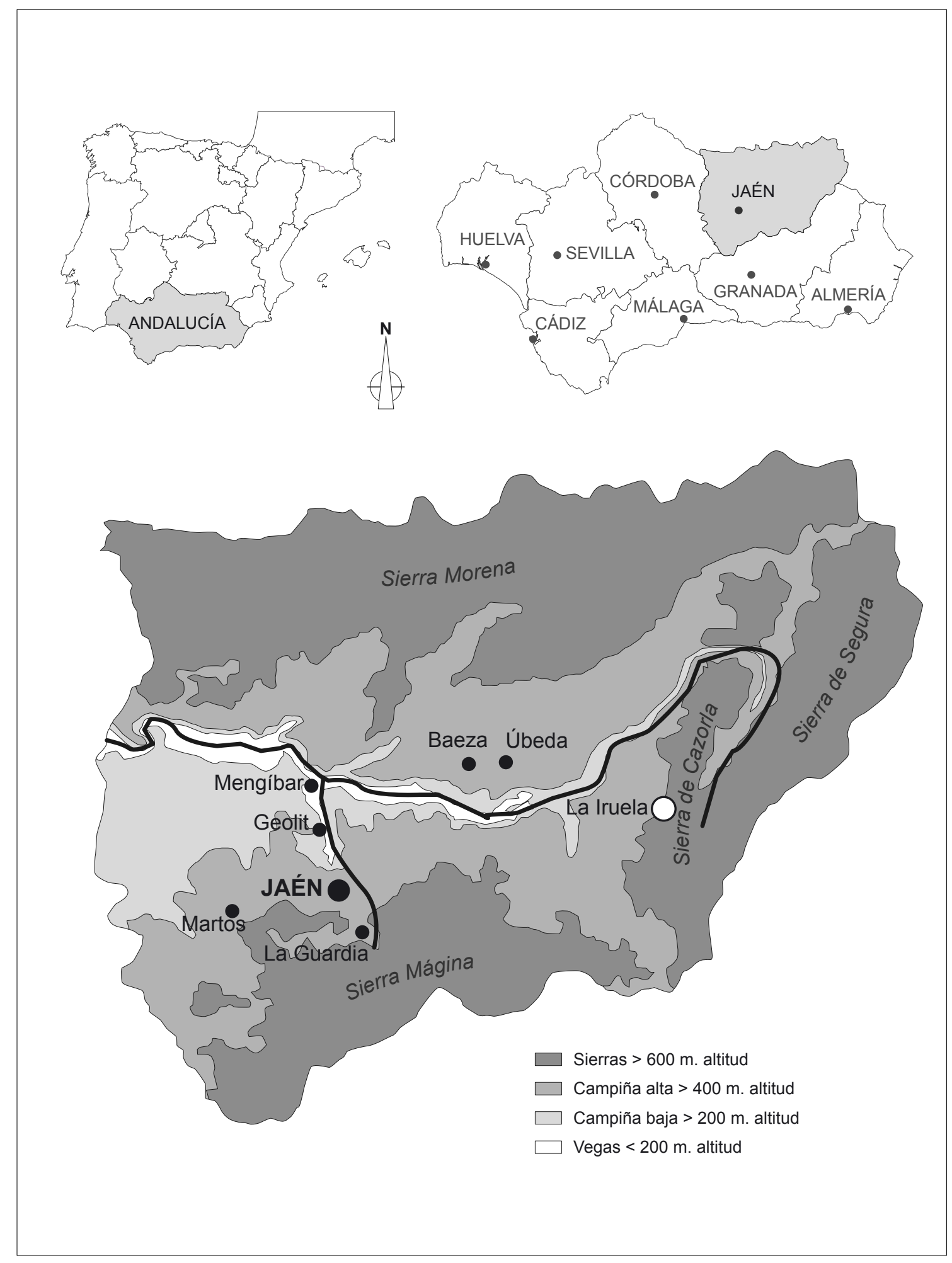

Fig. I. Situación de La Iruela 


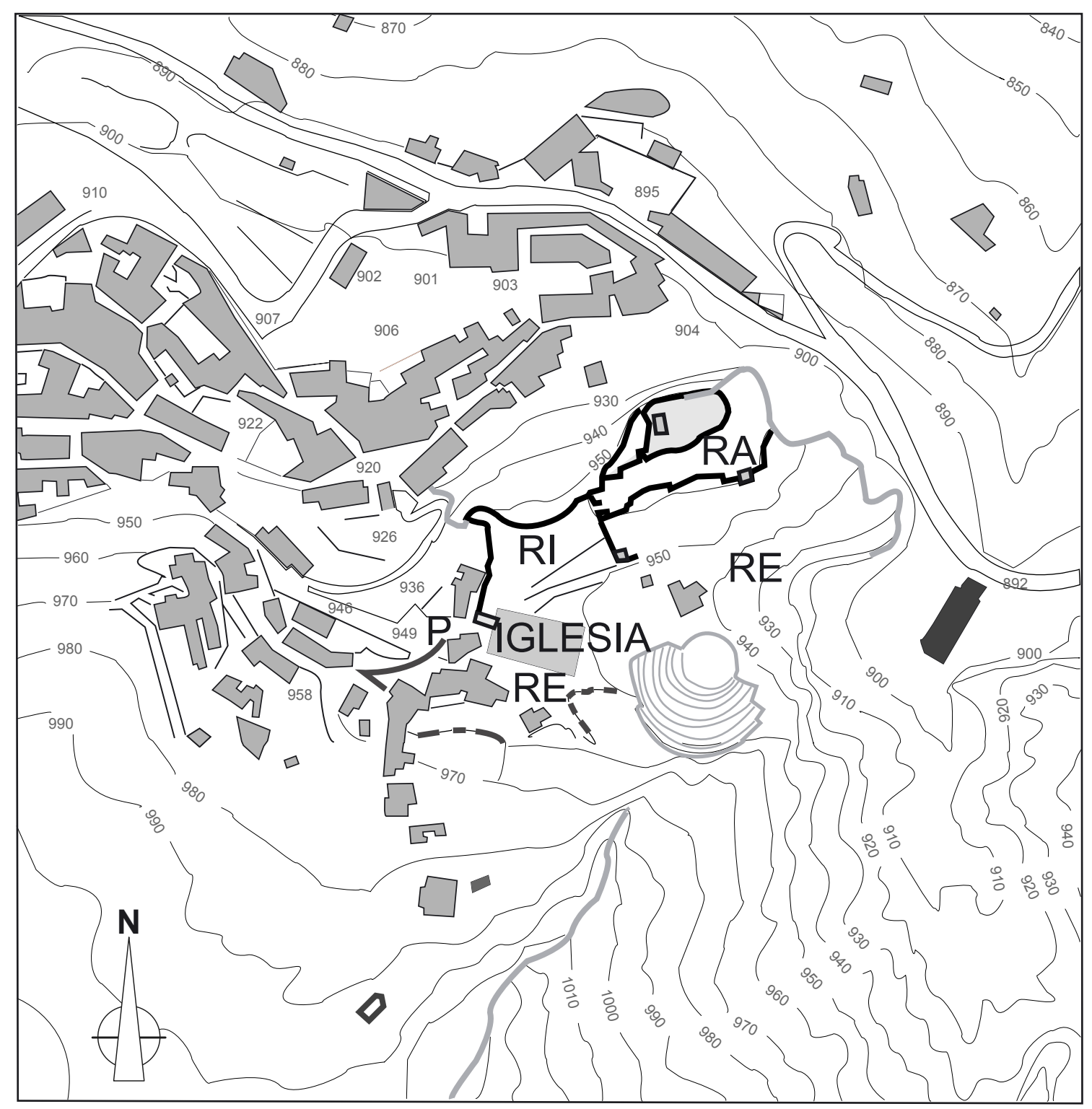

Fig. 2. La Iruela. Castillo y población 


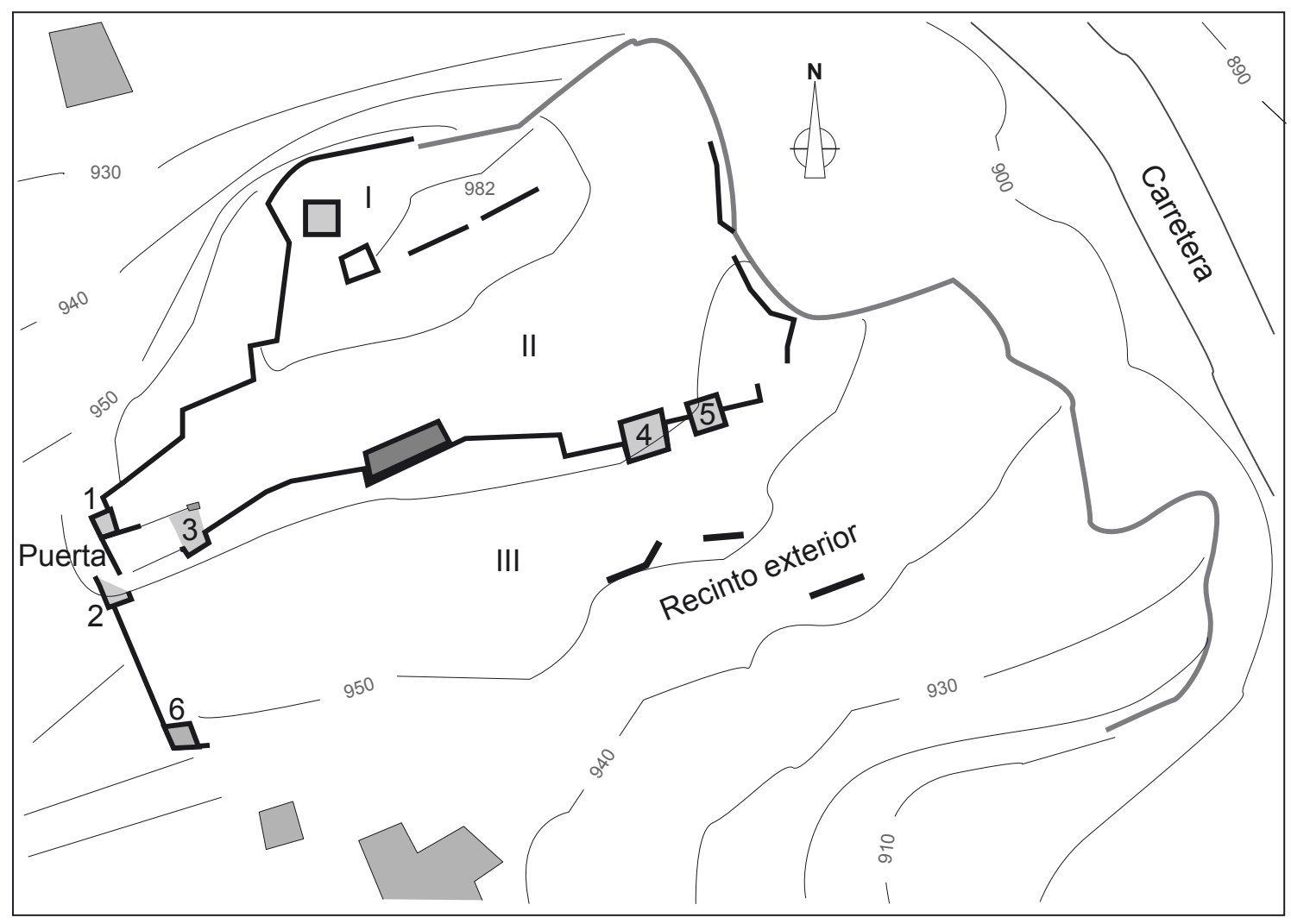

Fig. 3. La Iruela. Recintos de la fortaleza

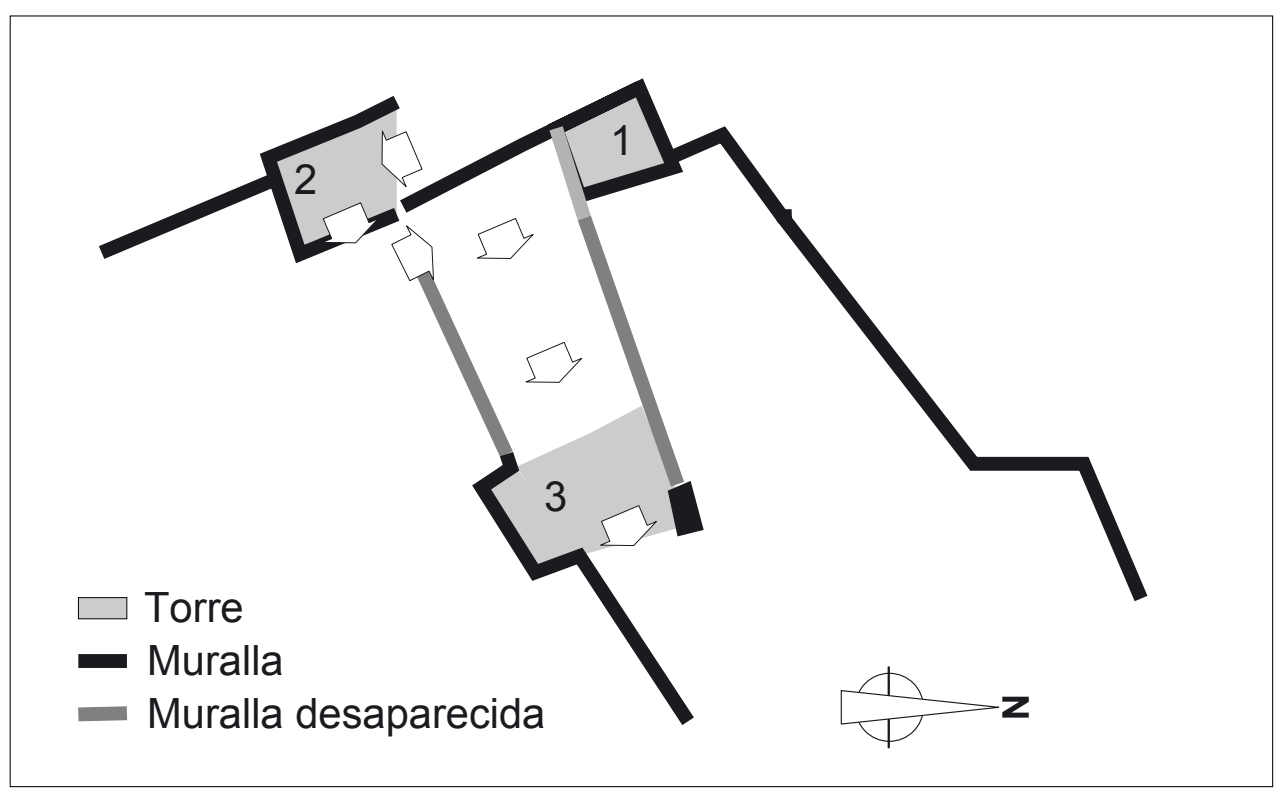

Fig. 4. Croquis de la puerta 


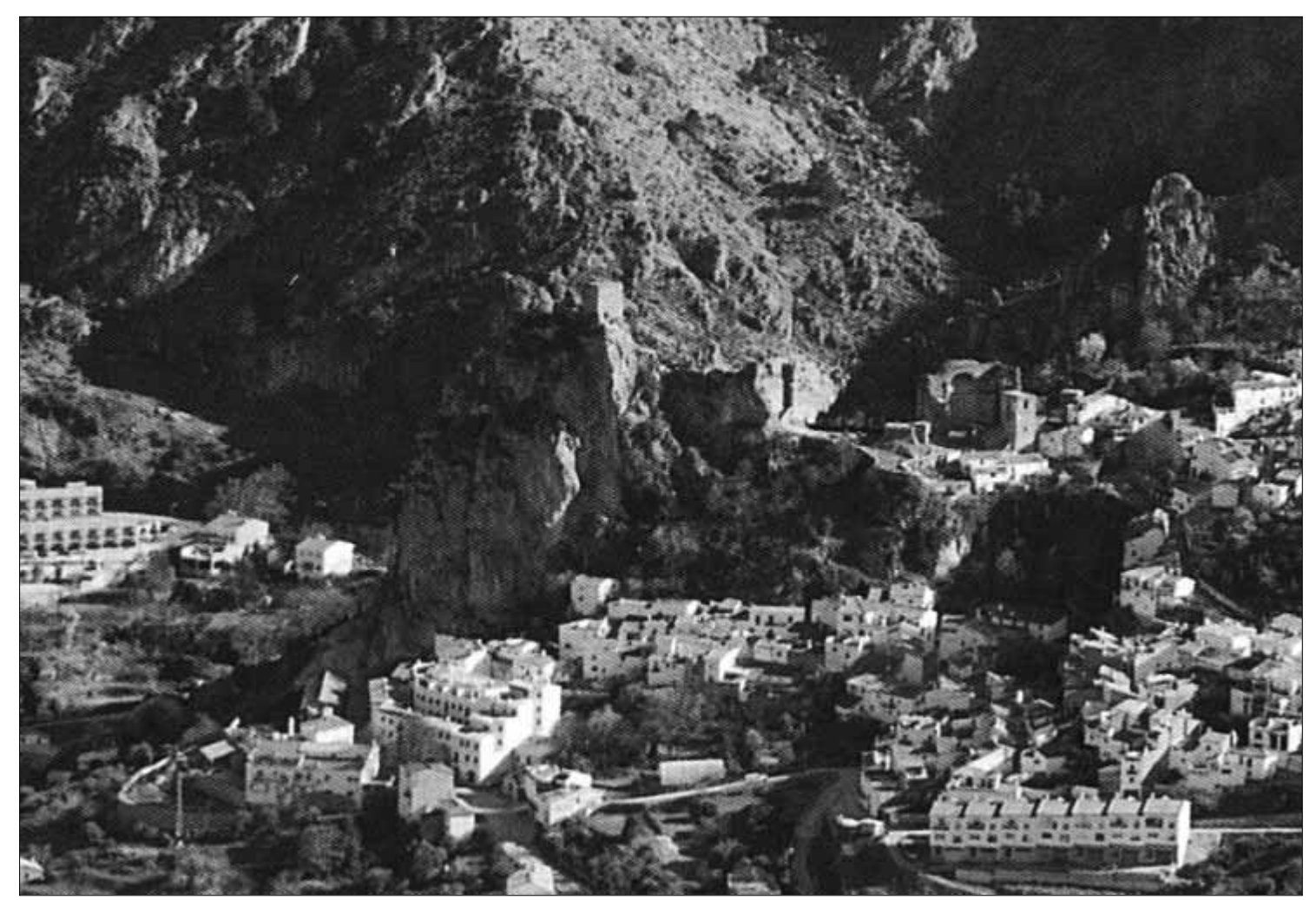

Lam. I. La Iruela. Vista general desde el Norte

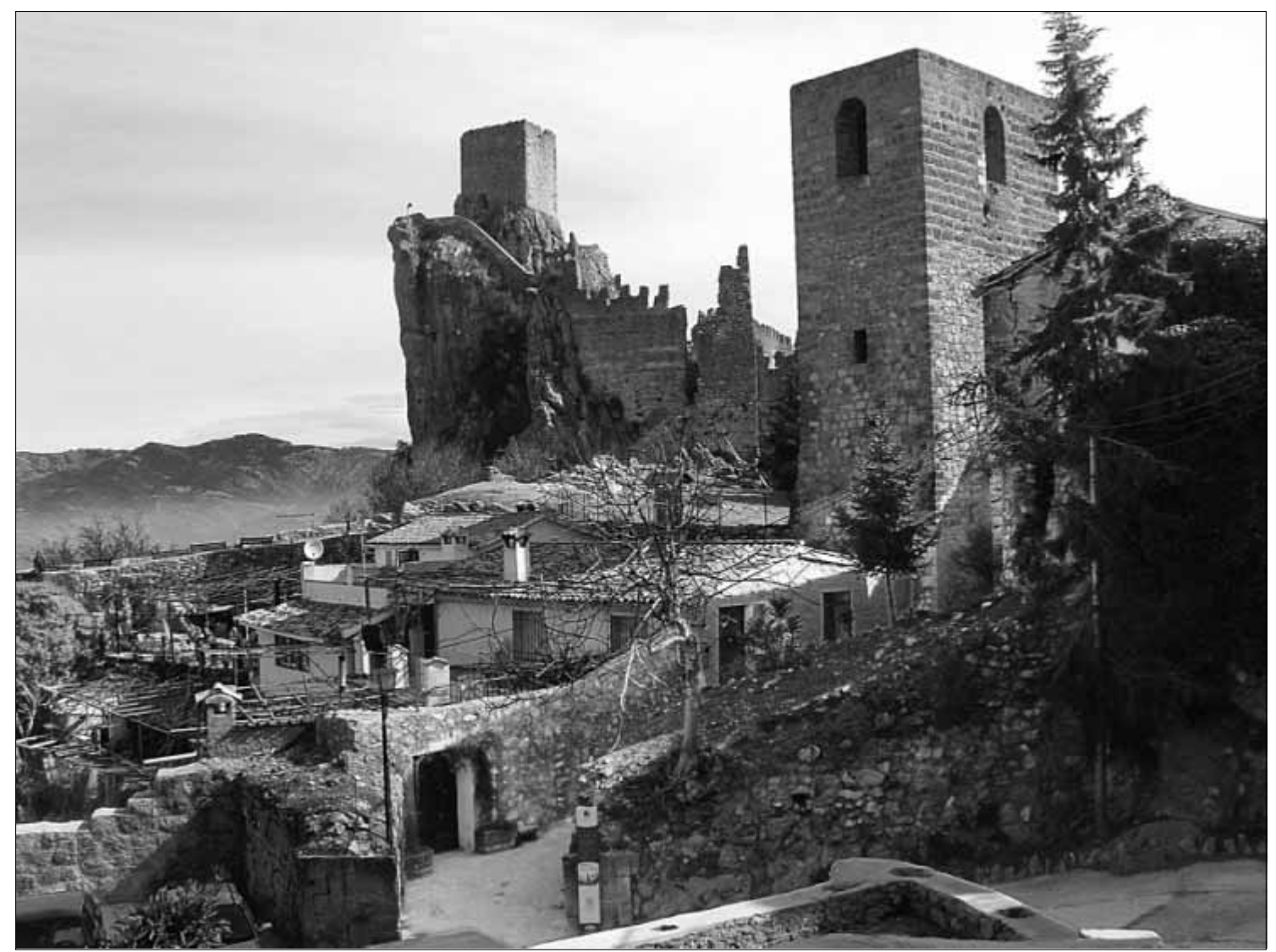

Lam. 2. La Iruela. El muro del Recinto Exterior en primer plano 


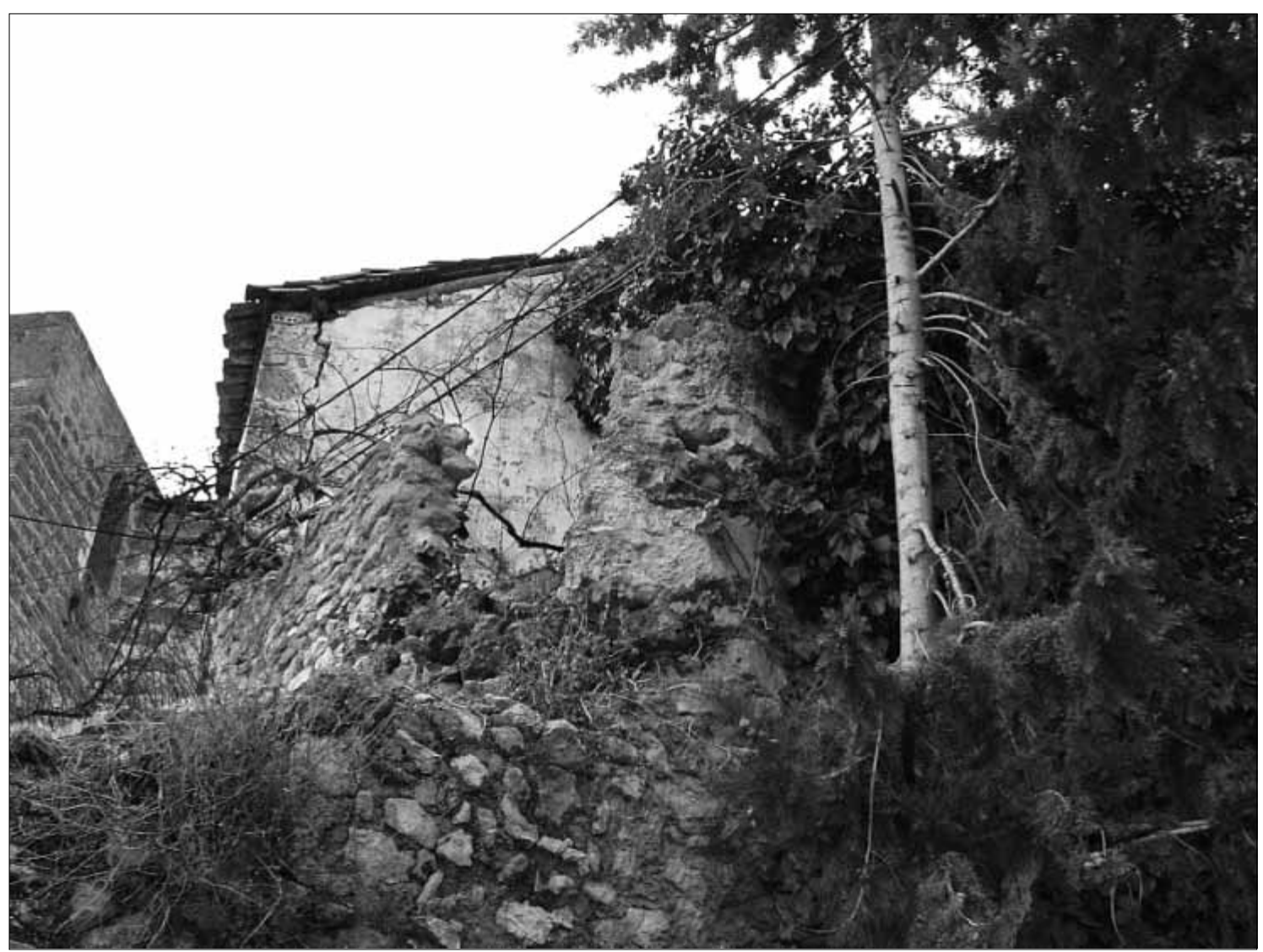

Lam. 3. El muro Oeste del Recinto Exterior. Detalle

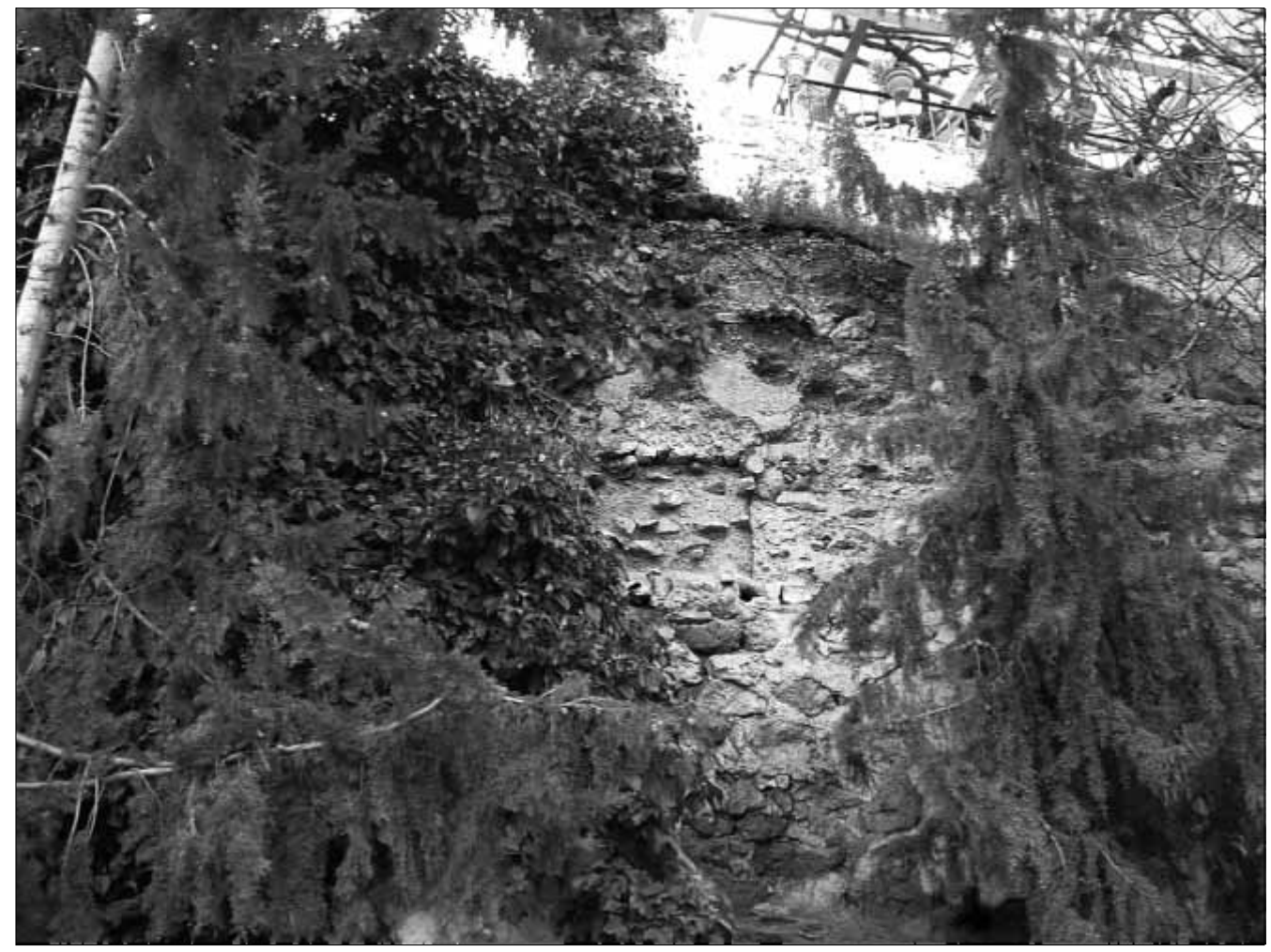

Lam. 4. El muro Oeste del Recinto Exterior. Detalle 


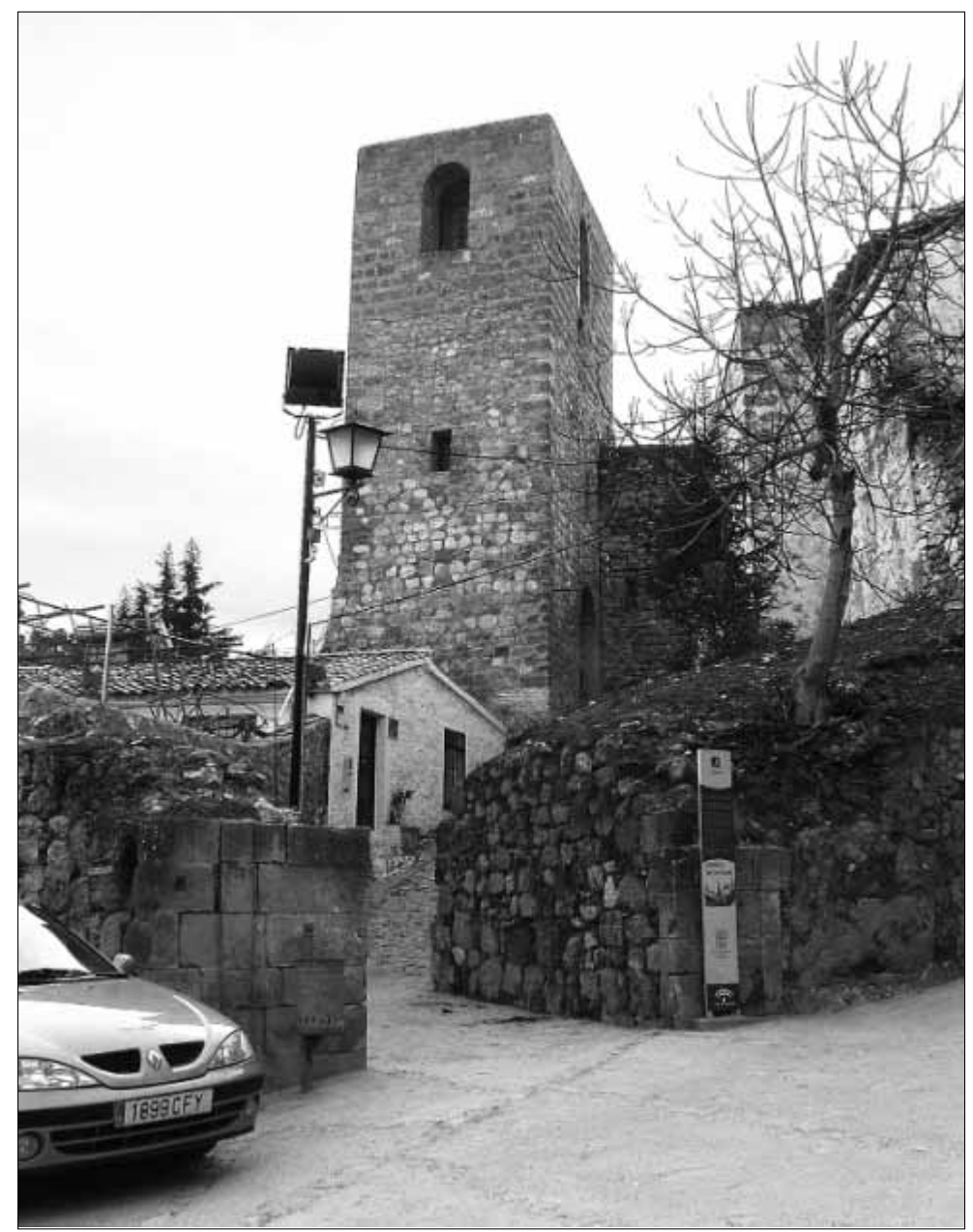

Lam. 5. Puerta del

Recinto Exterior

Lam. 6. Puerta del Recinto Exterio

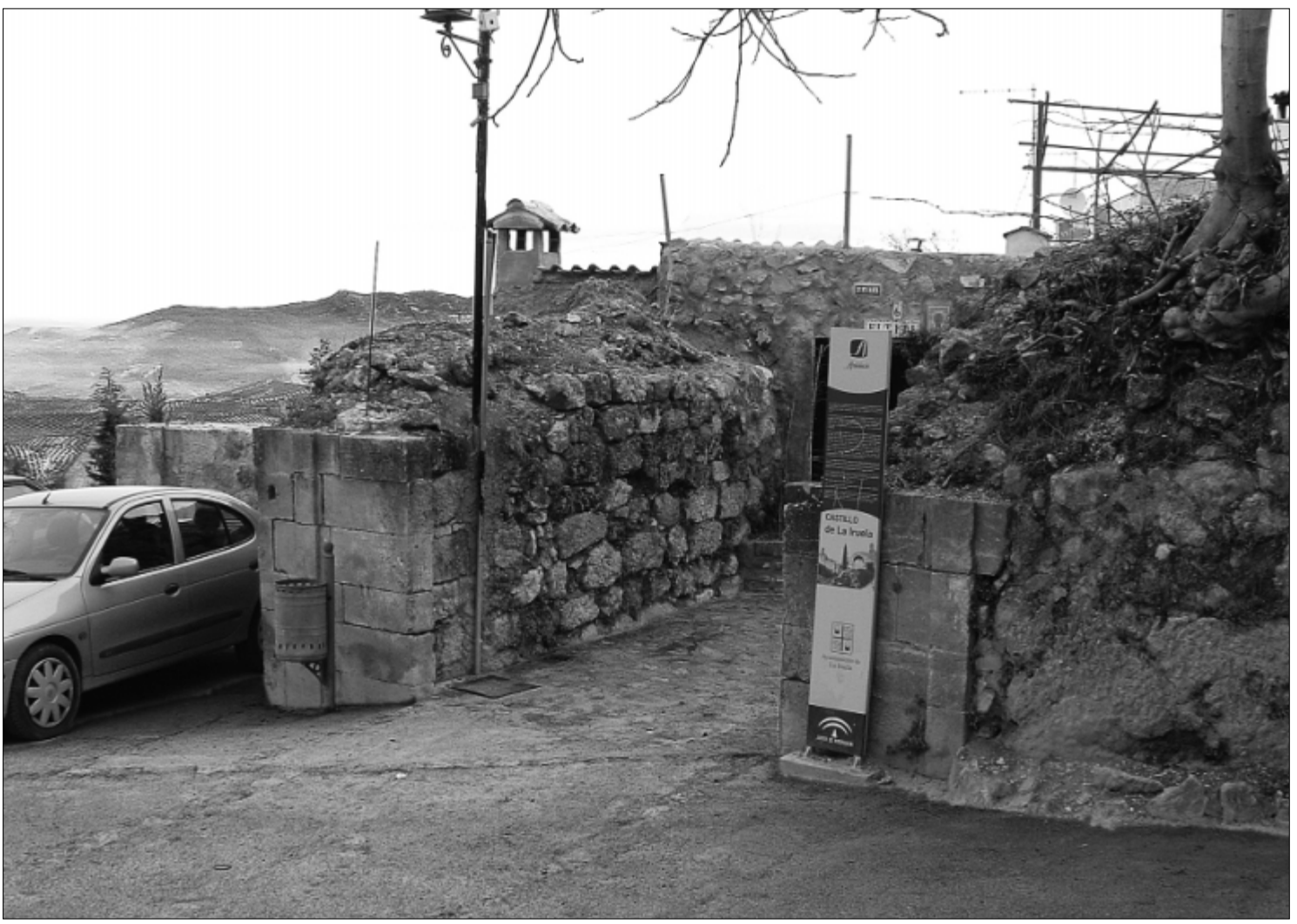




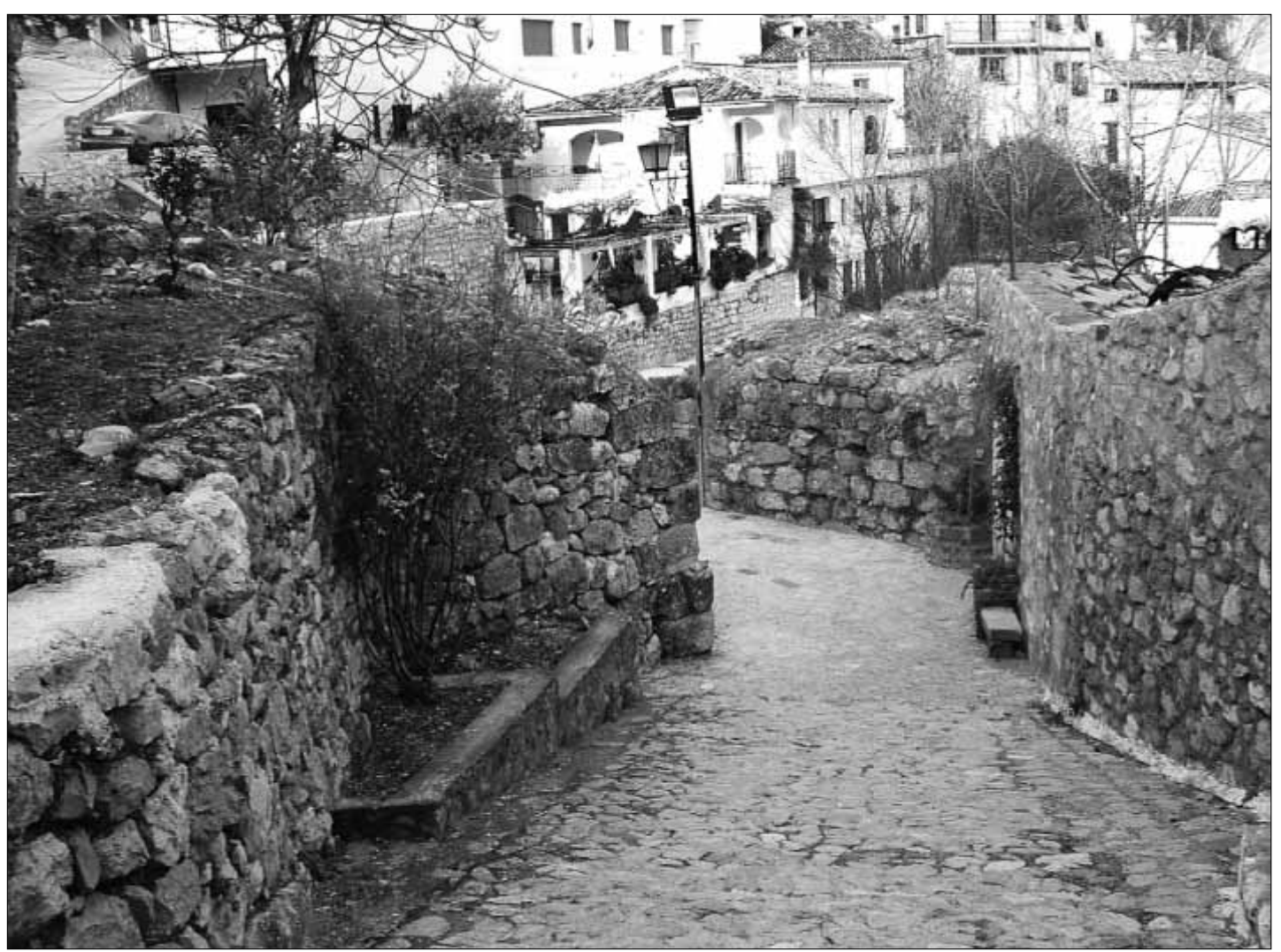

Lam. 7. Acceso al Recinto Exterior

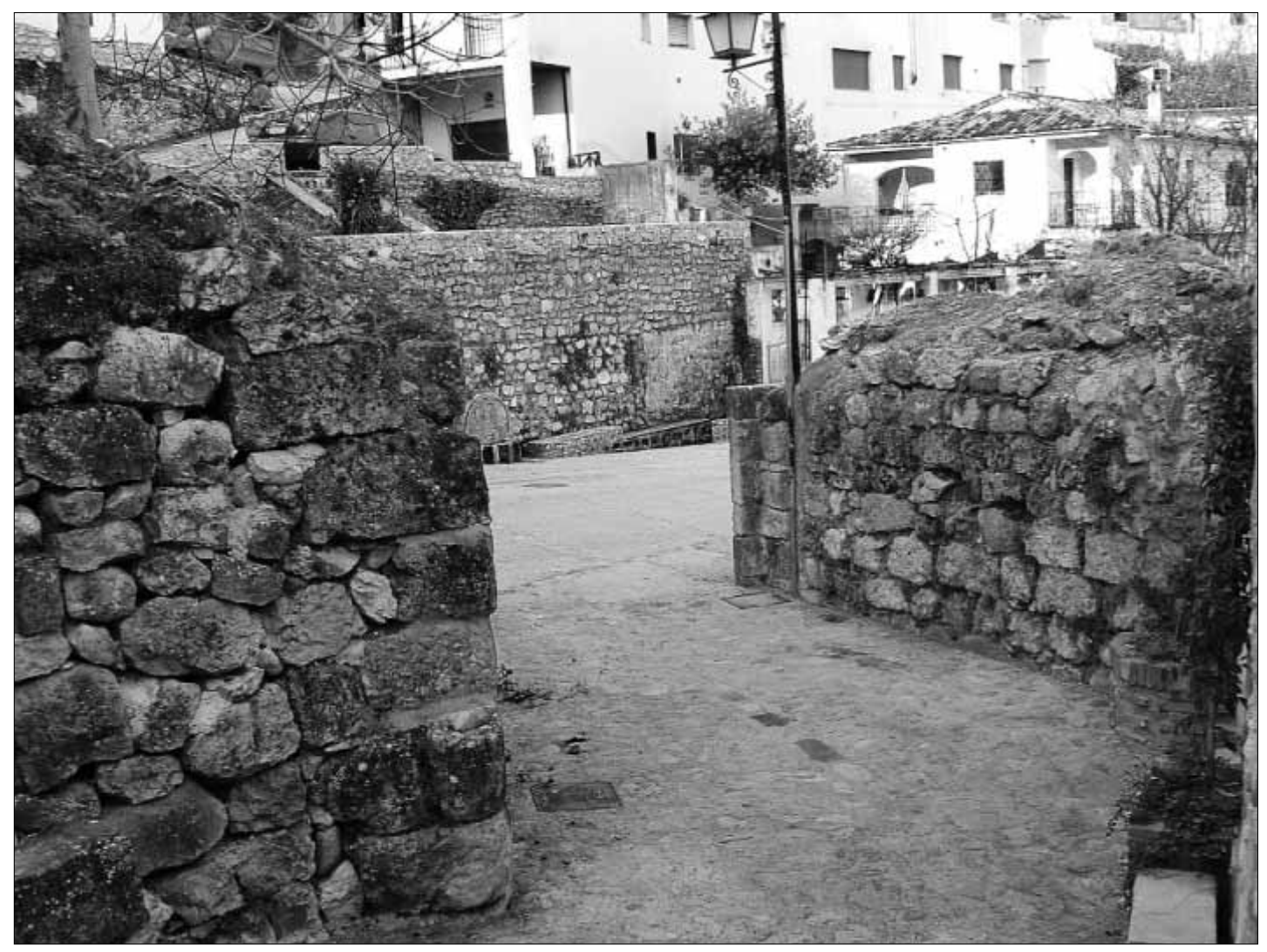

Lam. 8. Acceso al Recinto Exterior. Detalle 


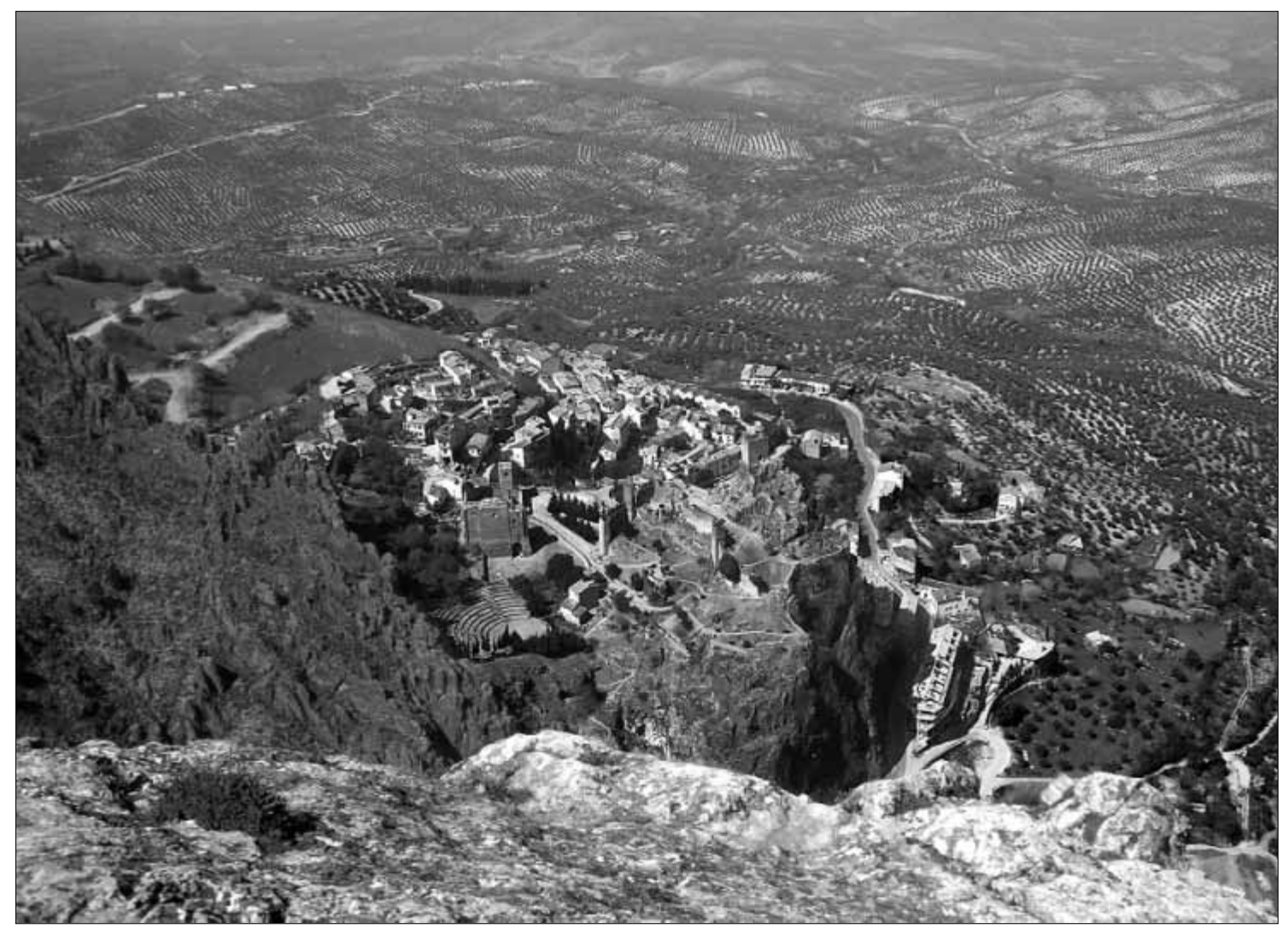

Lam. 9. Vista del Conjunto desde el Este

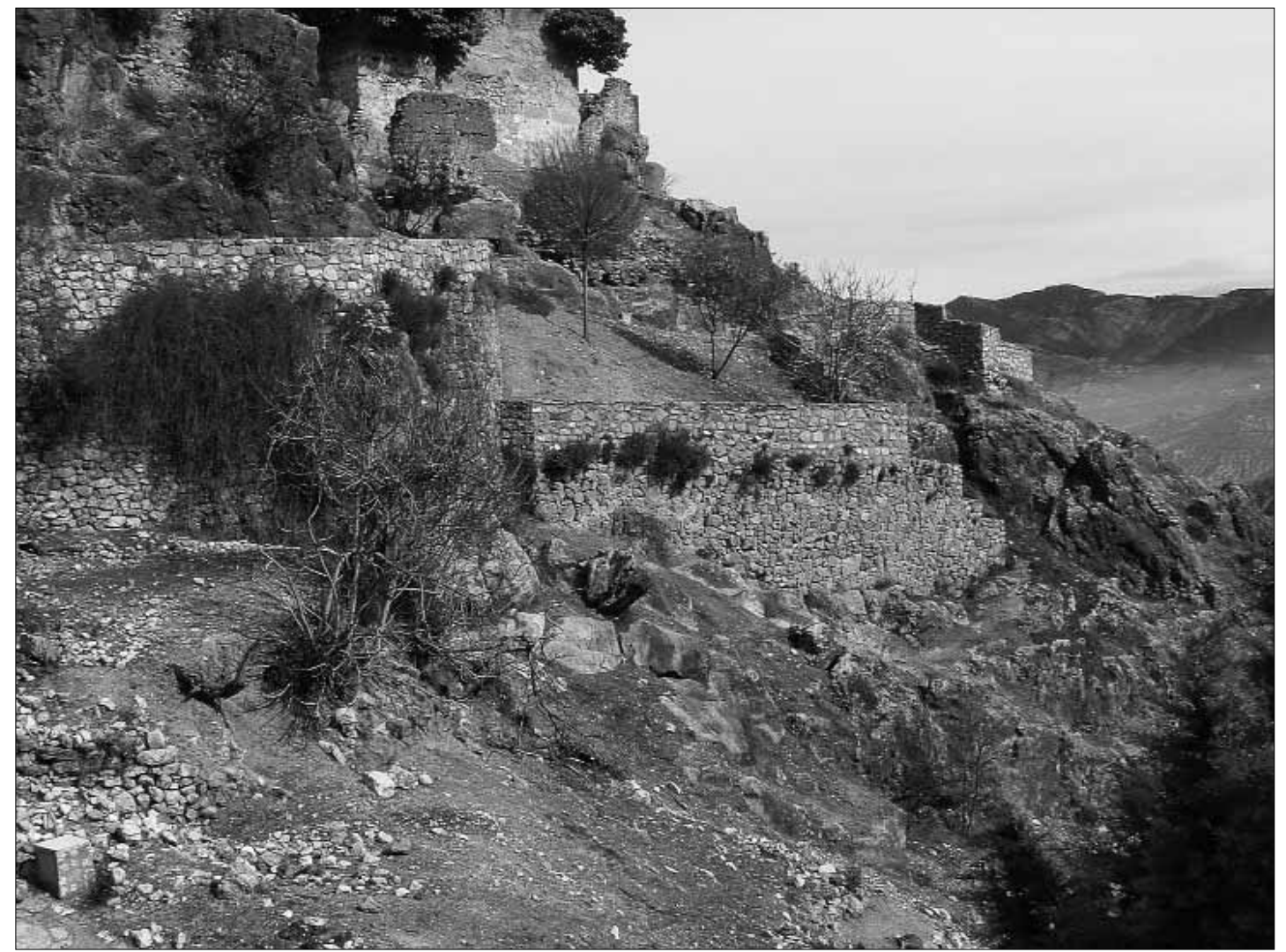

Lam. I0. Muros de aterrazamiento. Detalle 


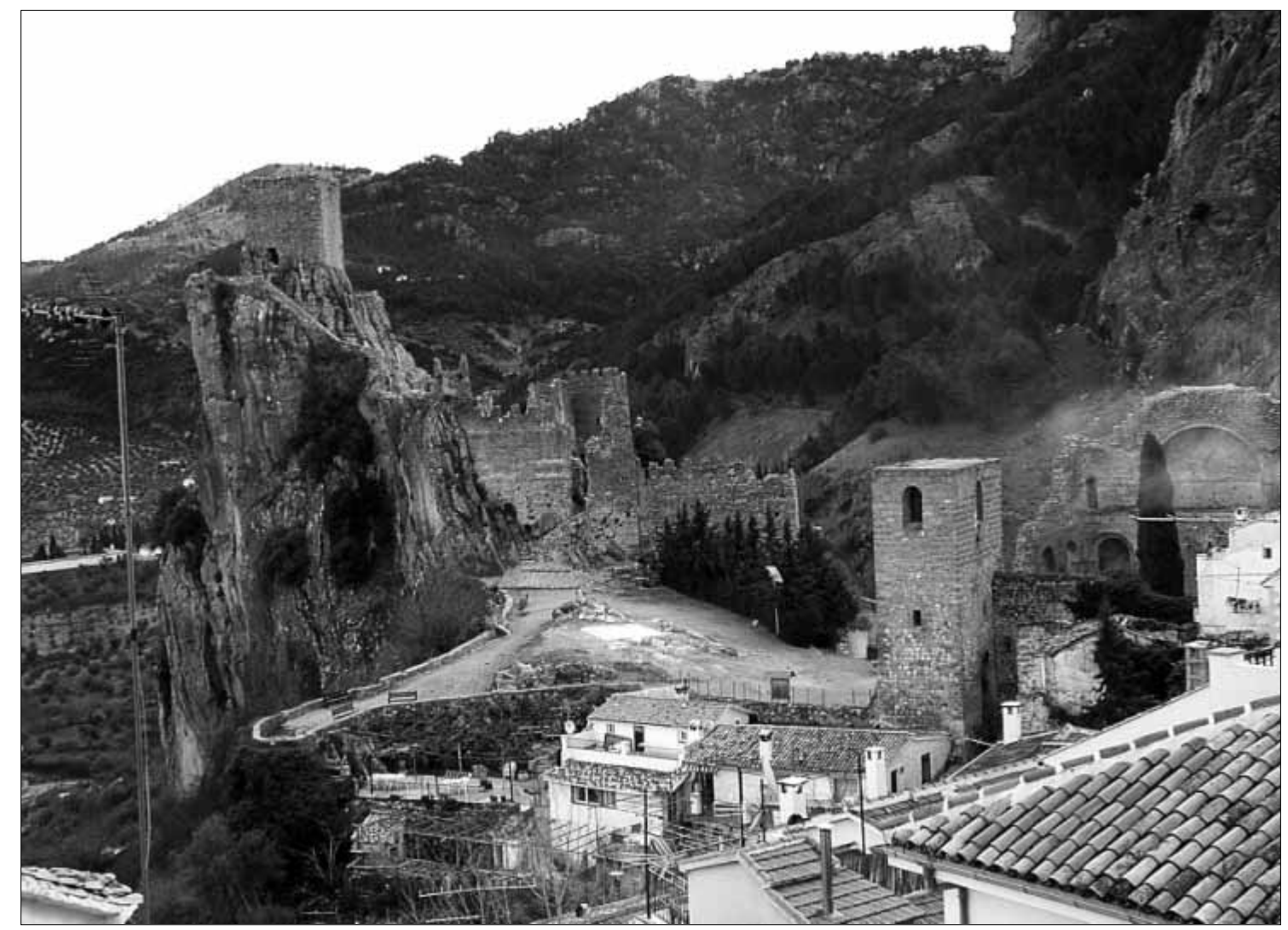

Lam. I I. Recinto Interior desde el Oeste

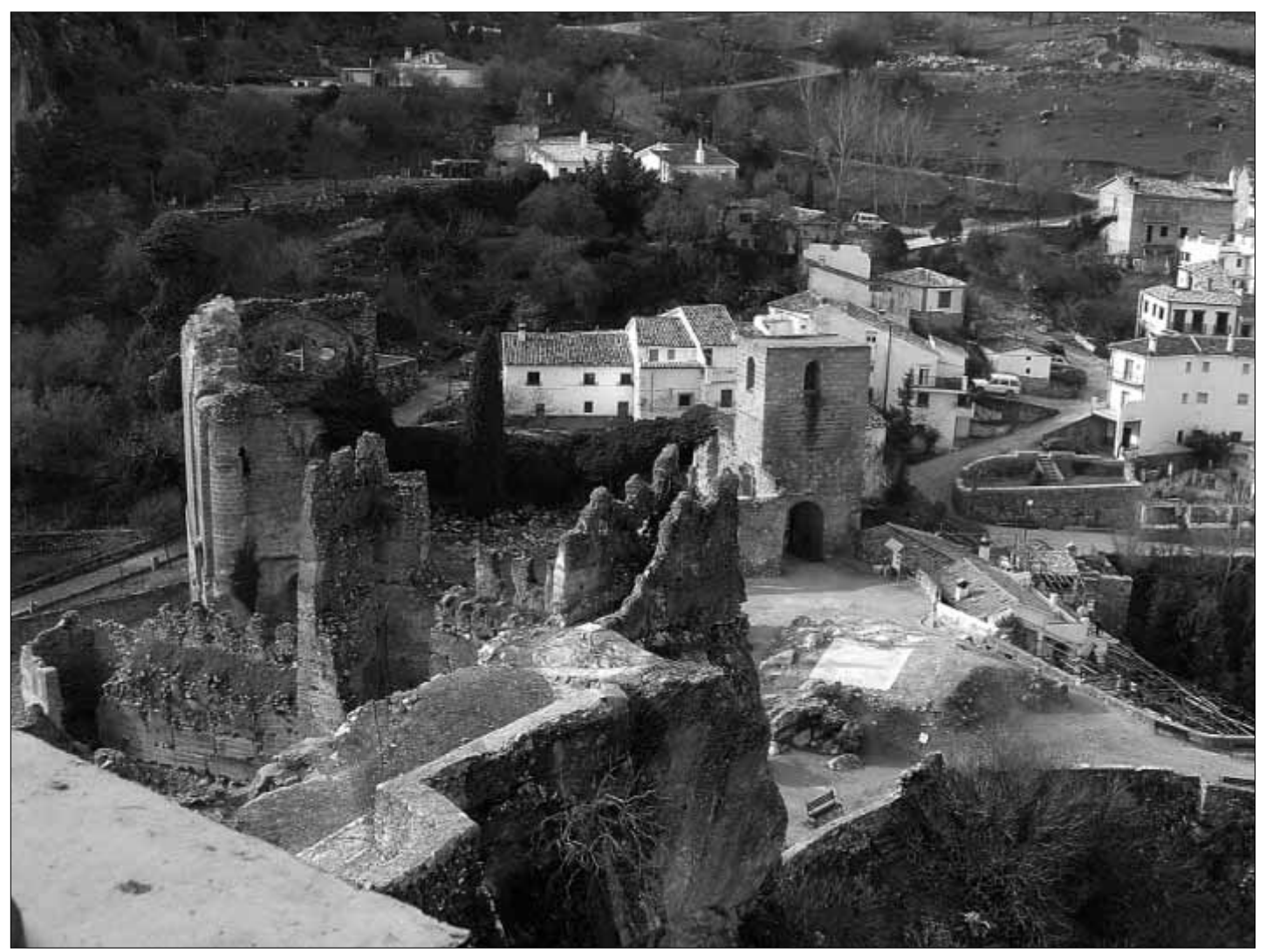

Lam. I2. Recinto Interior desde el Norte 


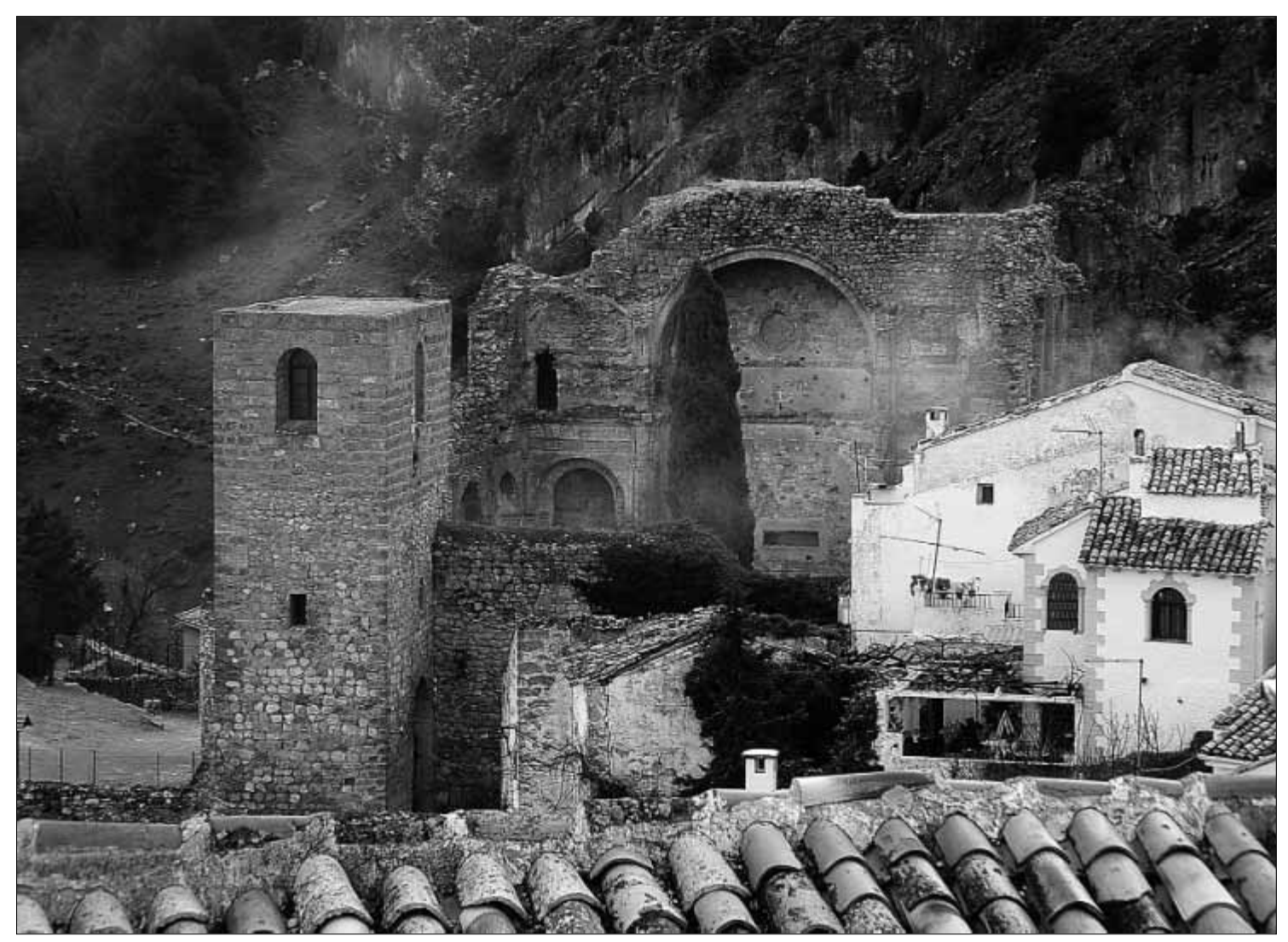

Lam. 13. Torre-Puerta

e Iglesia

Lam. 14. Torre-Puerta desde la plaza

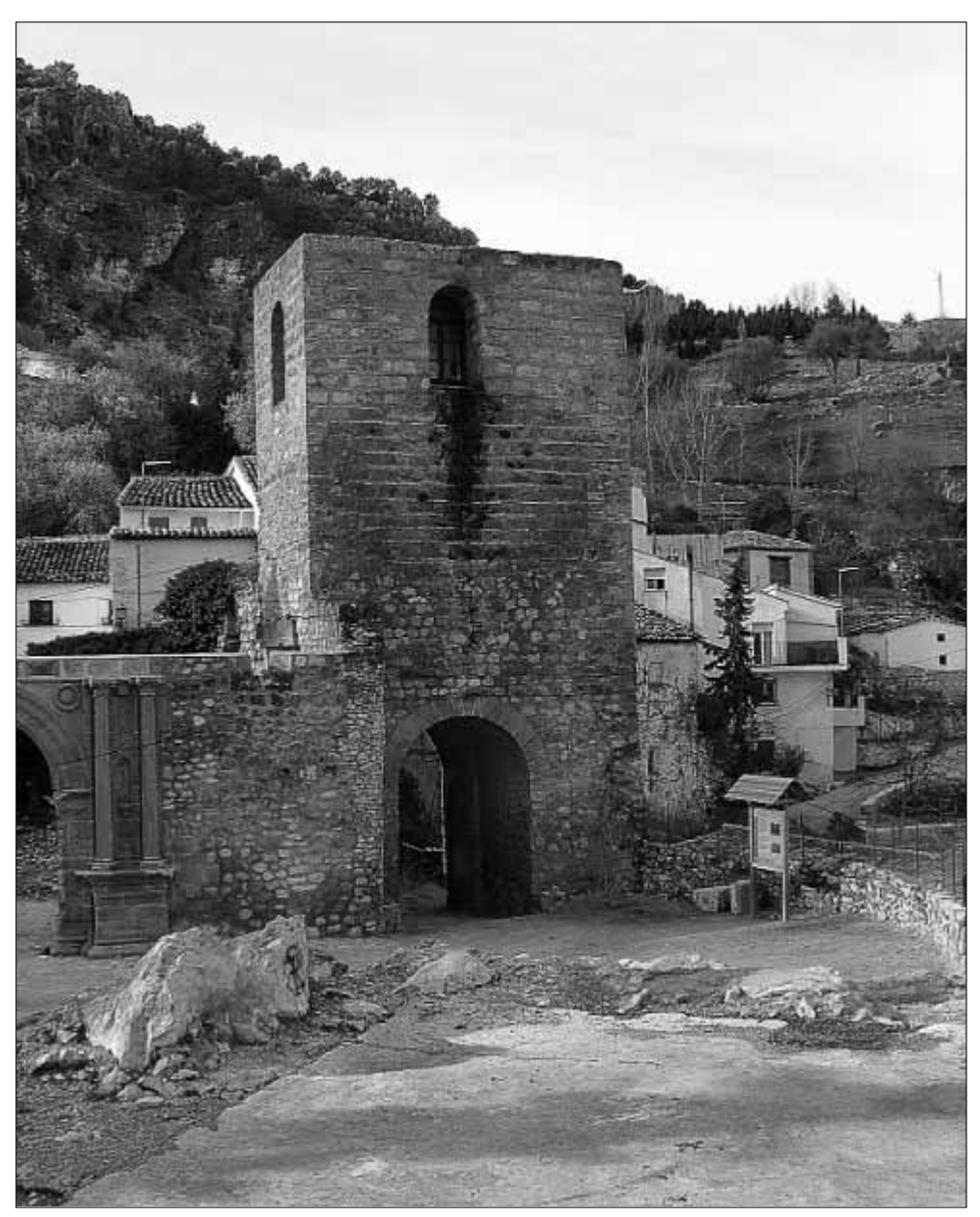




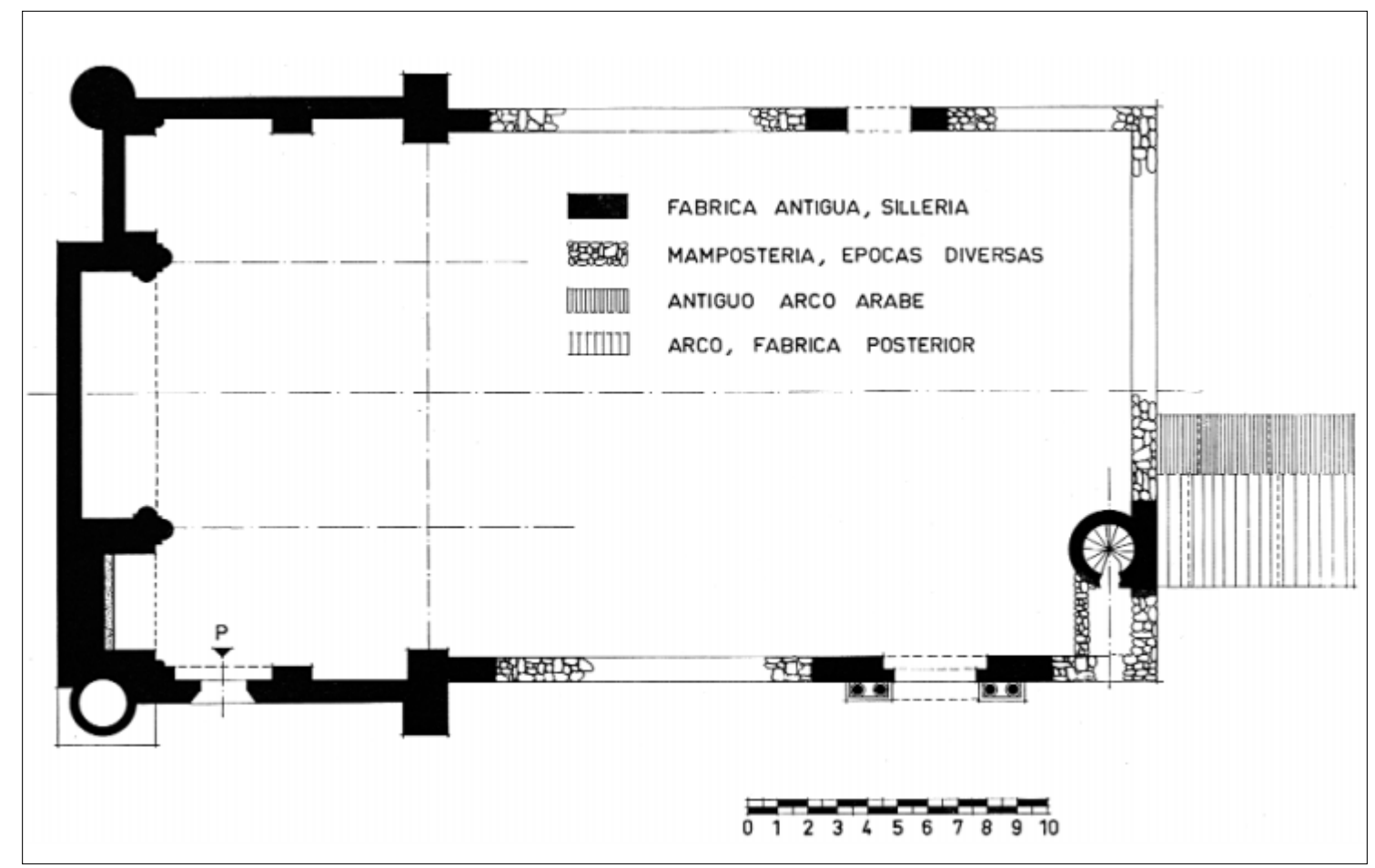

Lam. I5. Plano de la Iglesia

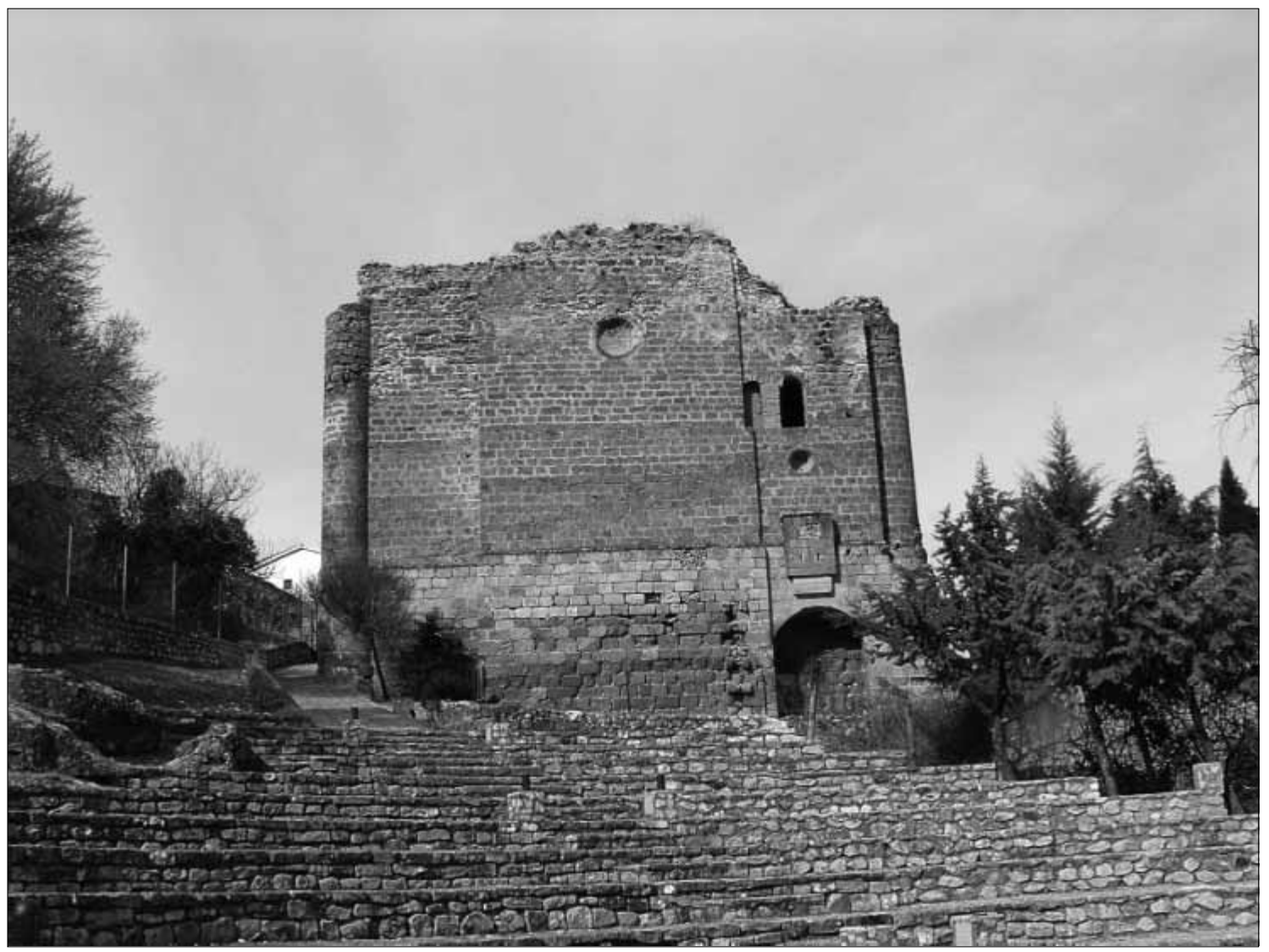

Lam. 16. Exterior de la cabecera desde el Este 


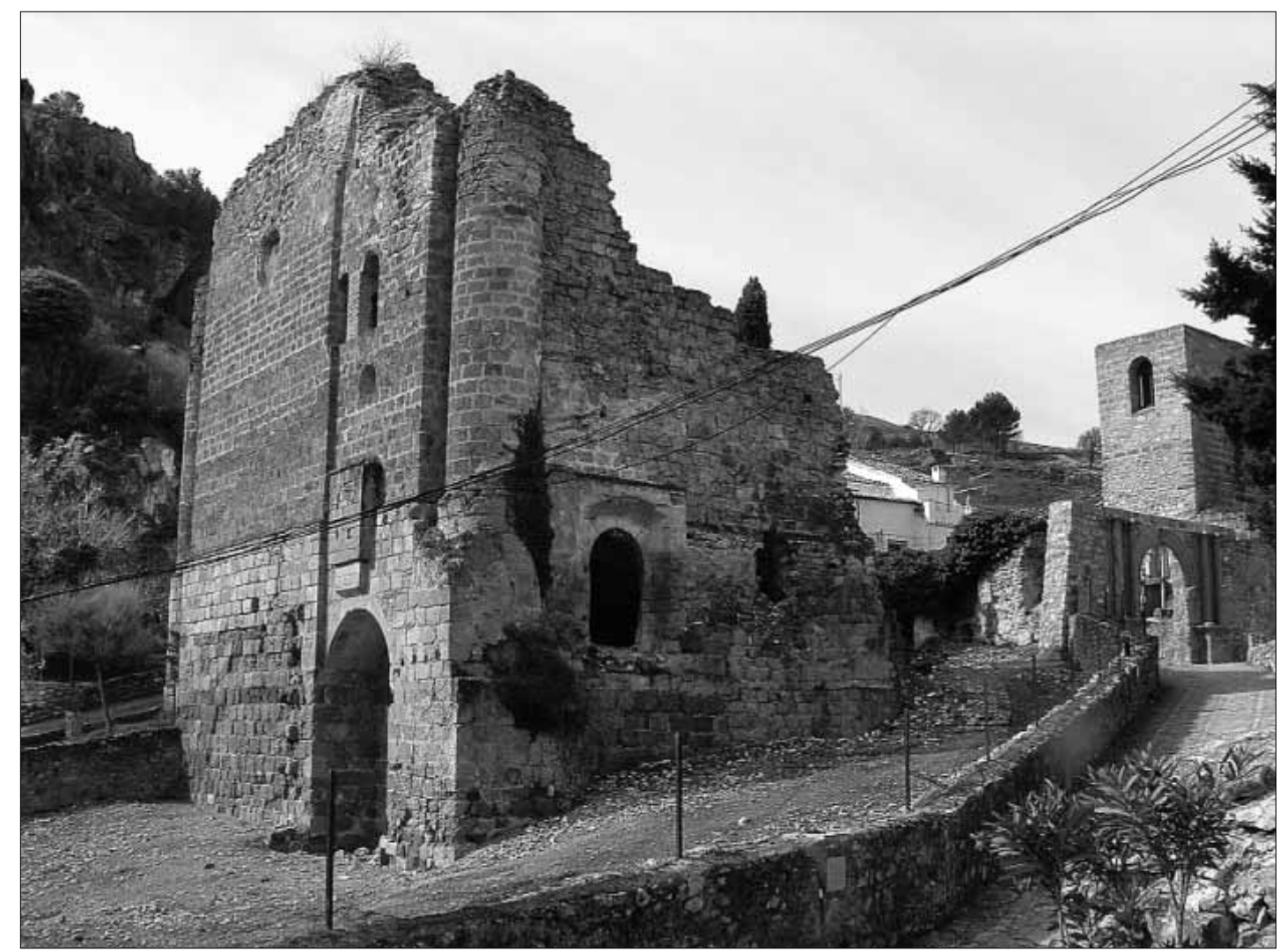

Lam. I7. Exterior de la cabecera desde el Noreste

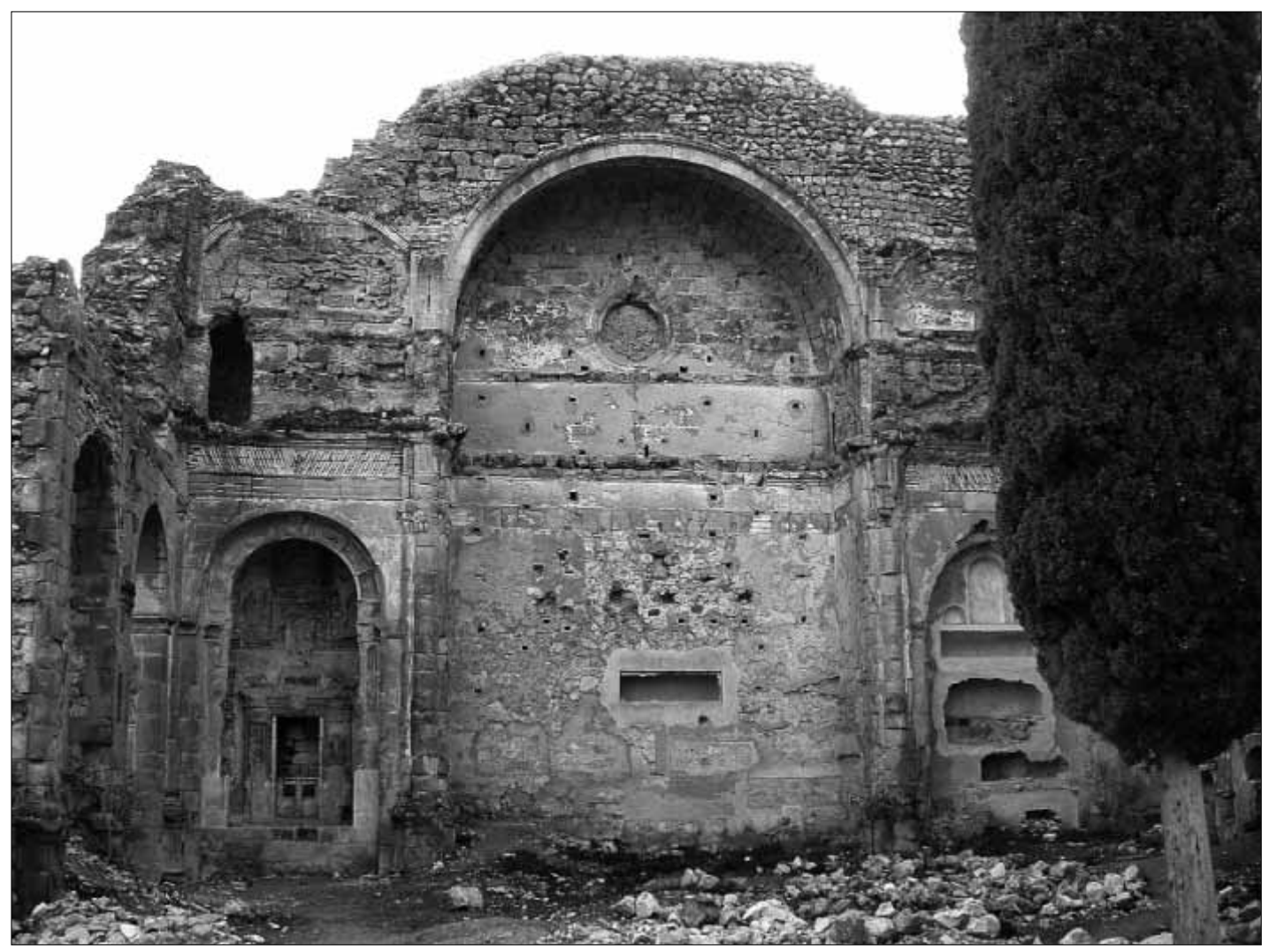

Lam. I 8. Interior de la cabecera 


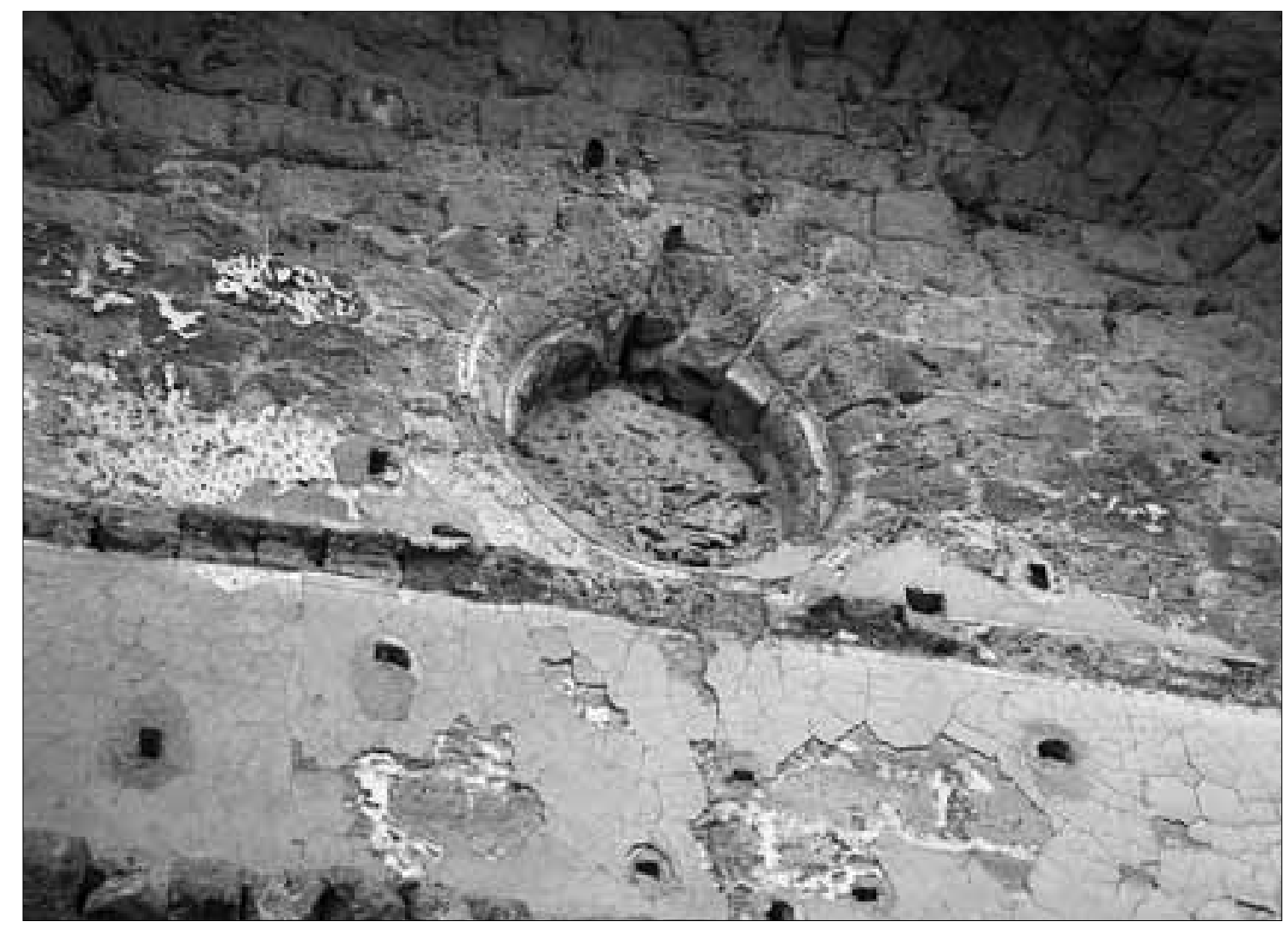

Lam. 19. Rosetón

Lam. 20. Capilla Norte

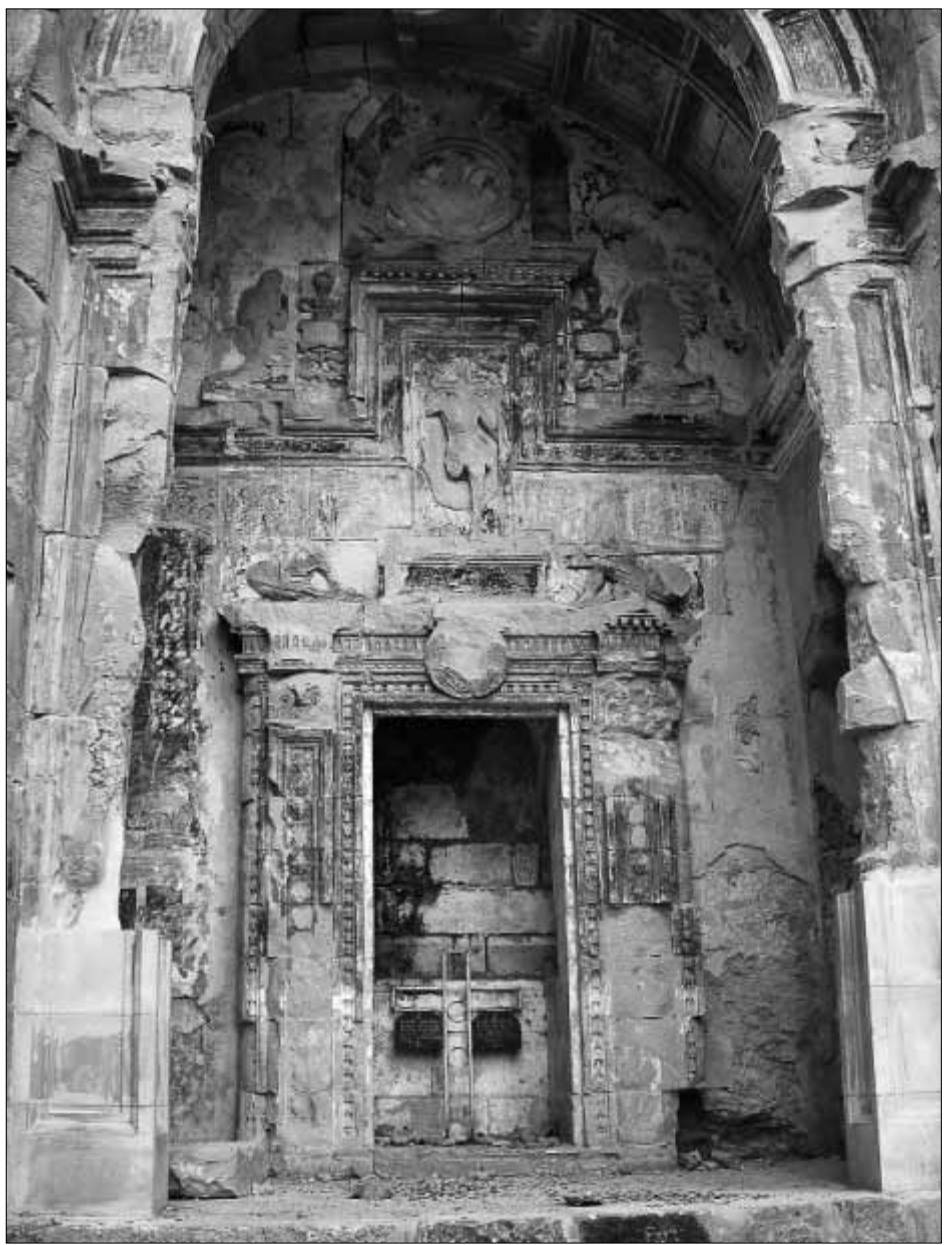



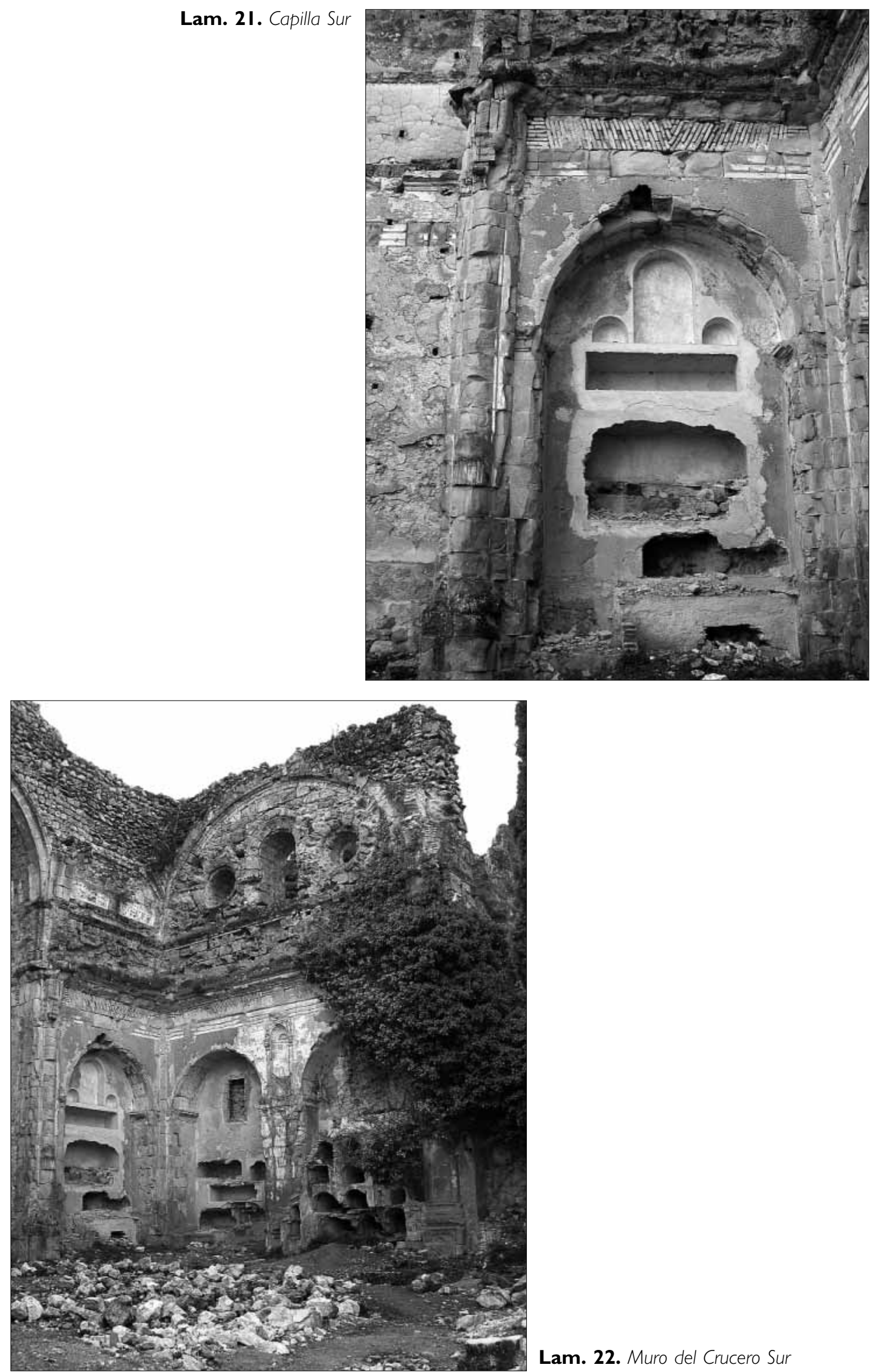

Lam. 22. Muro del Crucero Sur 


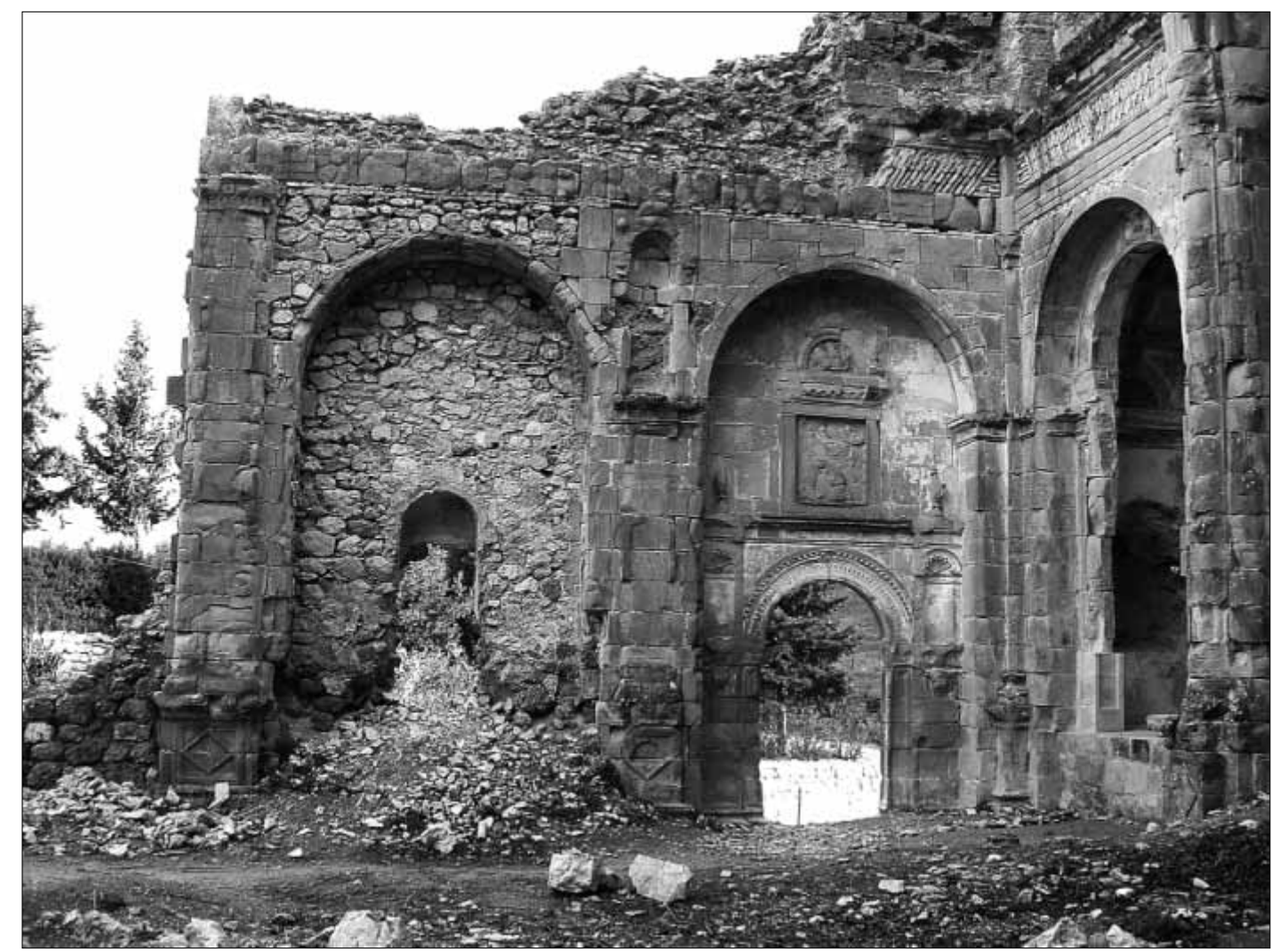

Lam. 23. Muro

del Crucero Norte

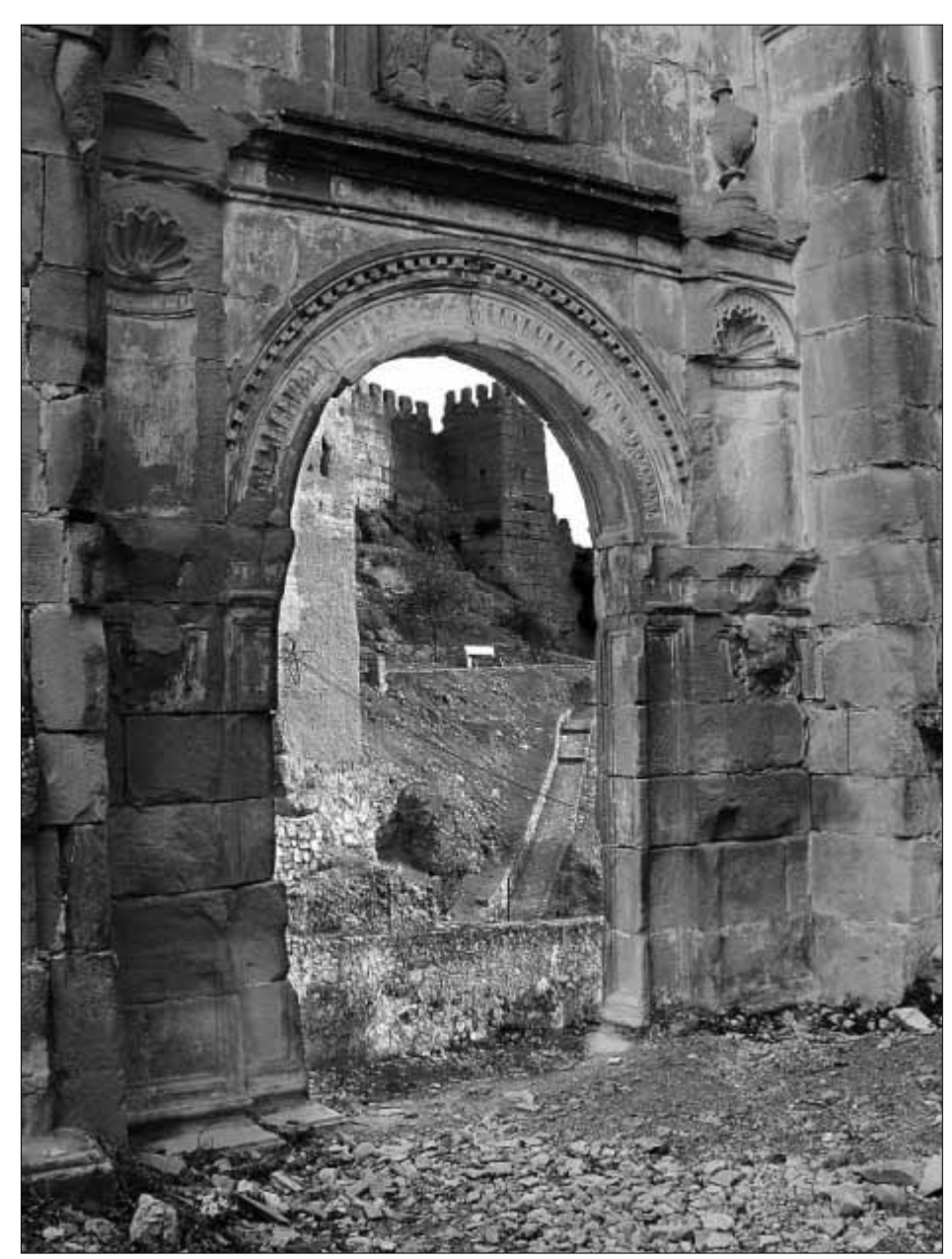




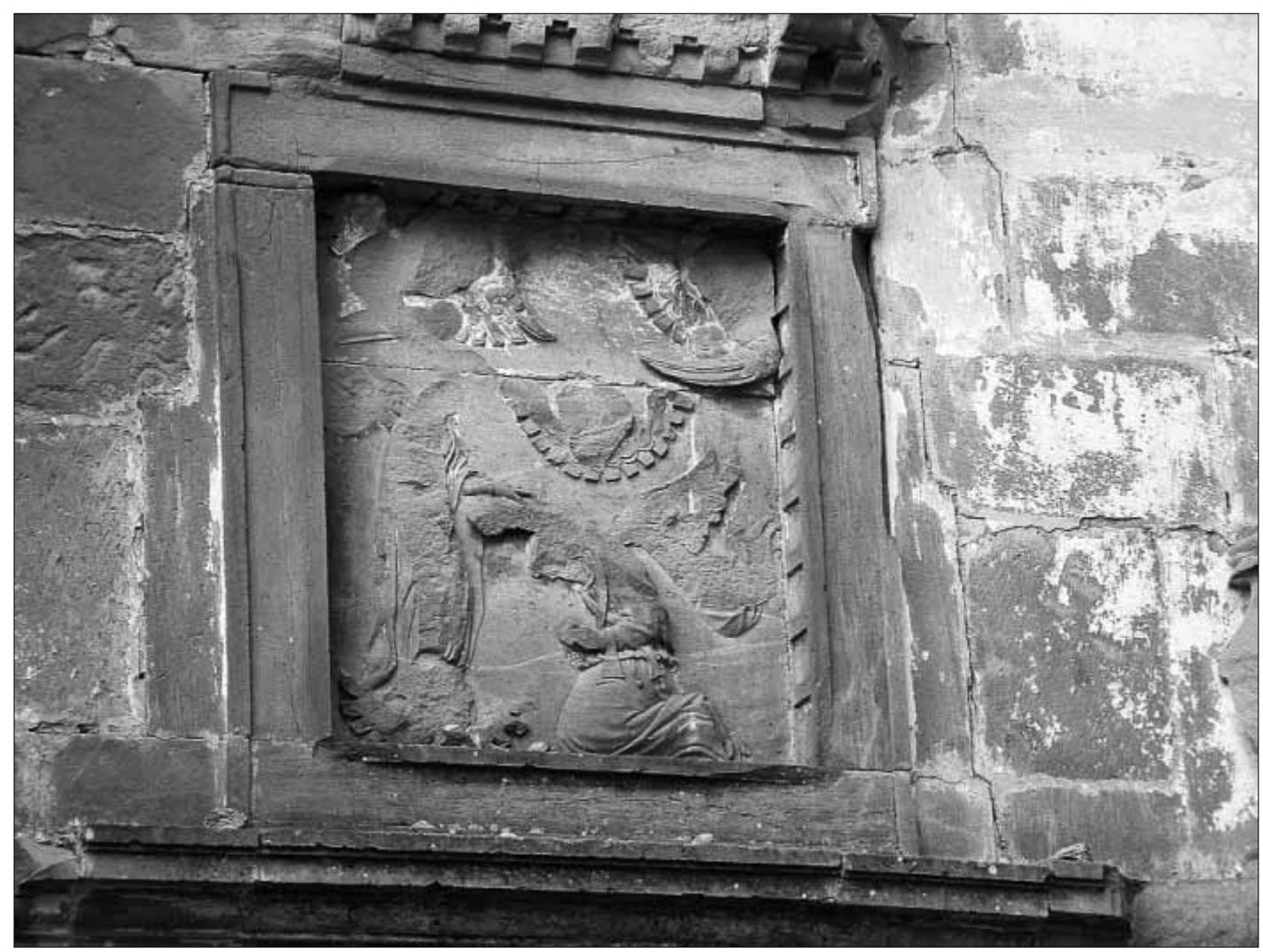

Lam. 25. Metopa encima de la puerta del Crucero Norte

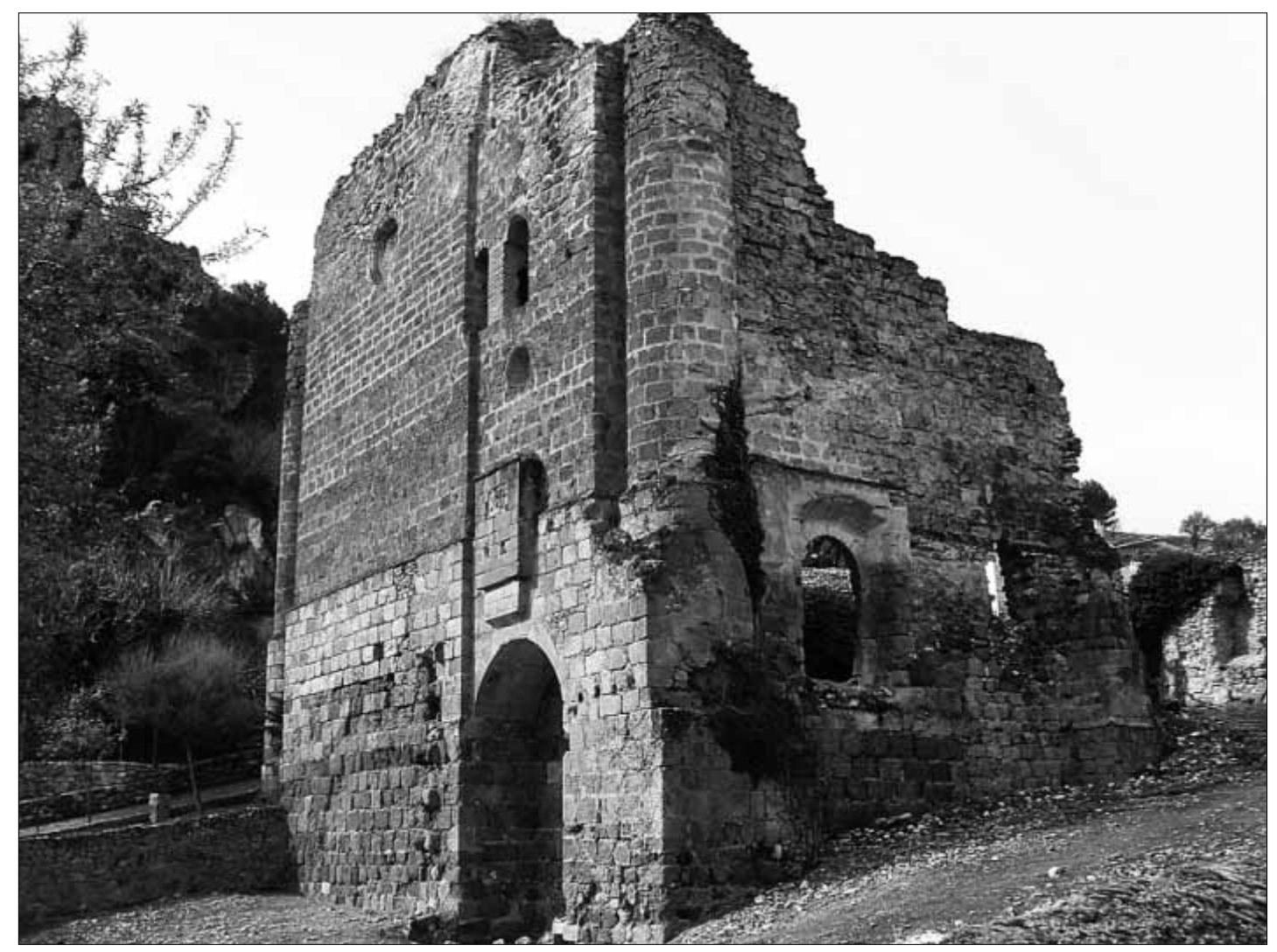

Lam. 26. Puerta del Crucero Norte. Exterior 


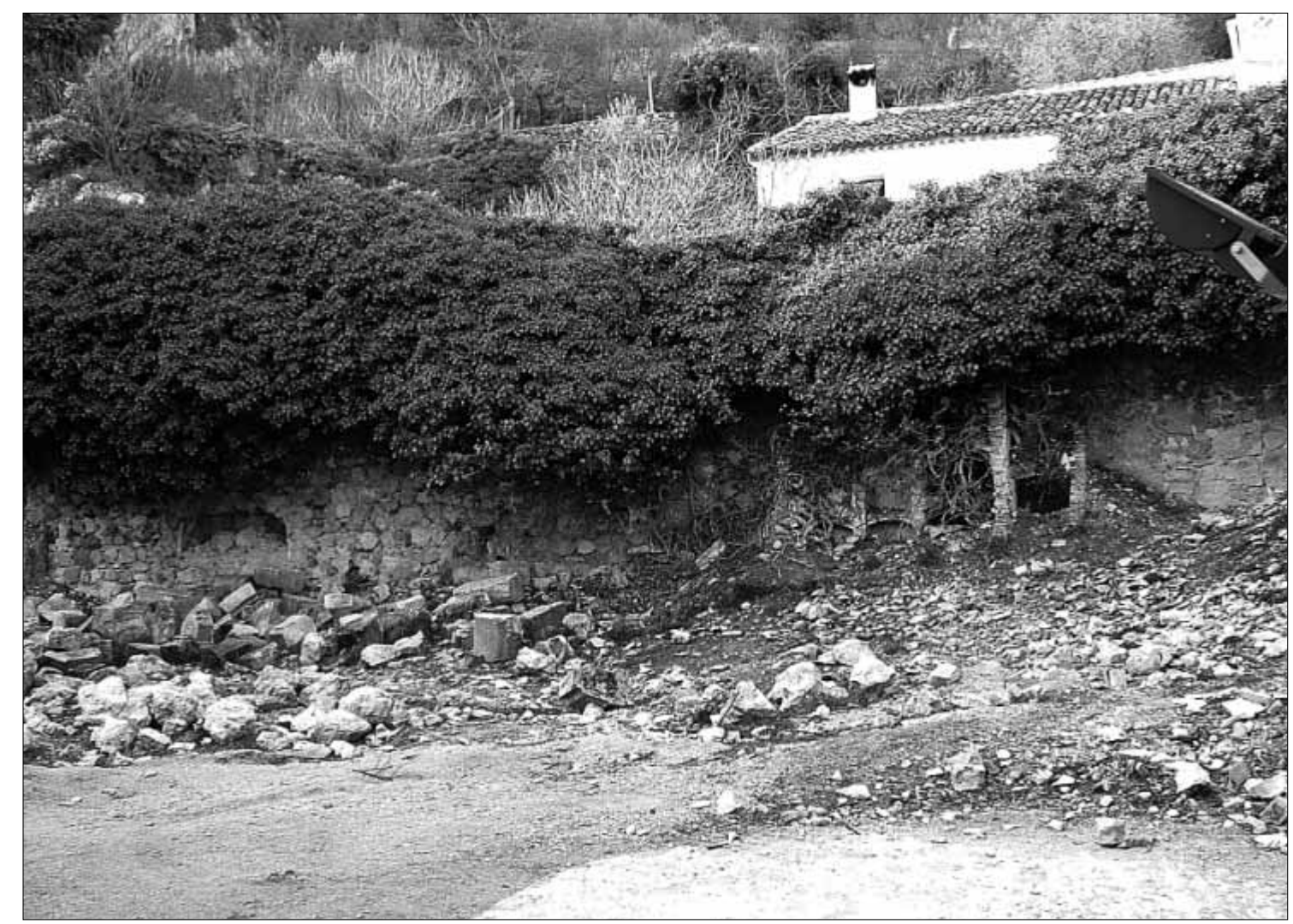

Lam. 27. Iglesia. Lateral Sur (a)

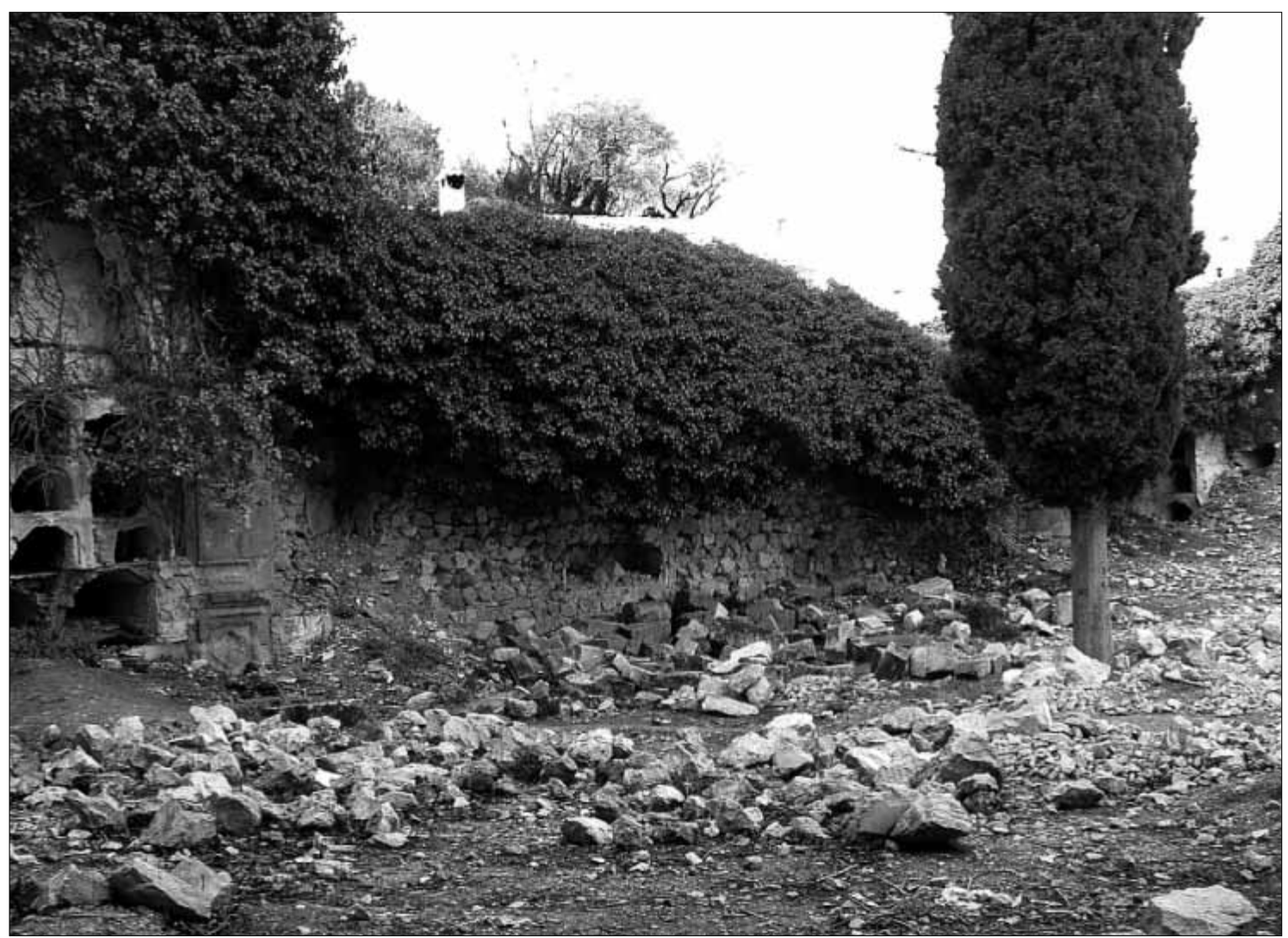

Lam. 28. Iglesia. Lateral Sur (b) 


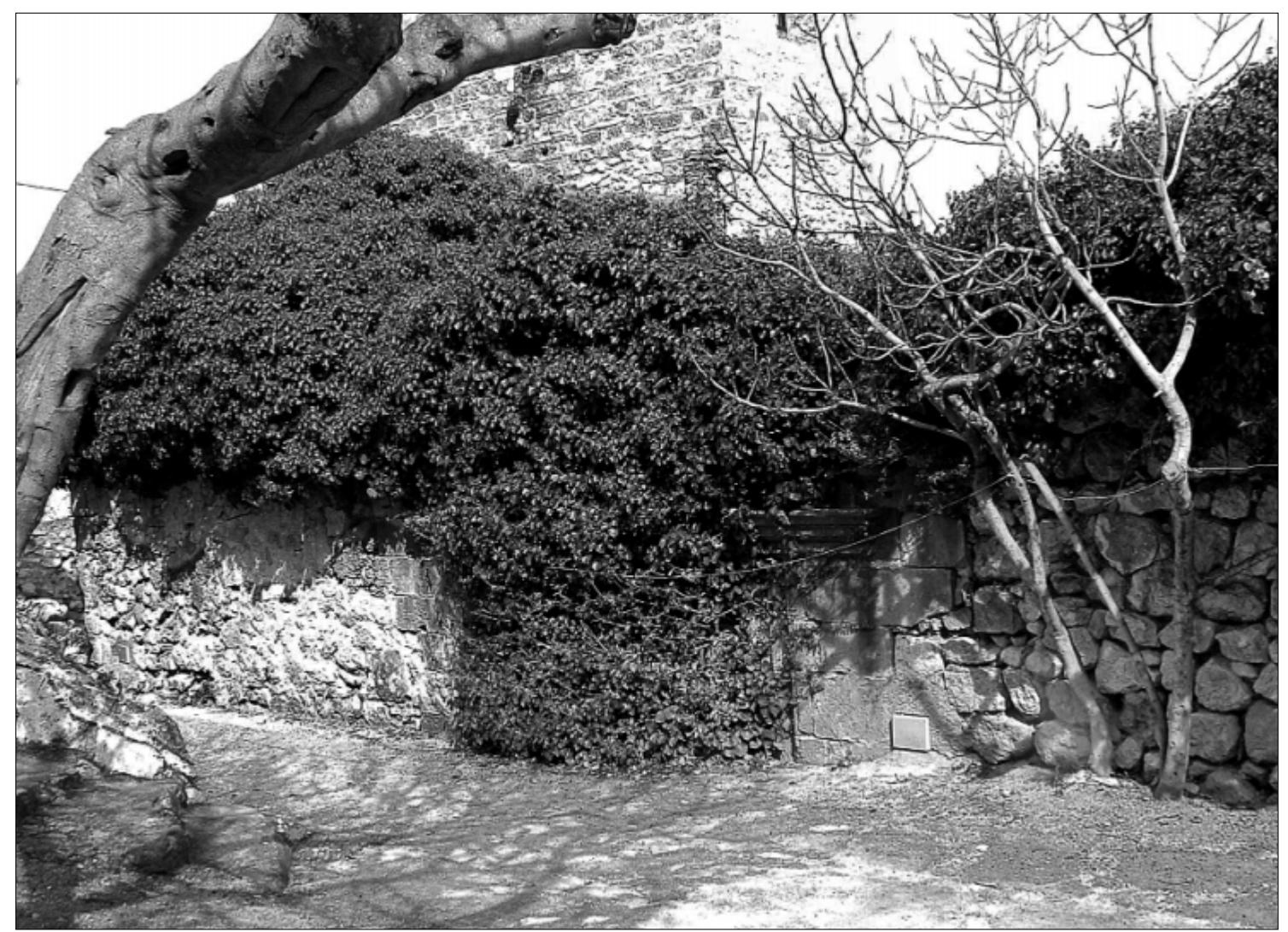

Lam. 29. Puerta Sur

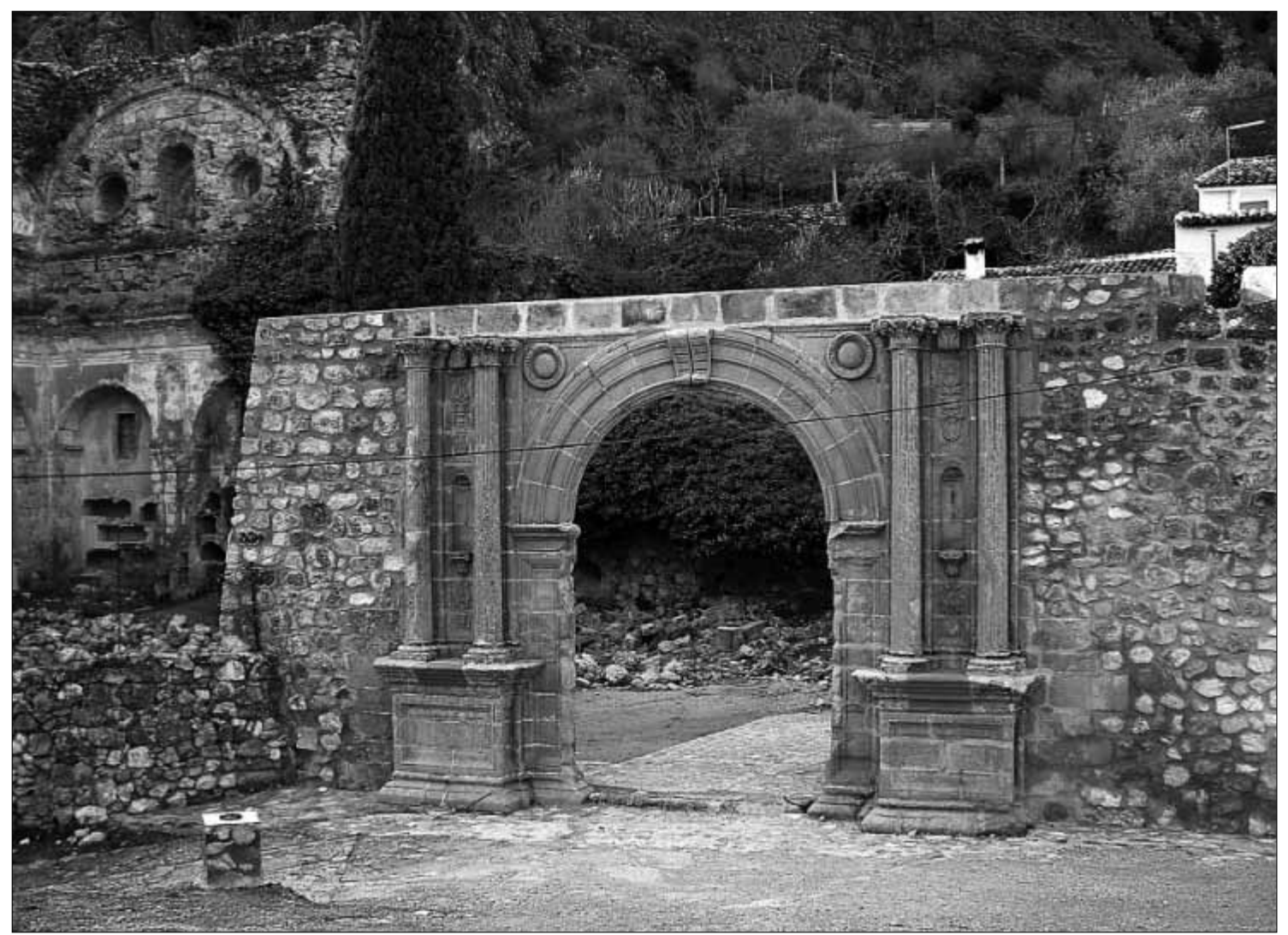

Lam. 30. Fachada principal 


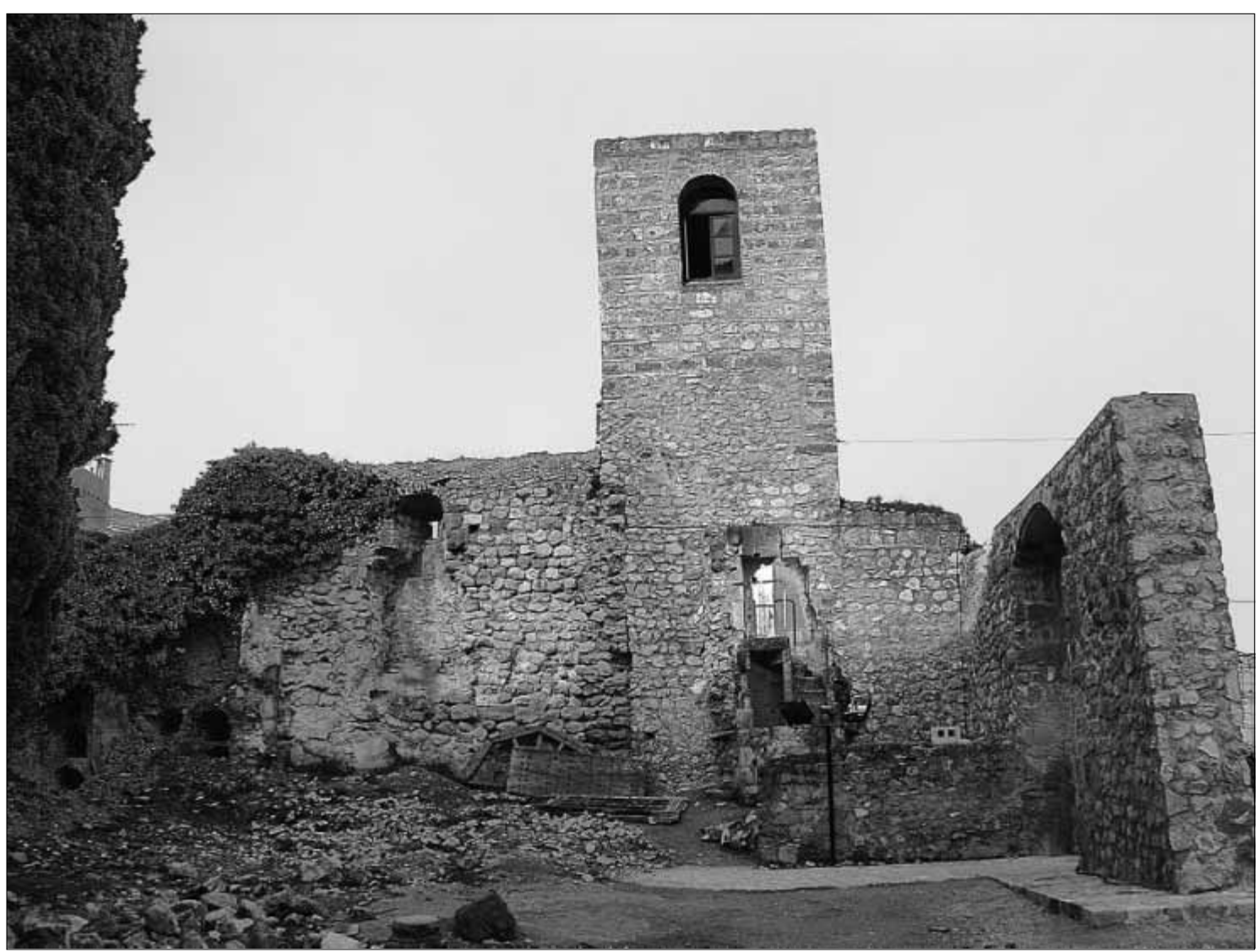

Lam. 3 I. Puerta principal (derecha) y Muro Oeste

Lam. 32. Escalera de acceso al campanario

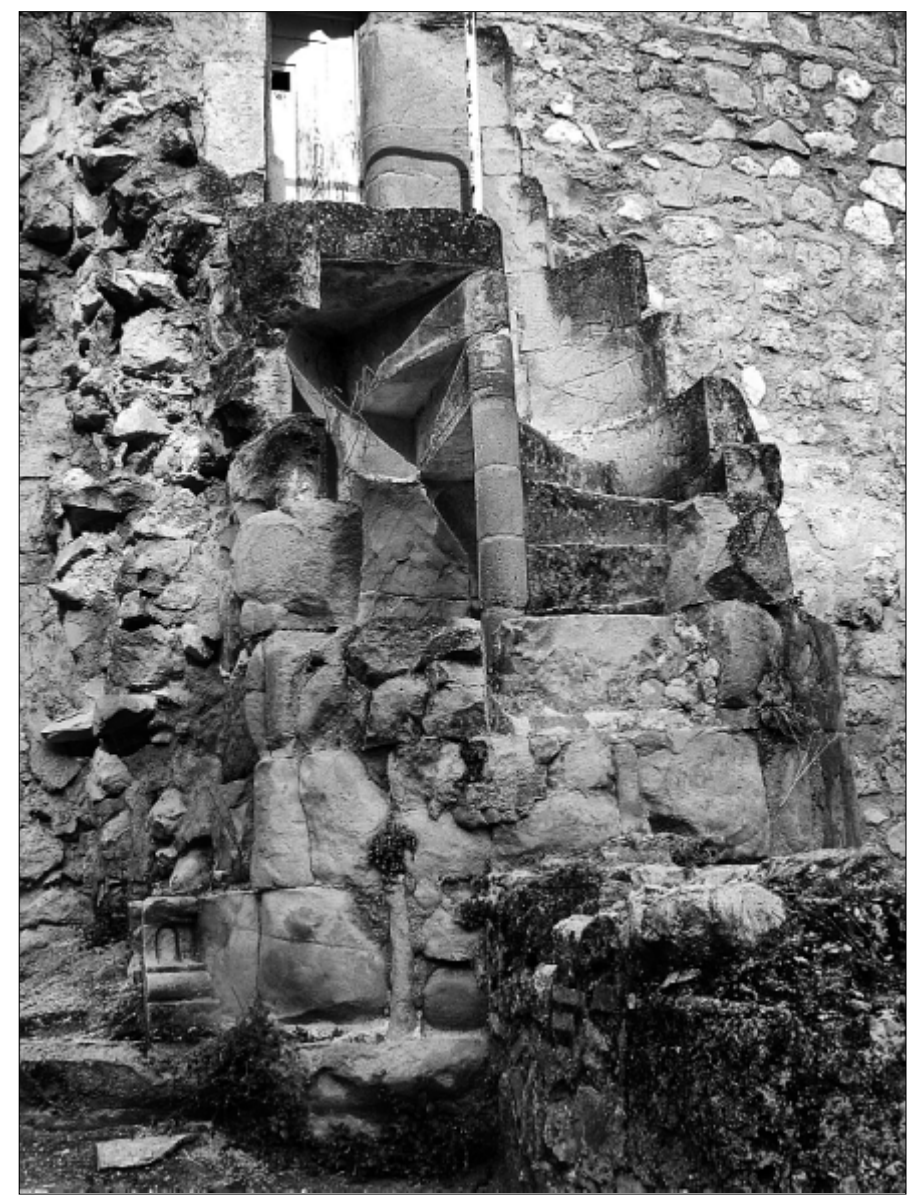




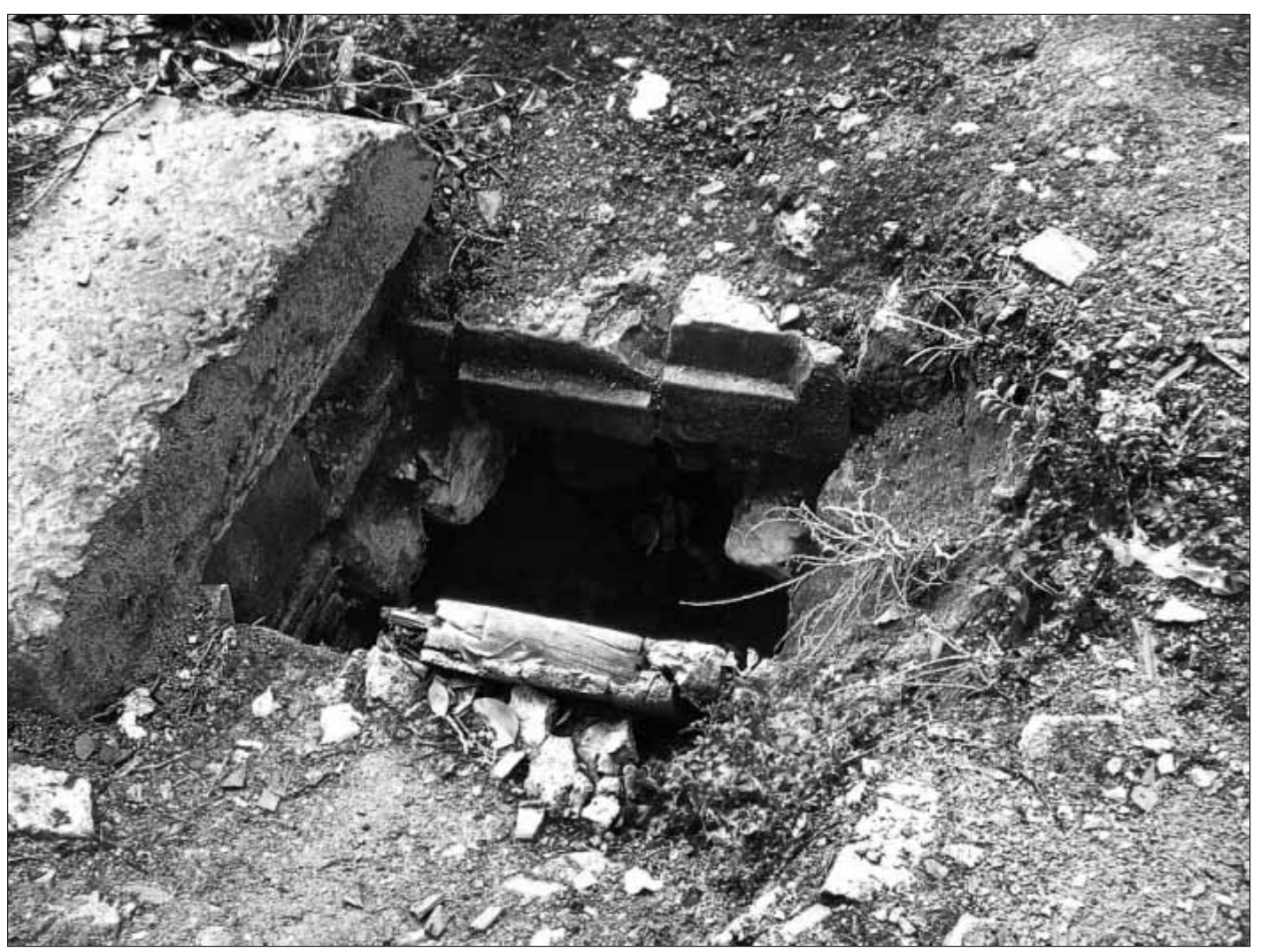

Lam. 33. Entrada a la cripta.

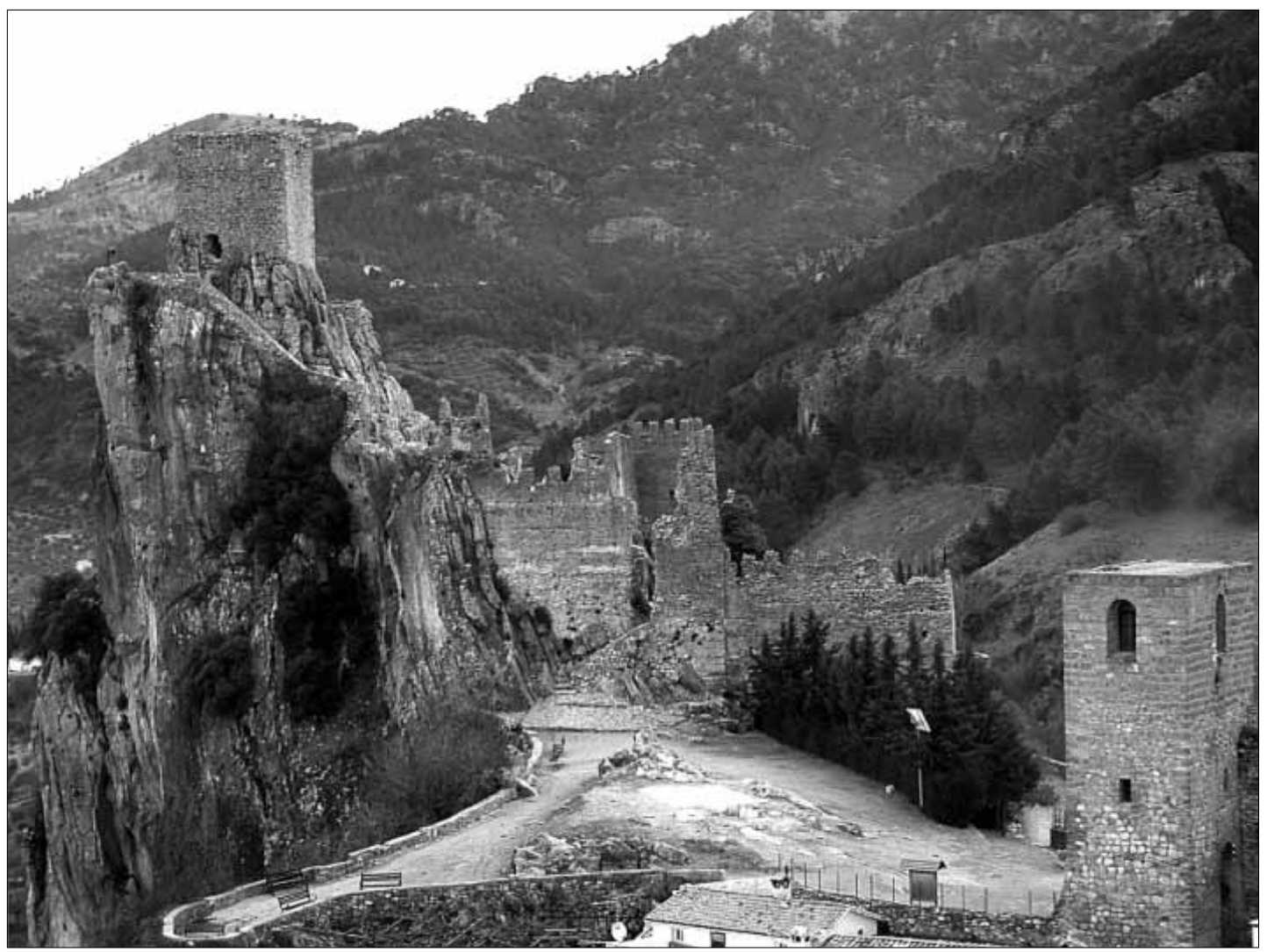

Lam. 34. El Lienzo de cierre de la fortaleza (La Cortina) desde el Oeste 


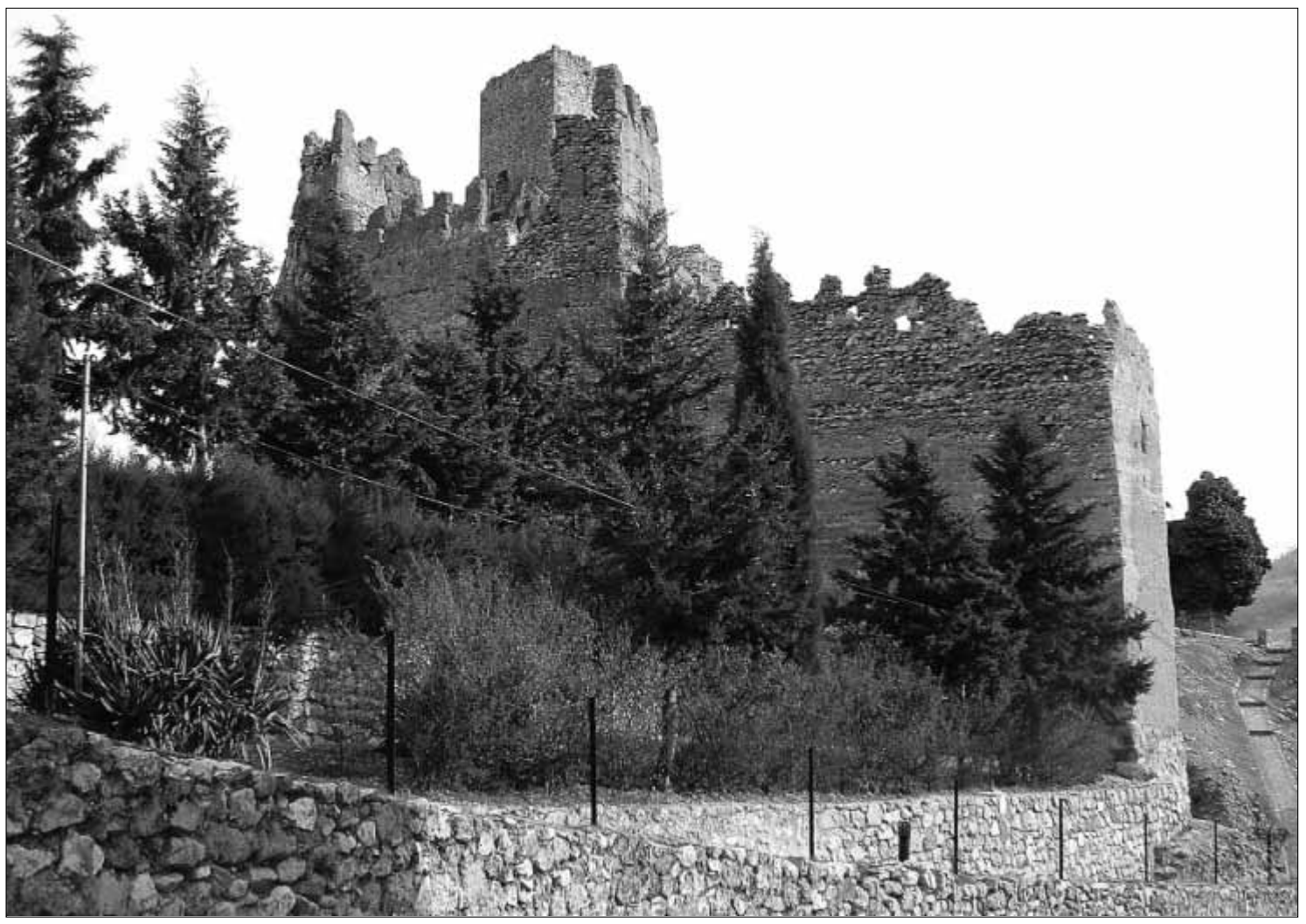

Lam. 35. La Cortina desde el Suroeste

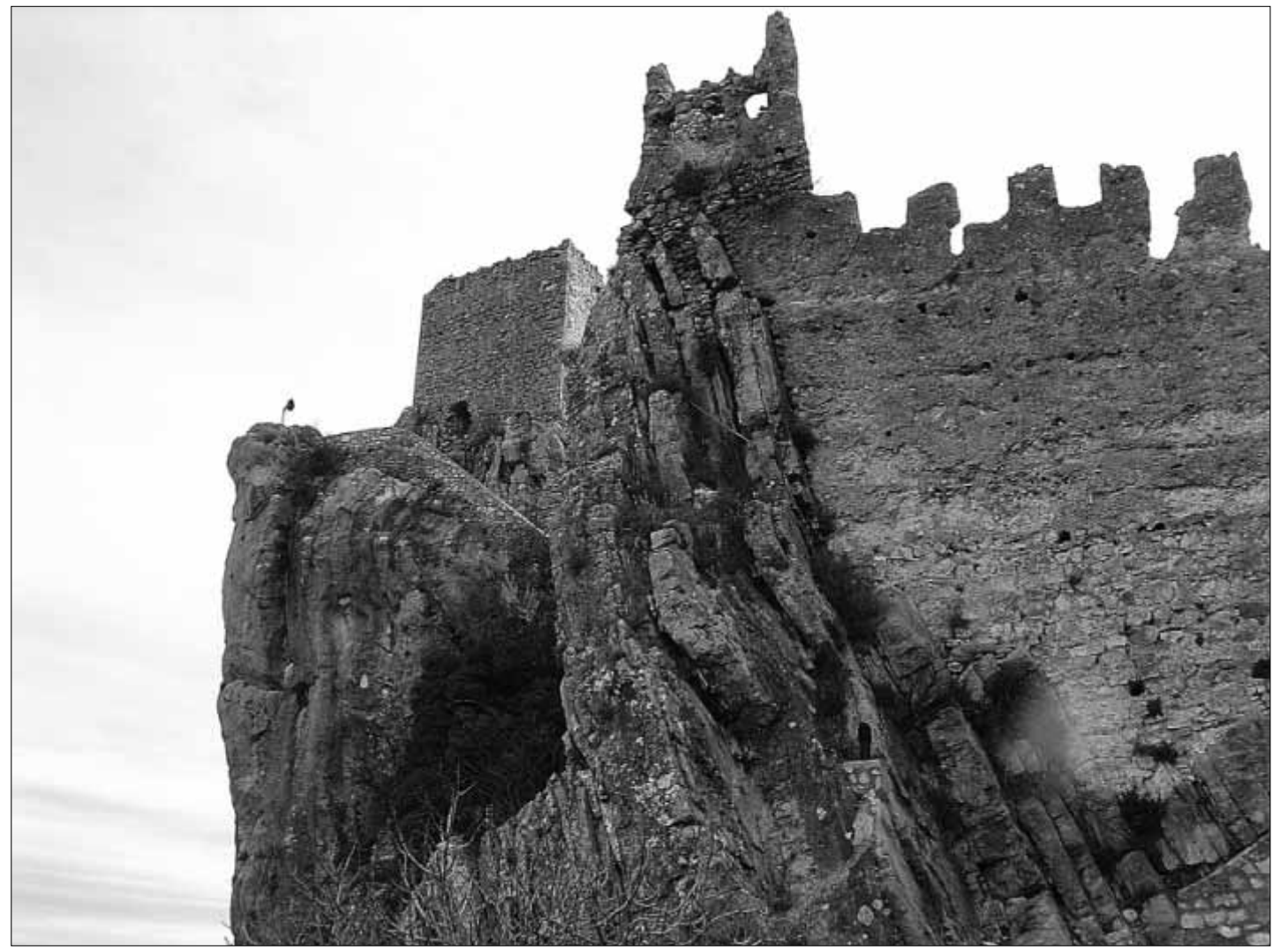

Lam. 36. La Torre I desde el Oeste 


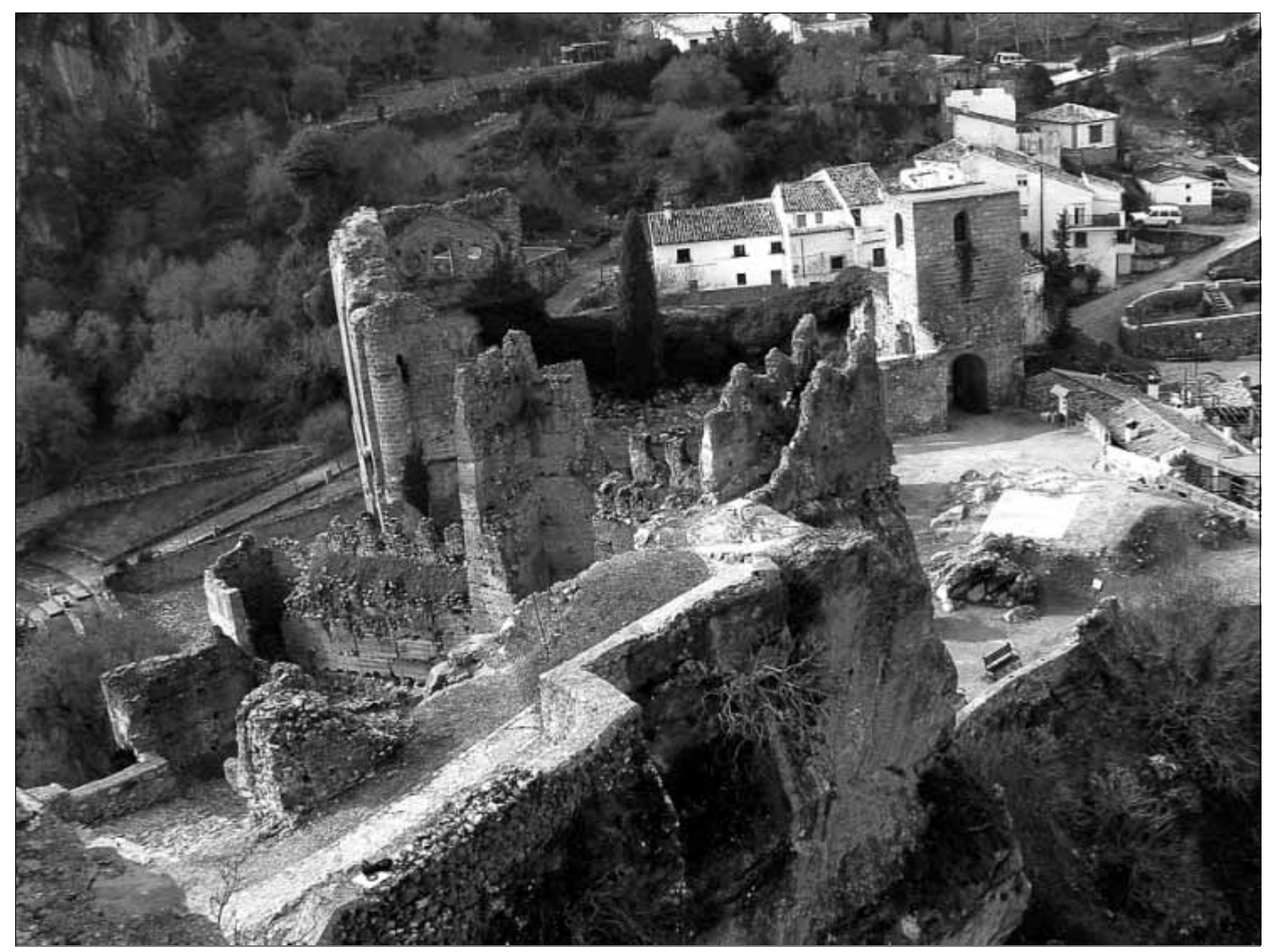

Lam. 37. La Torre / desde el Norte

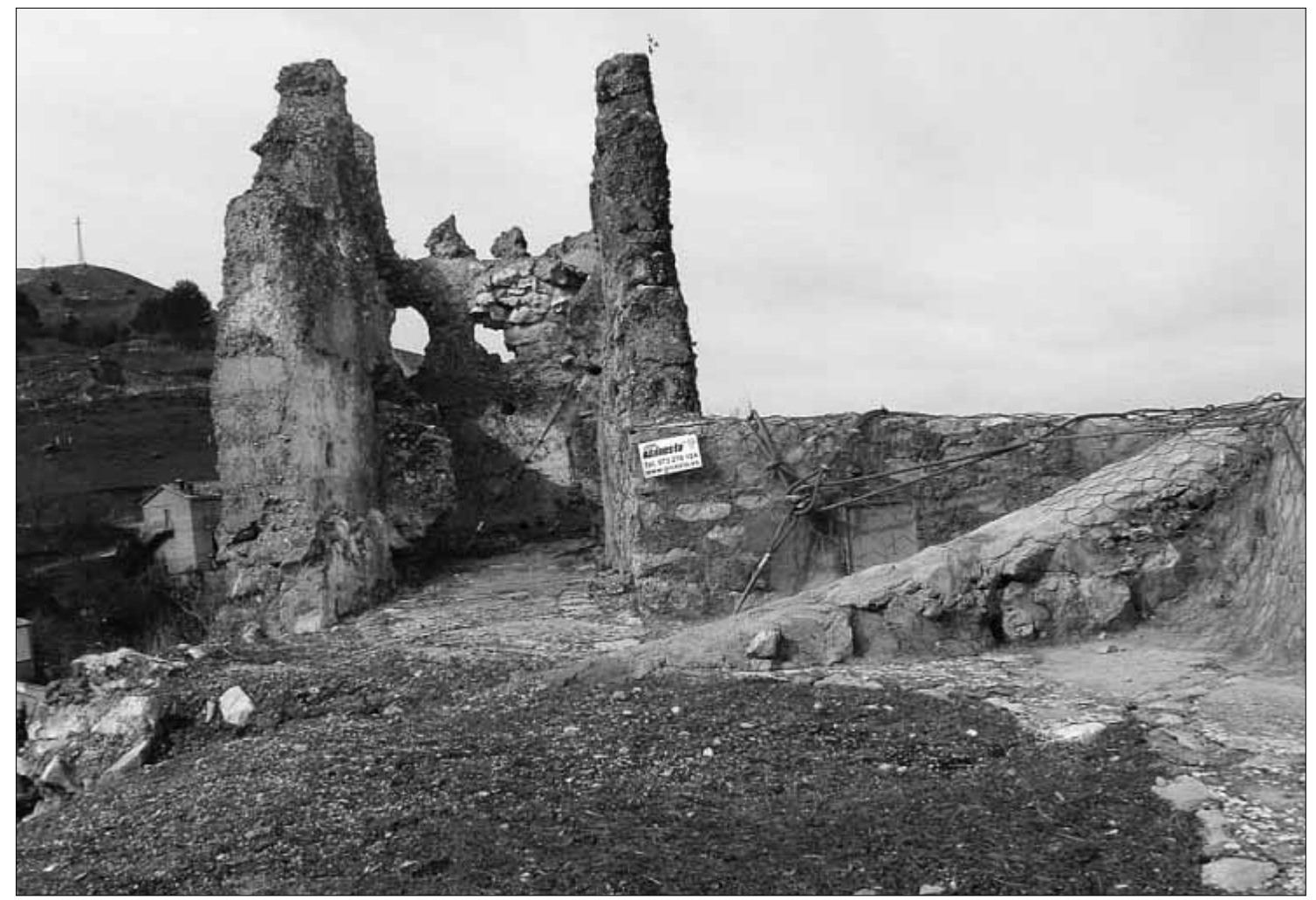

Lam. 38. Interior de la Torre I 


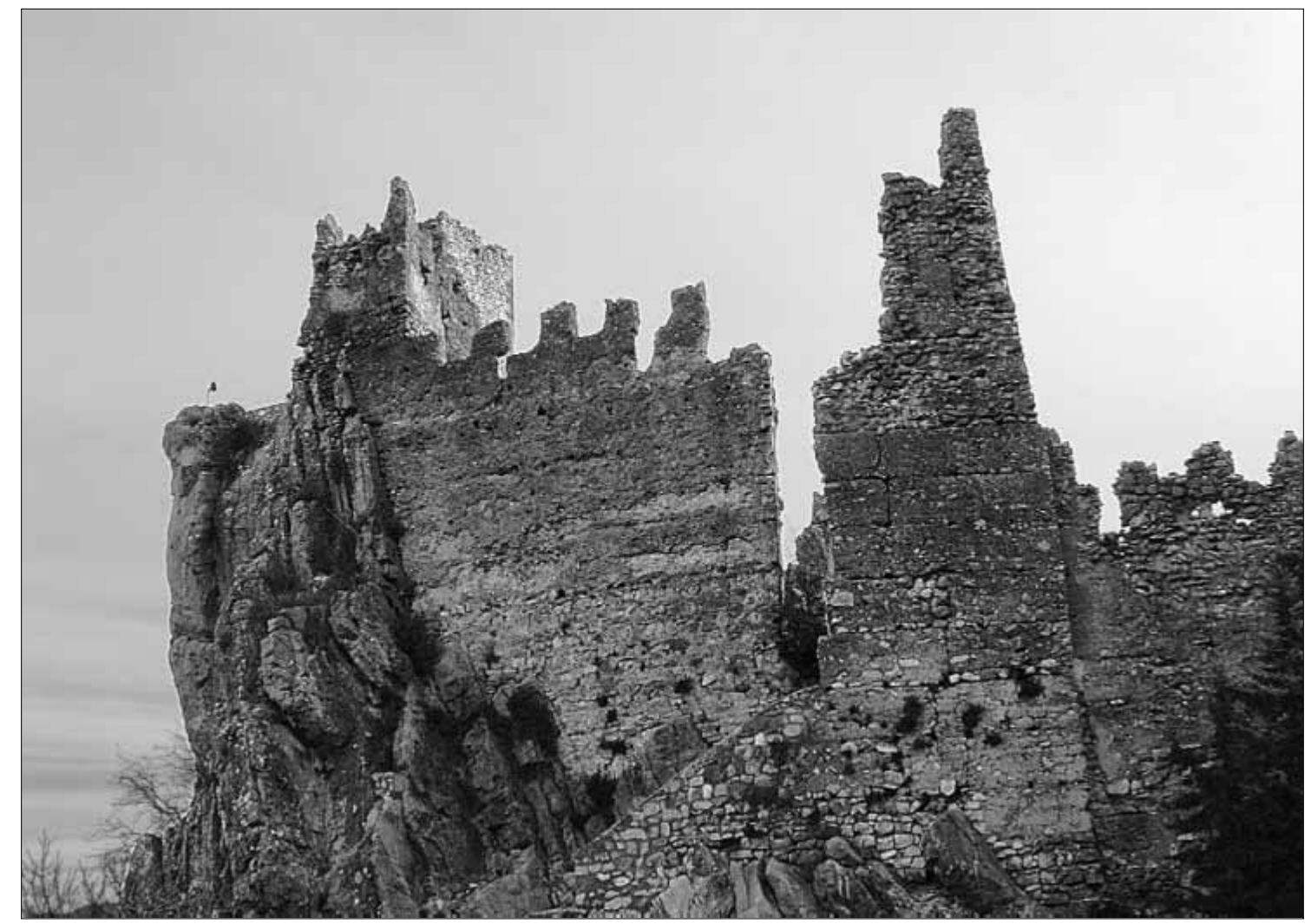

Lam. 39. La Torre II

desde el Oeste.

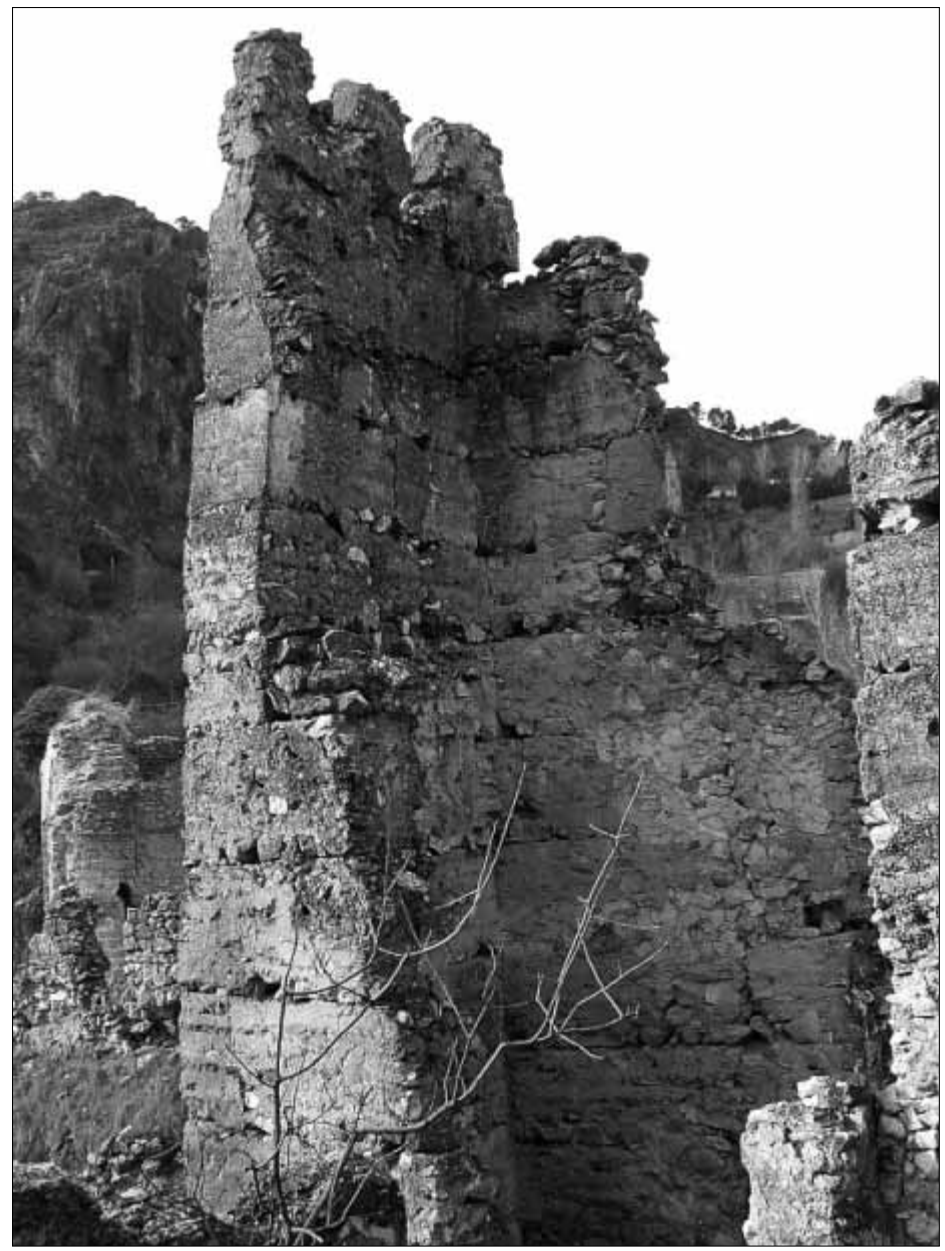




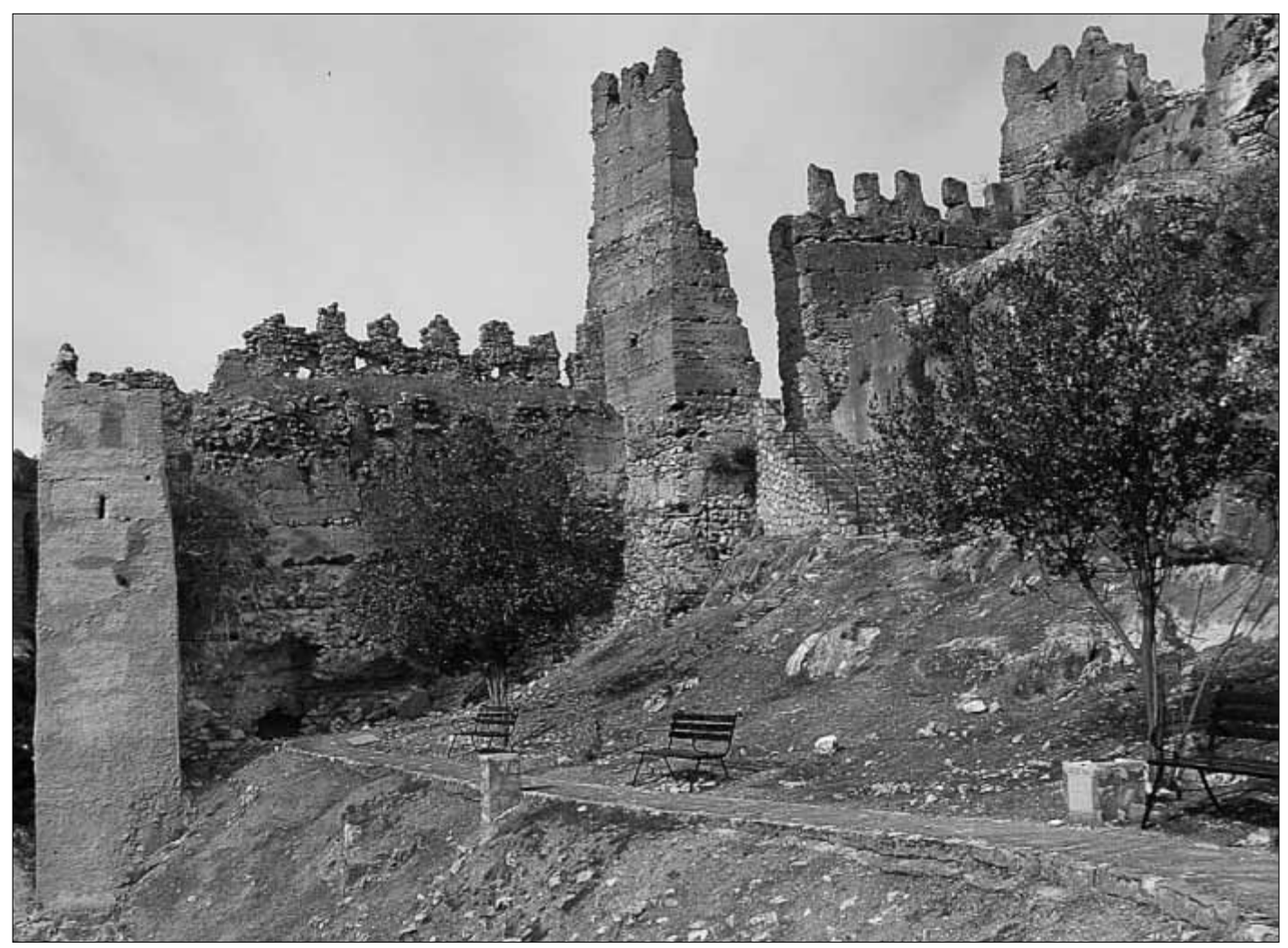

Lam. 4I. La Torre II desde el Ber Recinto.

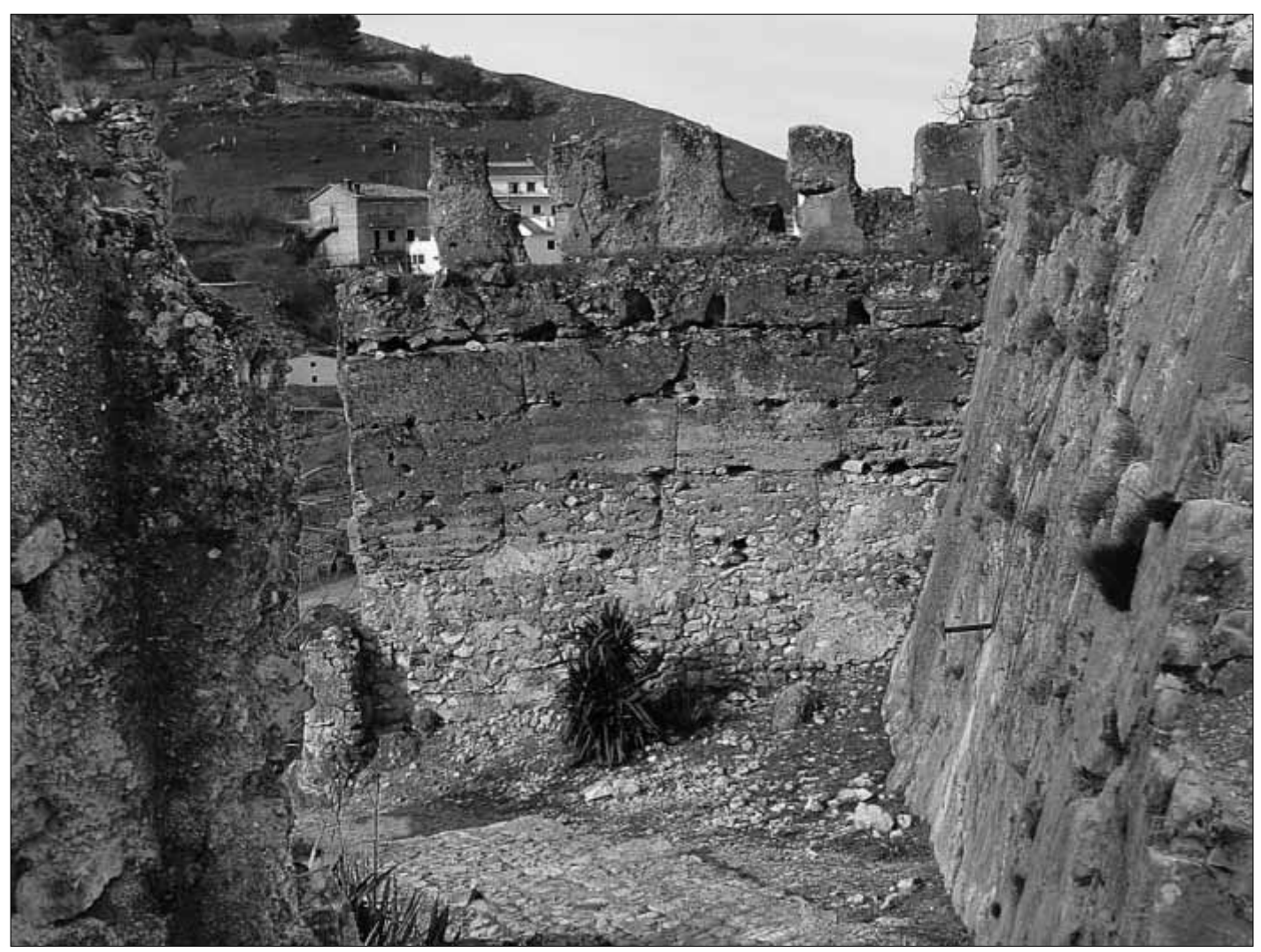

Lam. 42. Patio de acceso. Al fondo la muralla entre las torres I y II. A la derecha la roca sobre la que se asienta la Torre I. A la izquierda en primer plano la Torre III. 


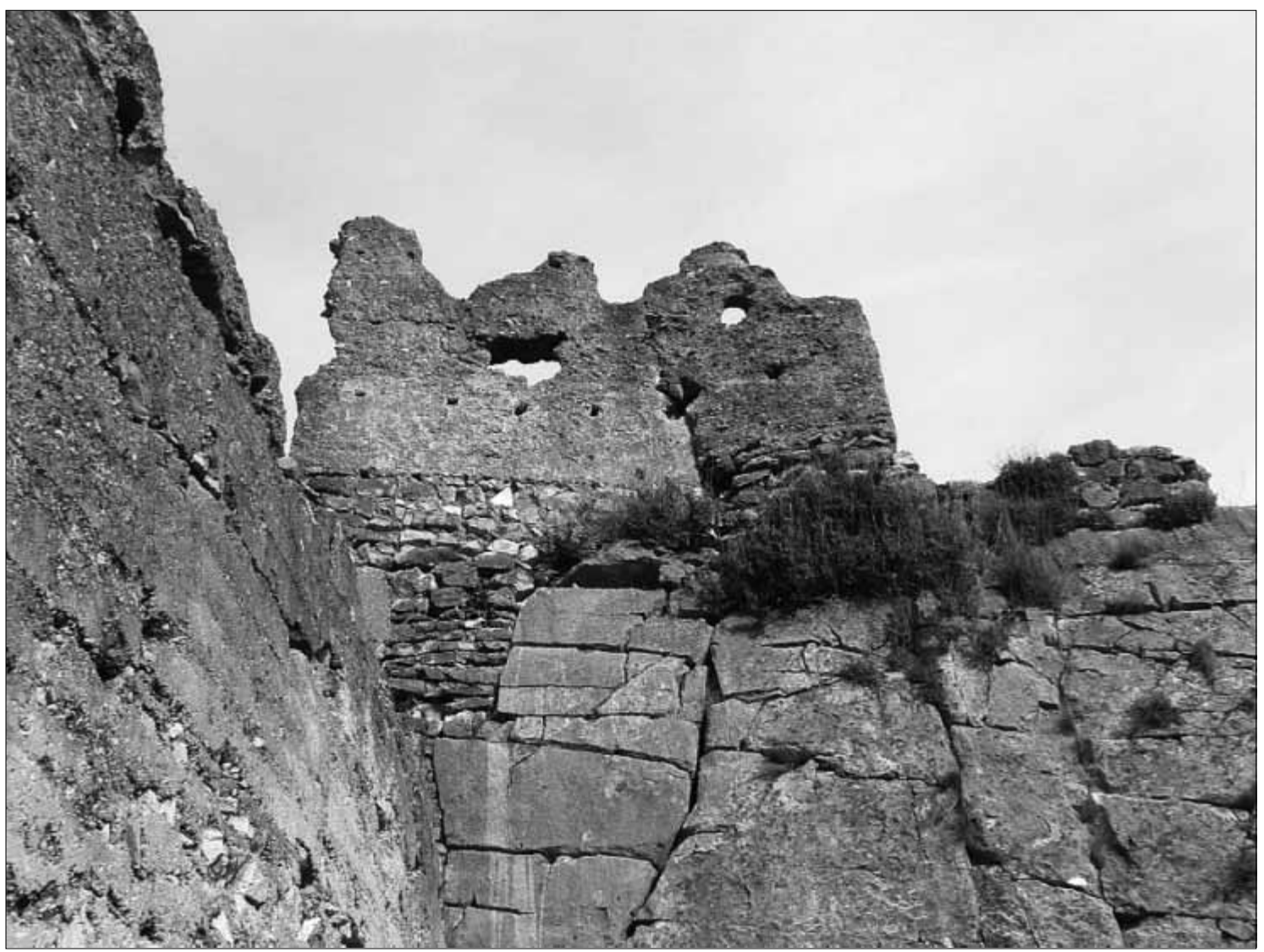

Lam. 43. La Torre / desde el patio de acceso.

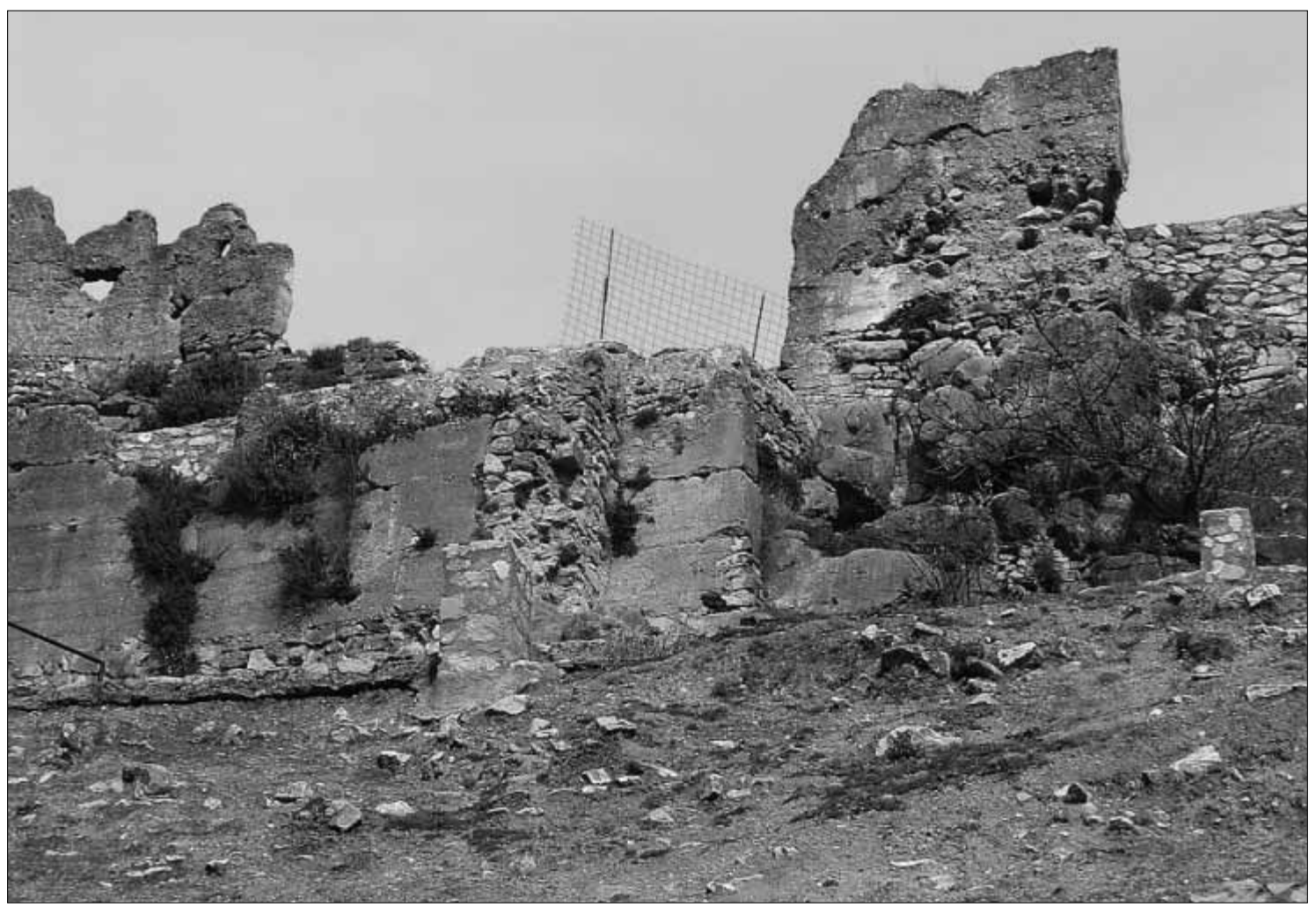

Lam. 44. Refuerzos del muro Sur entre las torres II y III, desde el 3er Recinto. 


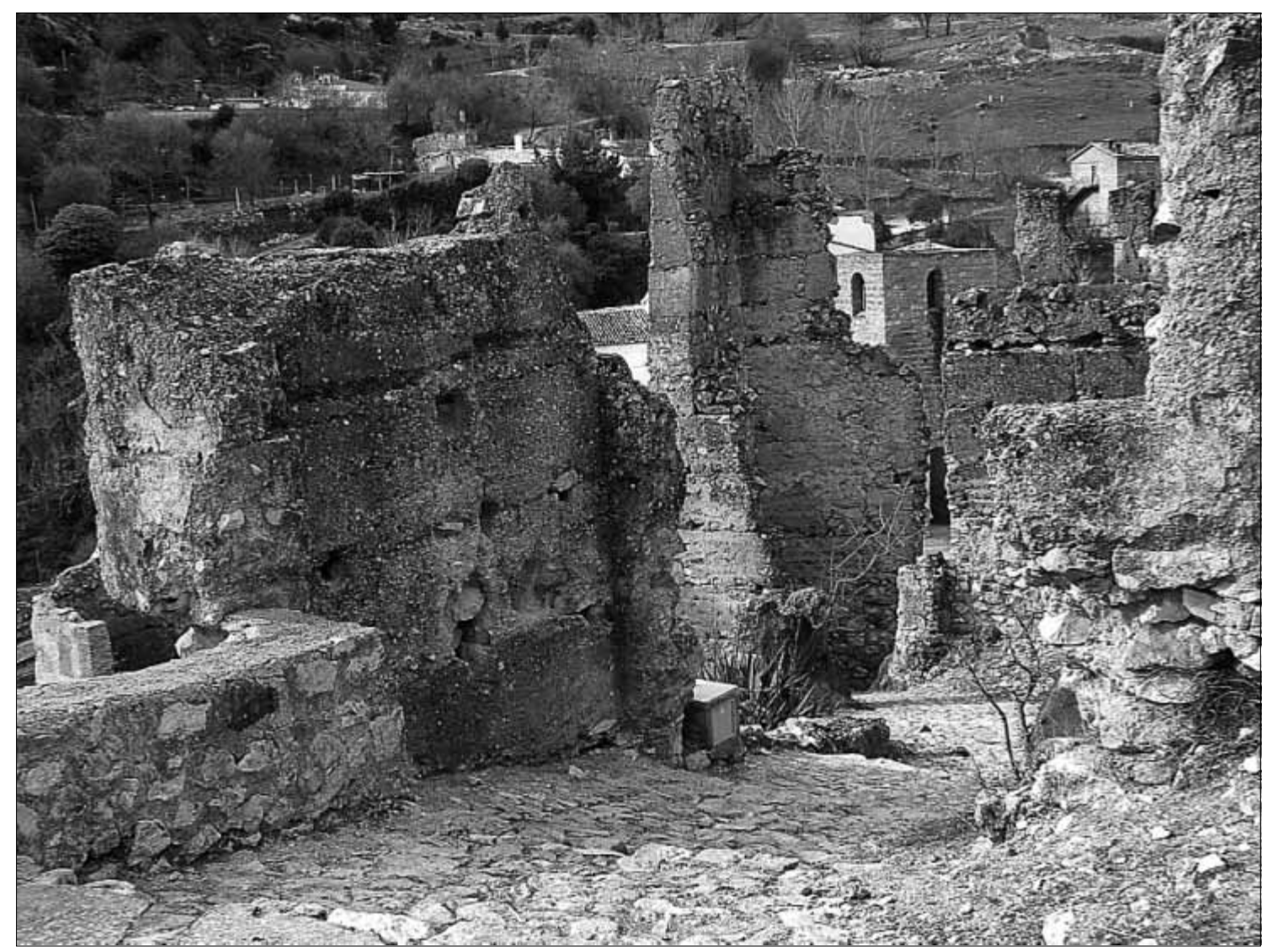

Lam. 45. Conjunto del complejo de acceso. En primer plano restos de la Torre III

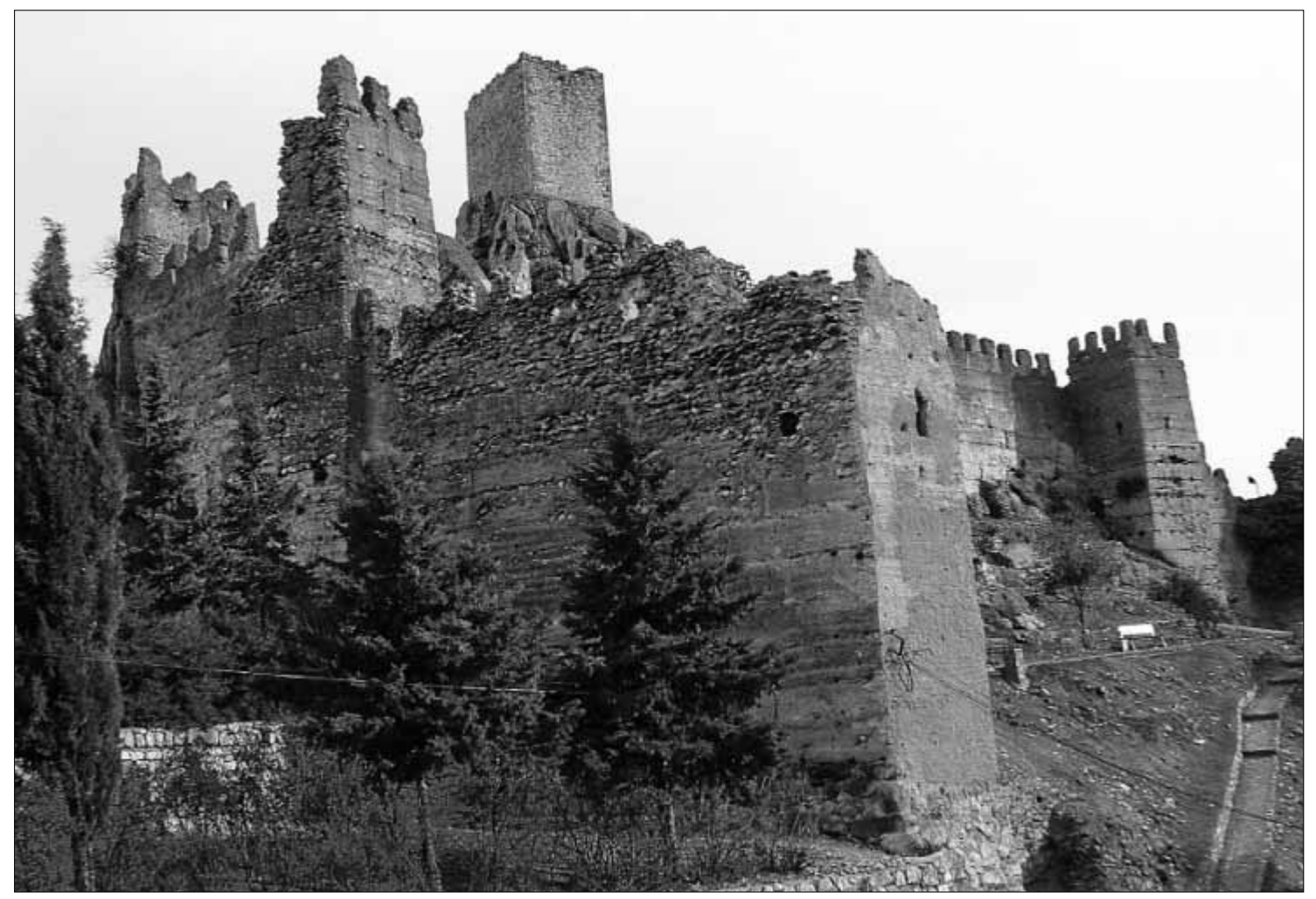

Lam. 46. La Torre VI desde el Suroeste. 
Lam. 47. Torre VI y desnivel respecto a la base de la Torre II

Lam. 48. Torre VI. Interior
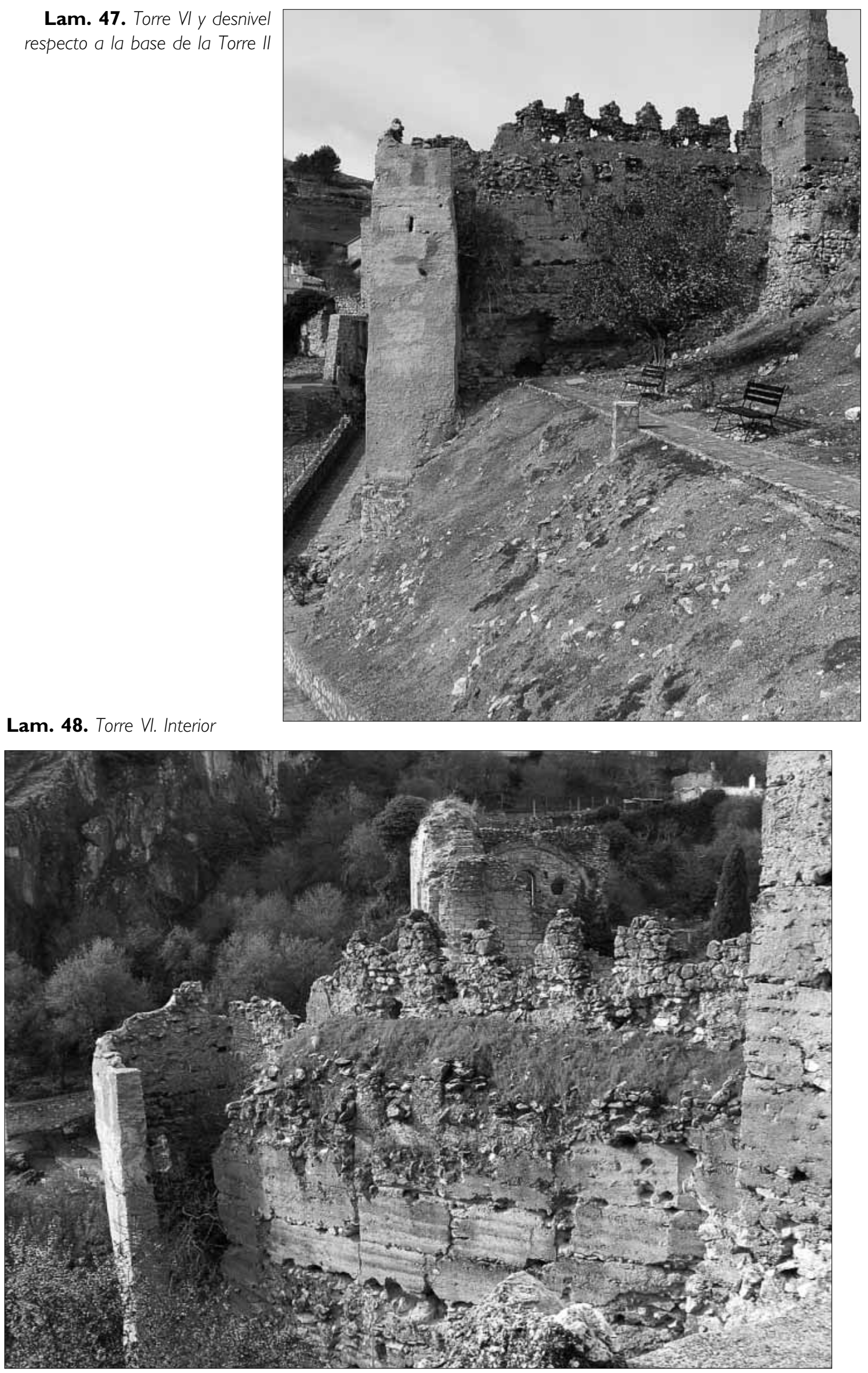


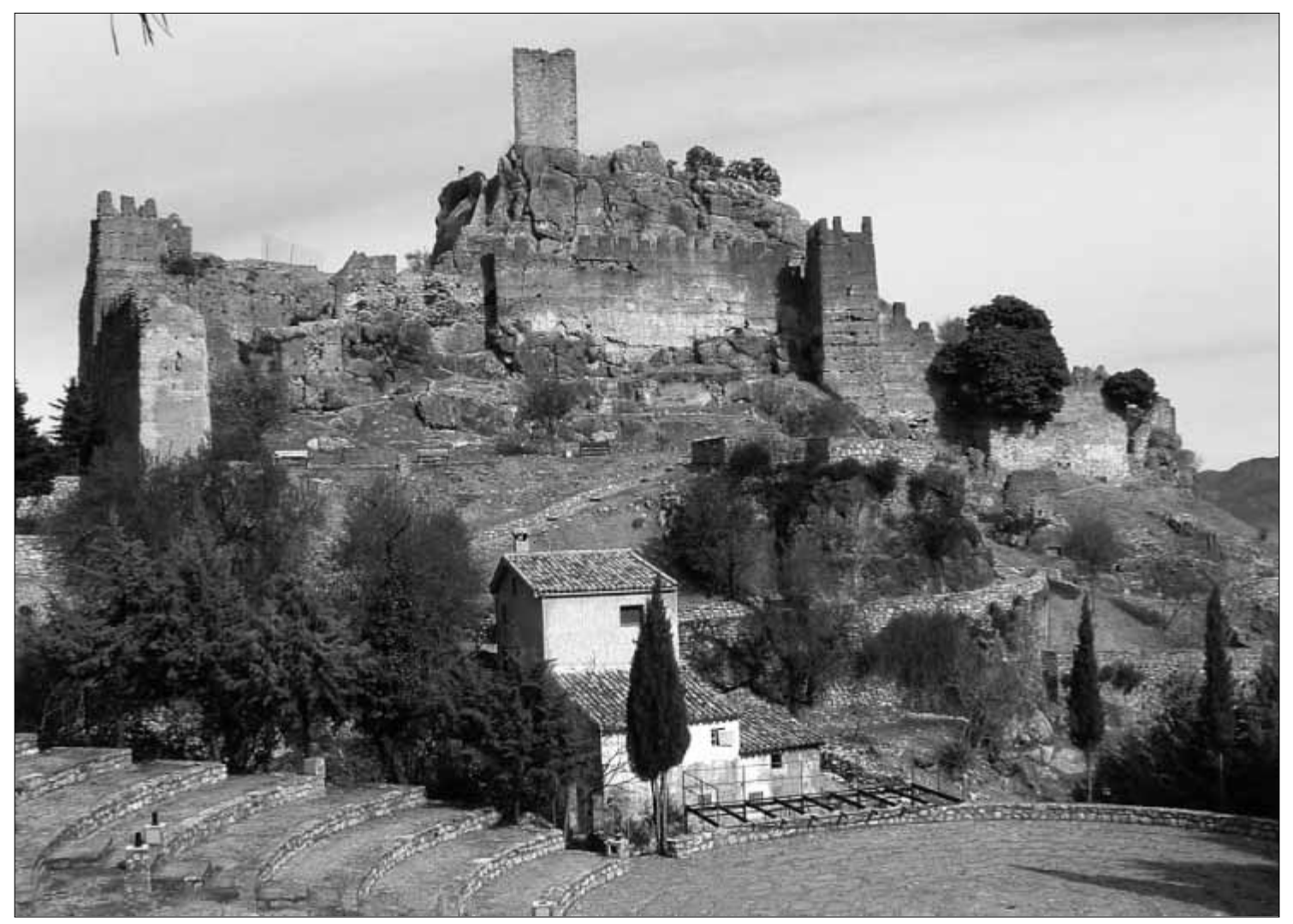

Lam. 49. Muralla entre los Recintos 2 y 3, visto desde este último

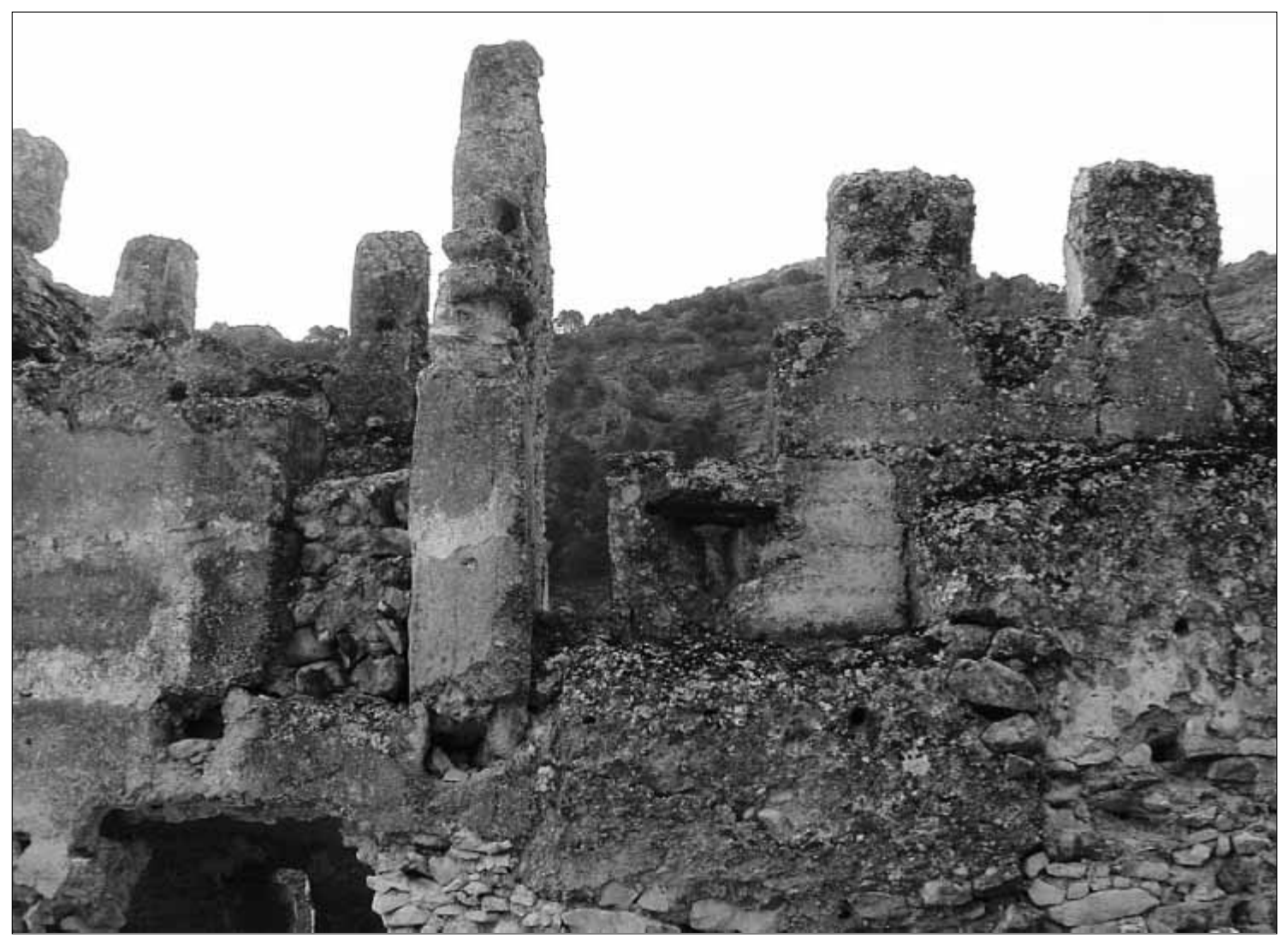

Lam. 50. Saetera en la muralla desde el $2^{\circ}$ Recinto 
Lam. 5 I. Saetera en la muralla desde el 3er Recinto

Lam. 52. Área entre el

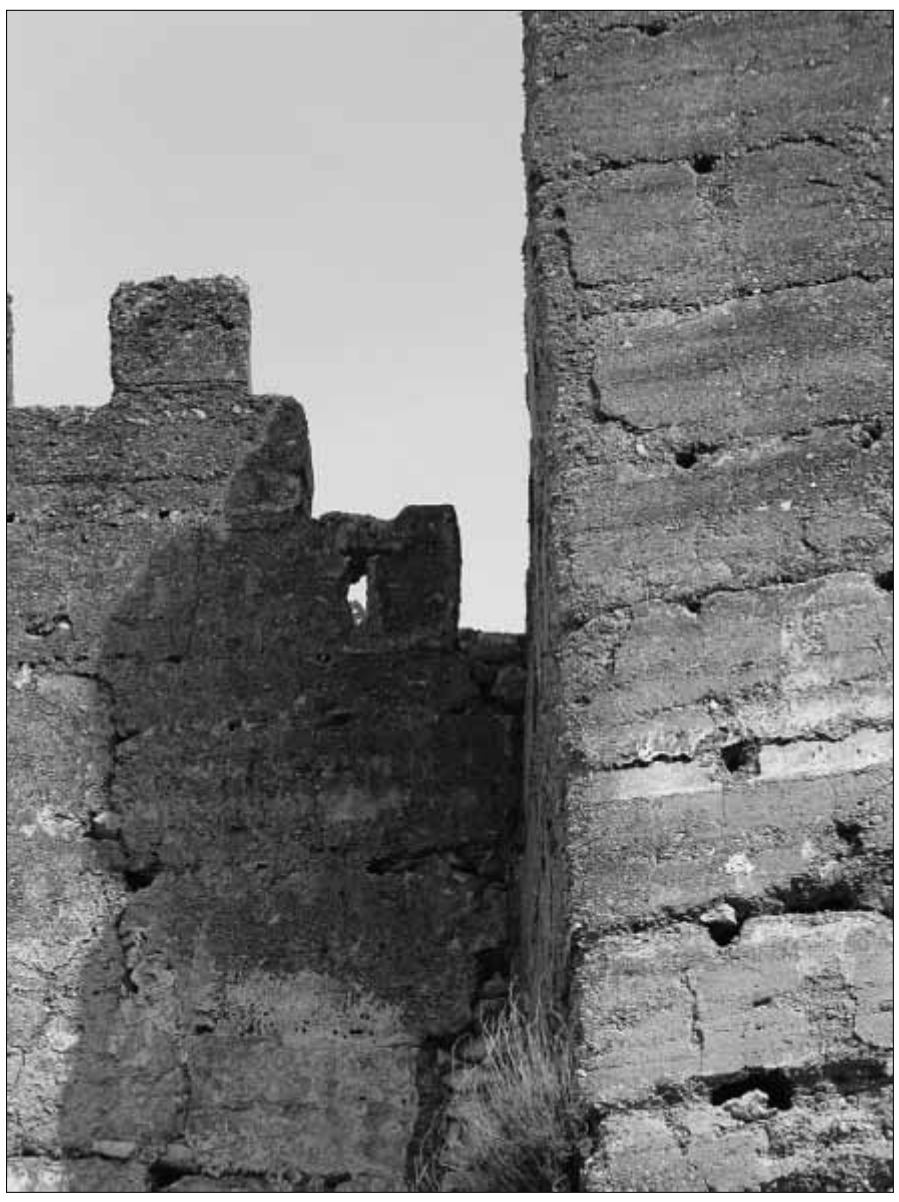

acceso y el aljibe

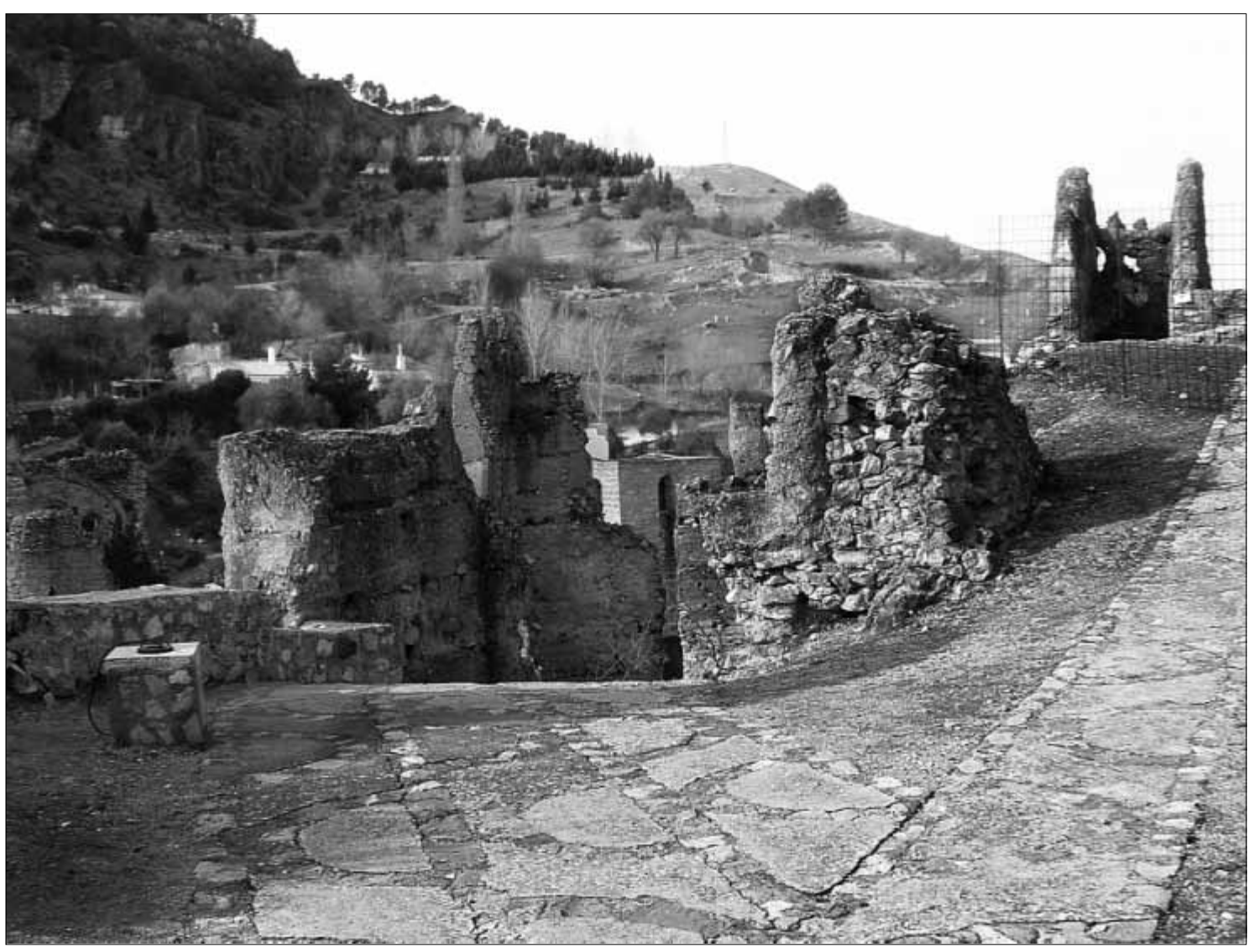




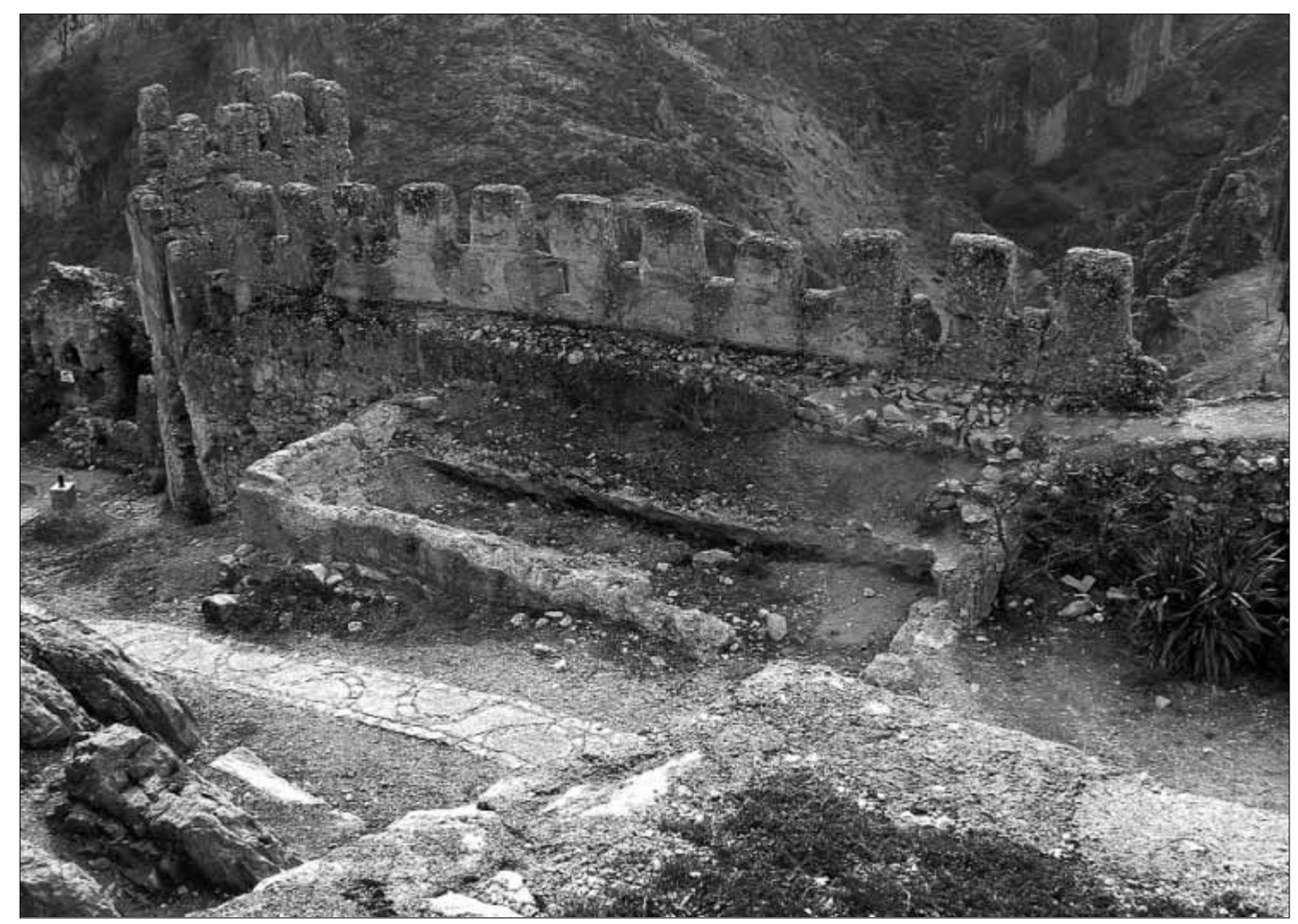

Lam. 53. Aljibe, adarve y almenas

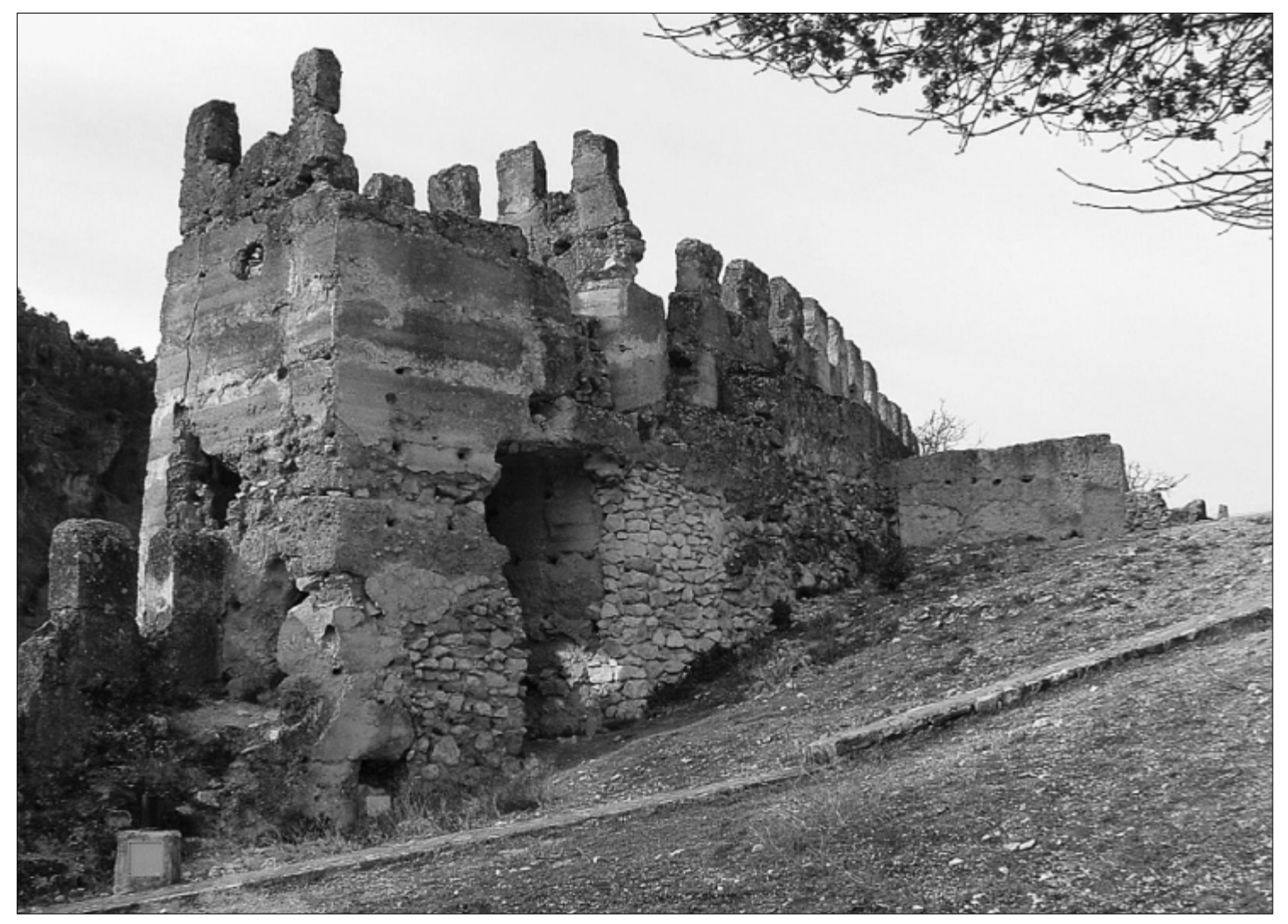

Lam. 54. Torre IV y lateral Sur del Aljibe 


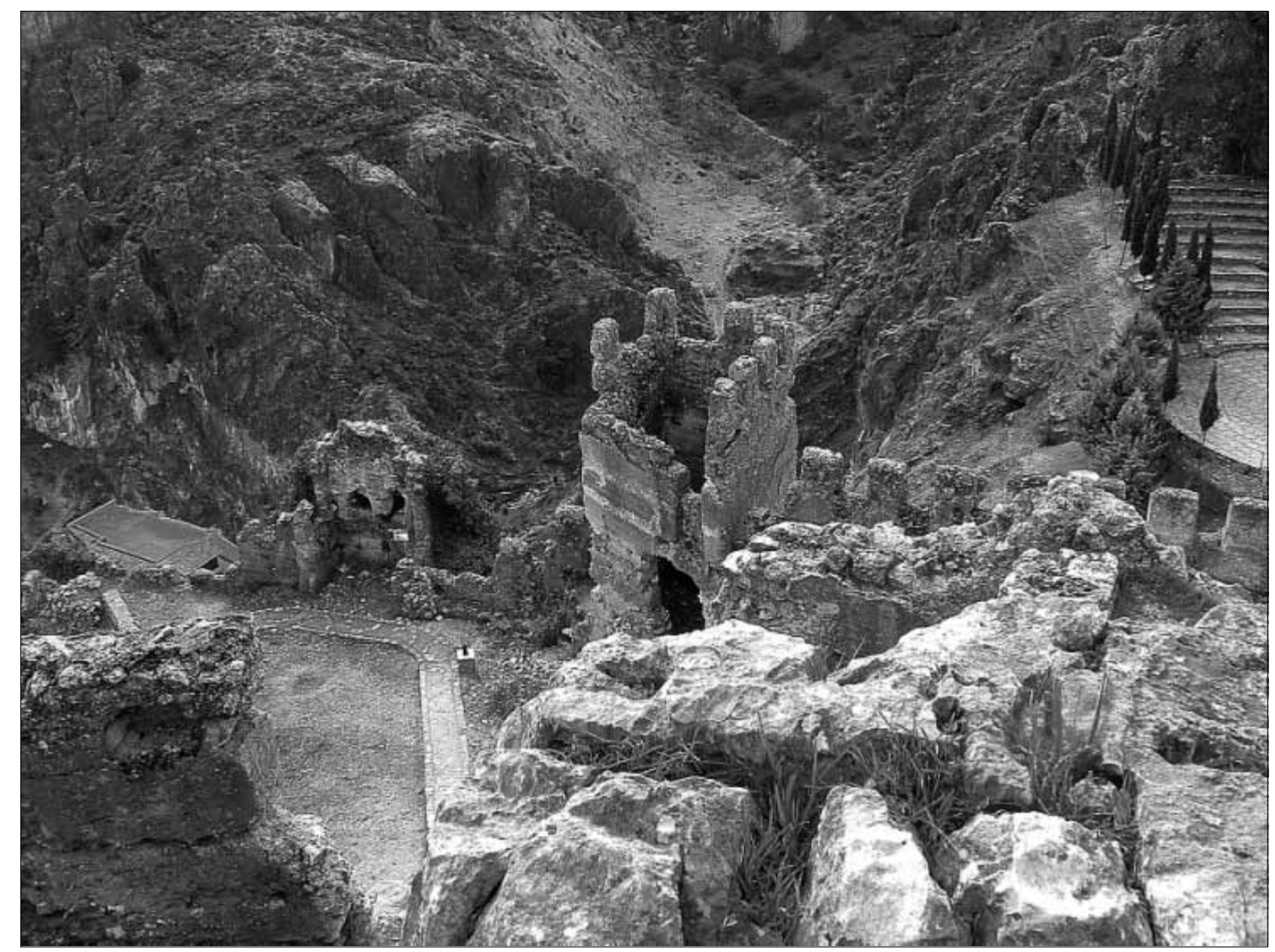

Lam. 55. Torres IV y V

desde el primer Recinto

Lam. 56. Interior de la Torre IV, se aprecian las dos saeteras del lado Sur

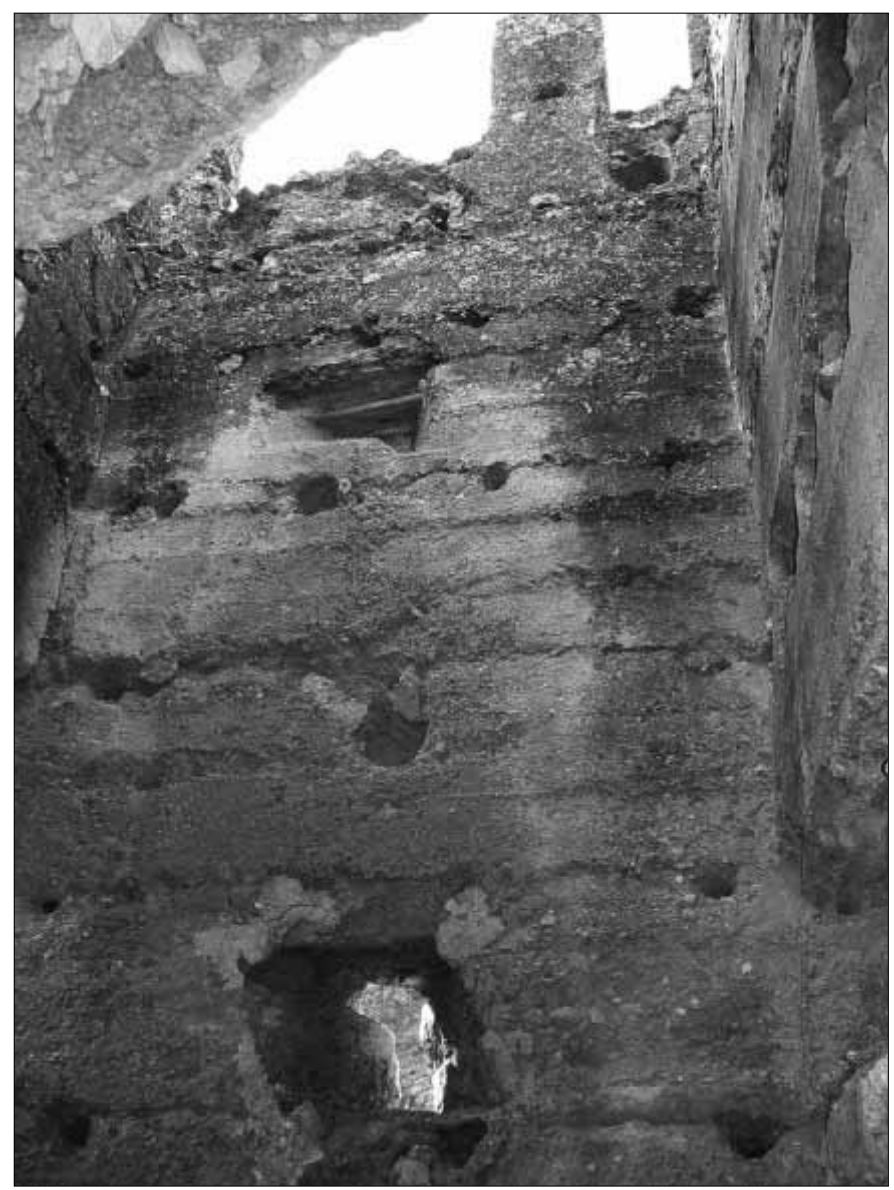




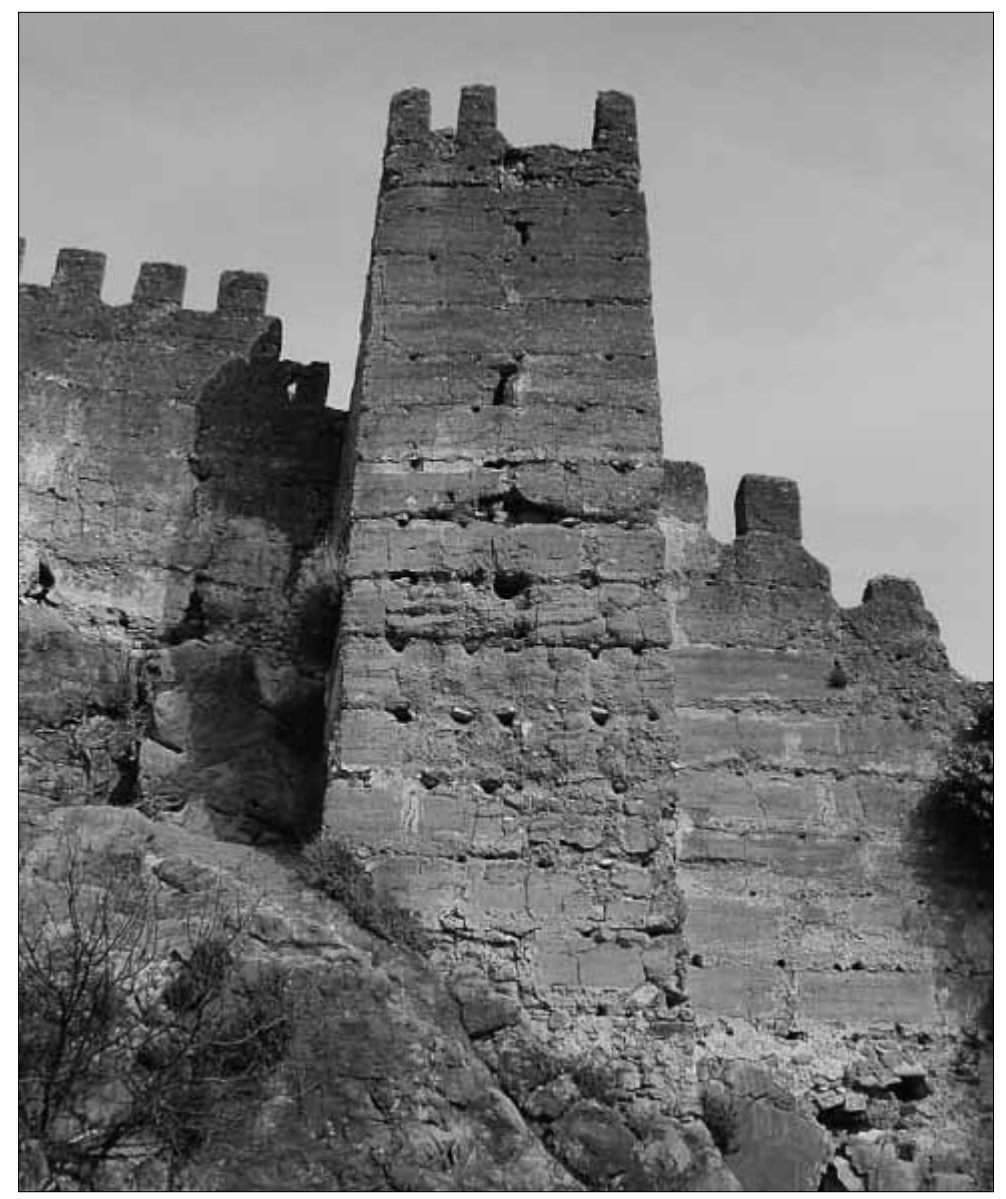

Lam. 57. Exterior de la

Torre IV desde el Sur

Lam. 58. Exterior de la

Torre IV desde el Oeste

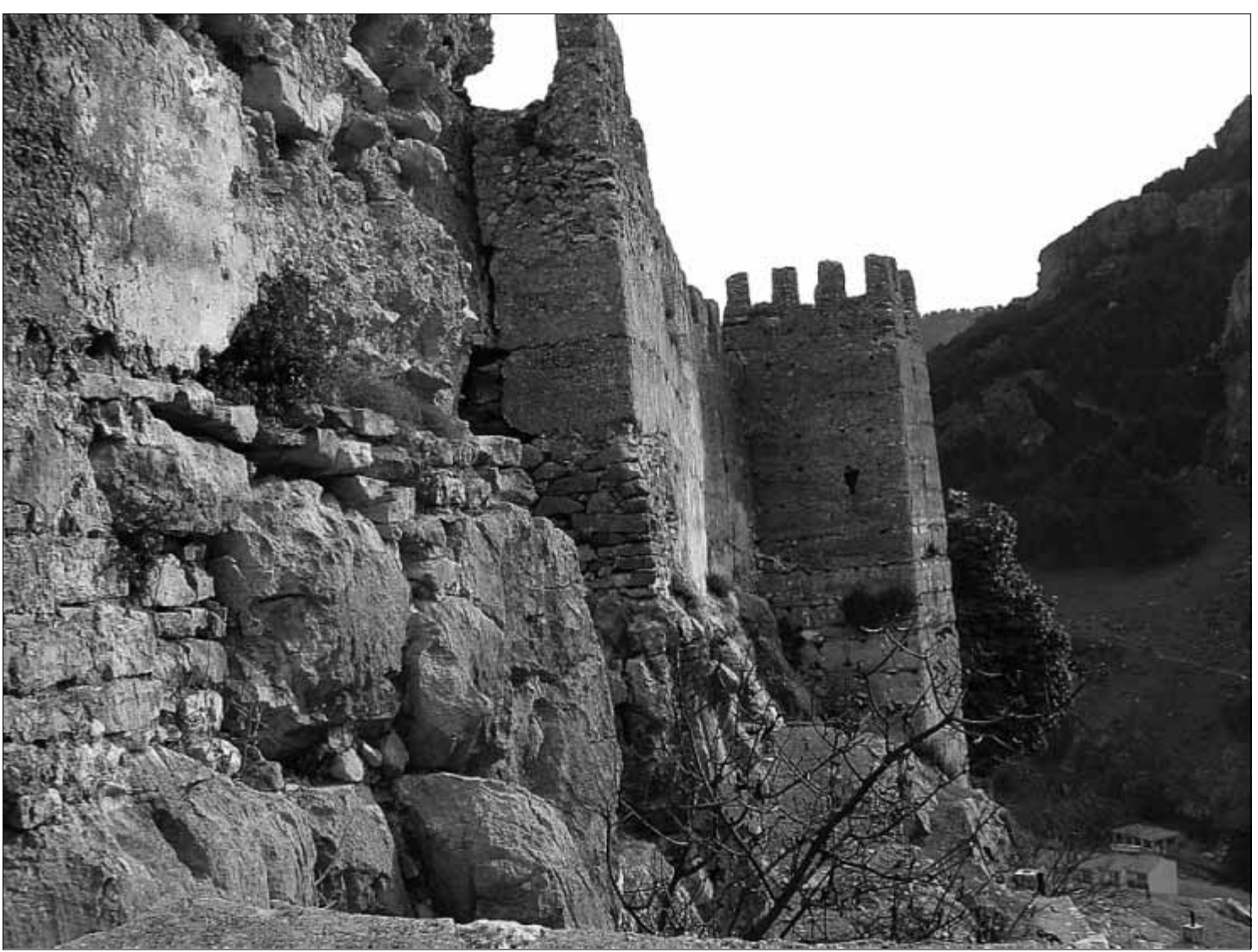




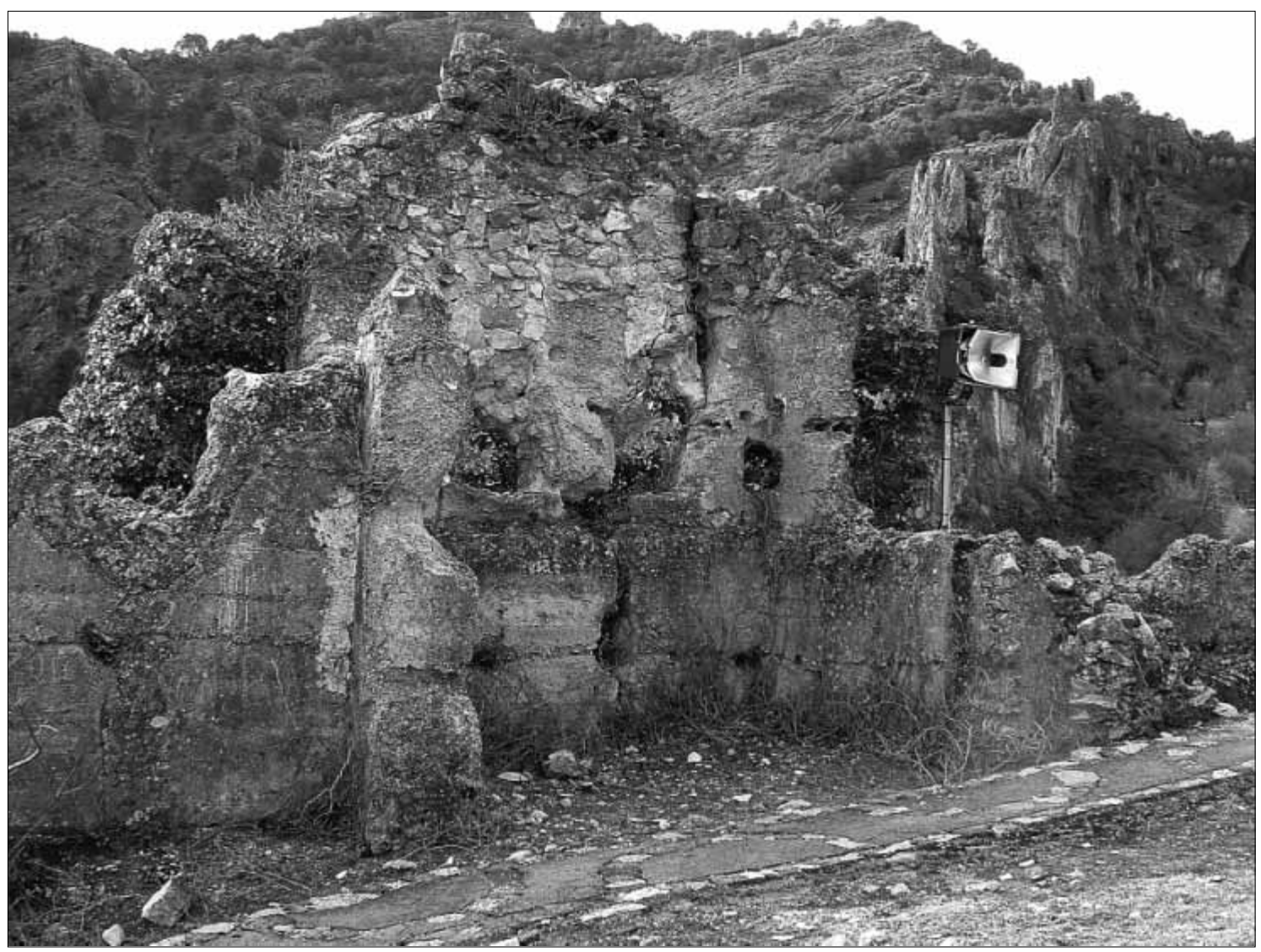

Lam. 59. Restos de la

Torre $V$ por al lado Norte

Lam. 60. Exterior de la Torre V

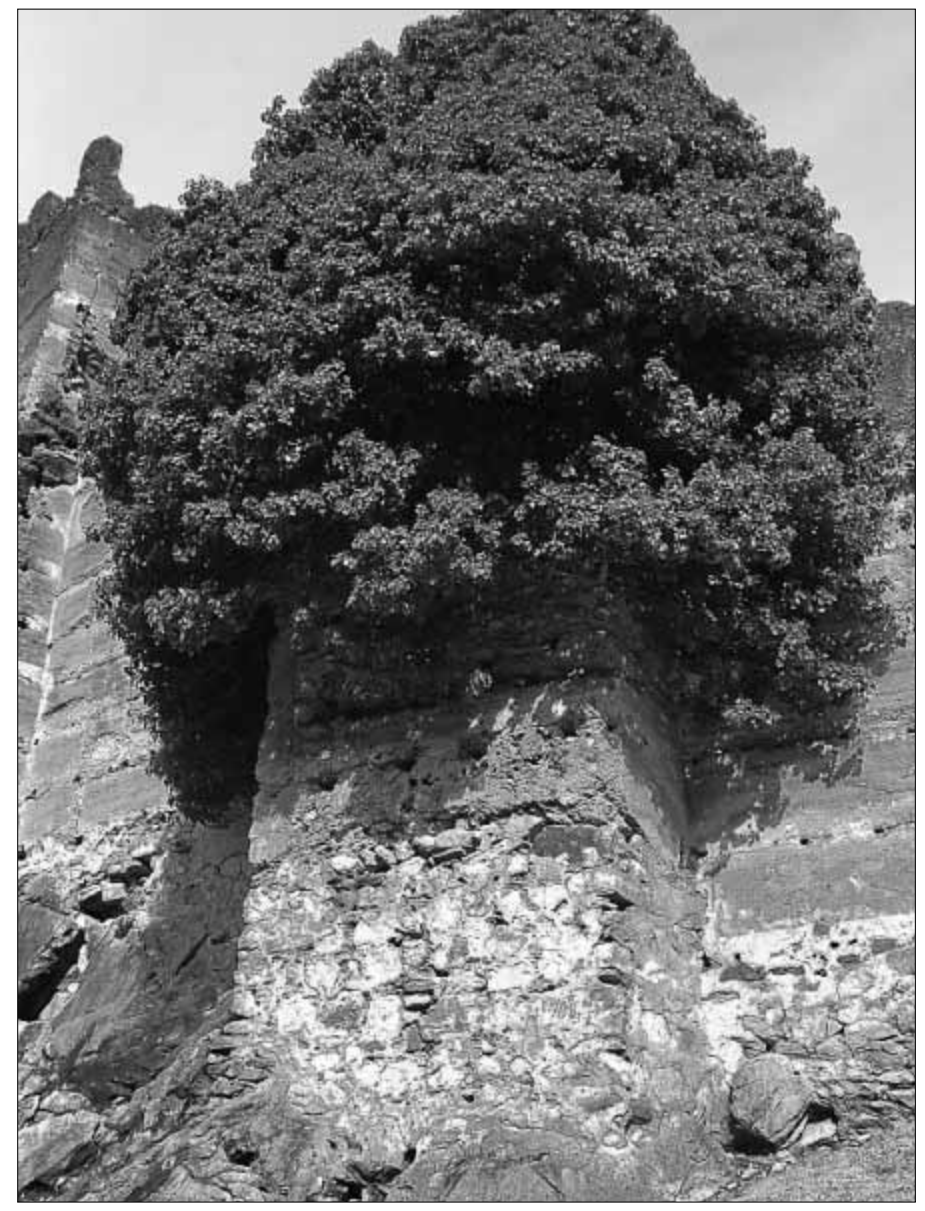




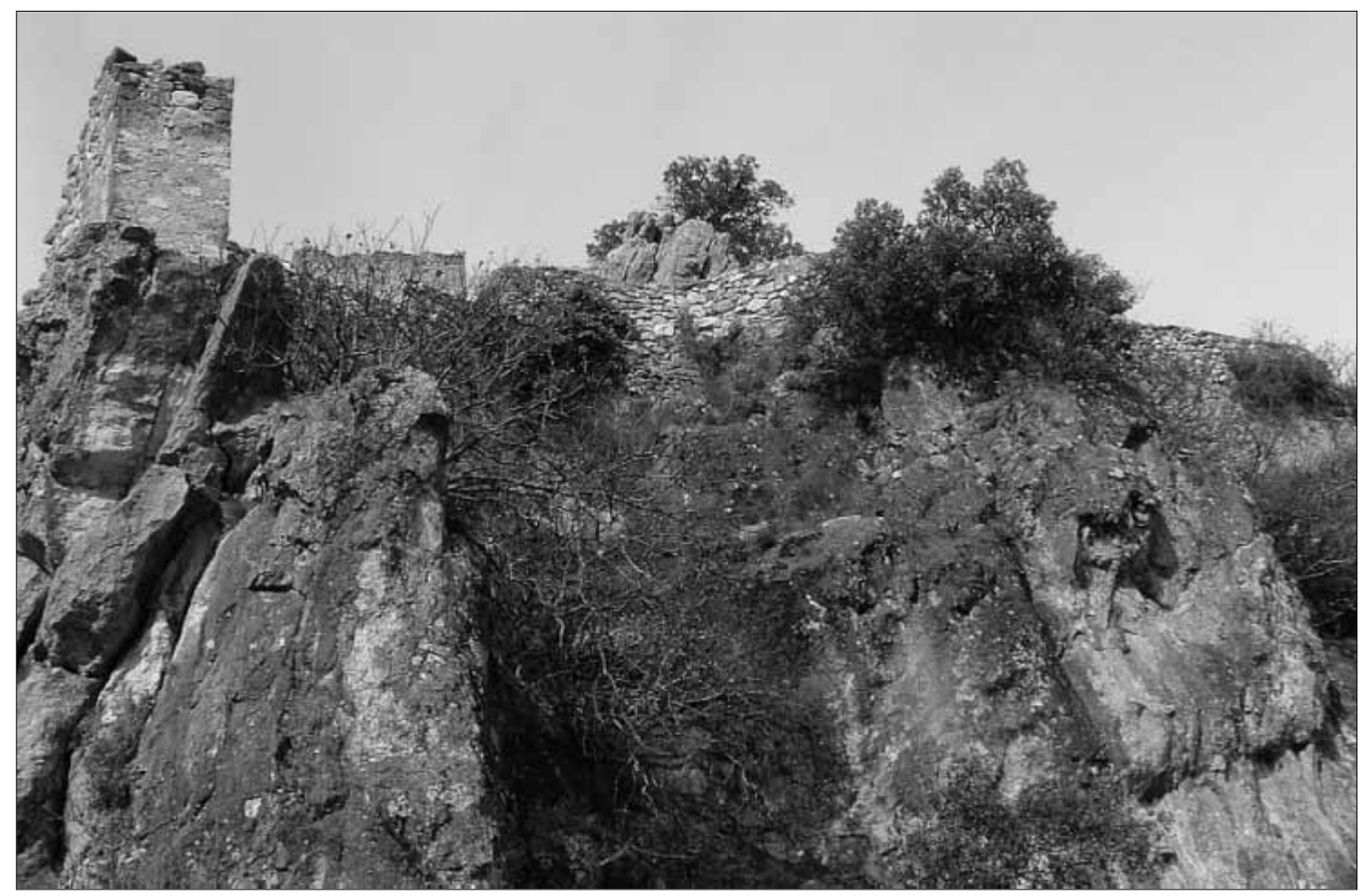

Lam. 6I. Precipicio del lado Este

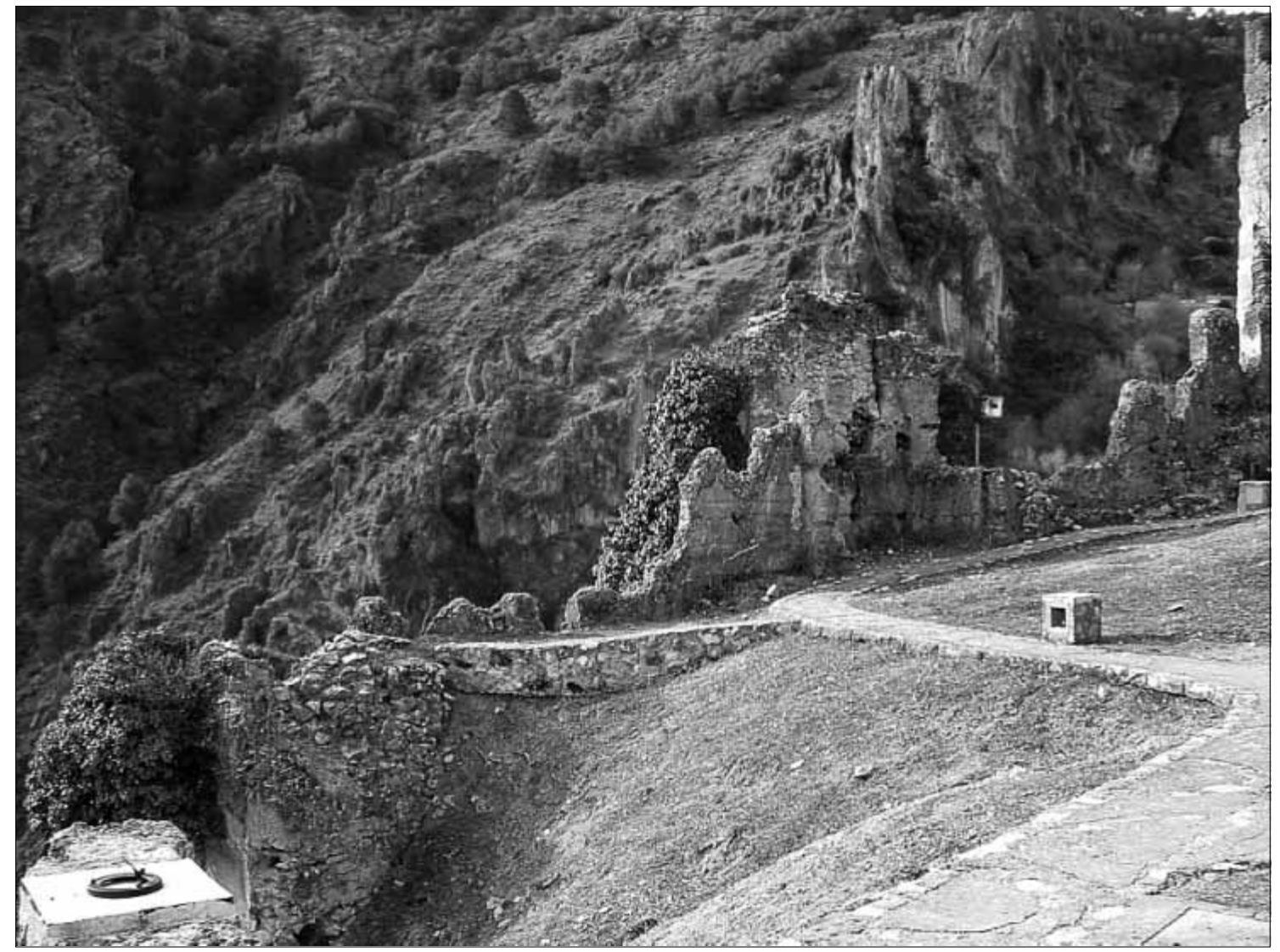

Lam. 62. Extremo Este de la muralla visto desde arriba. 


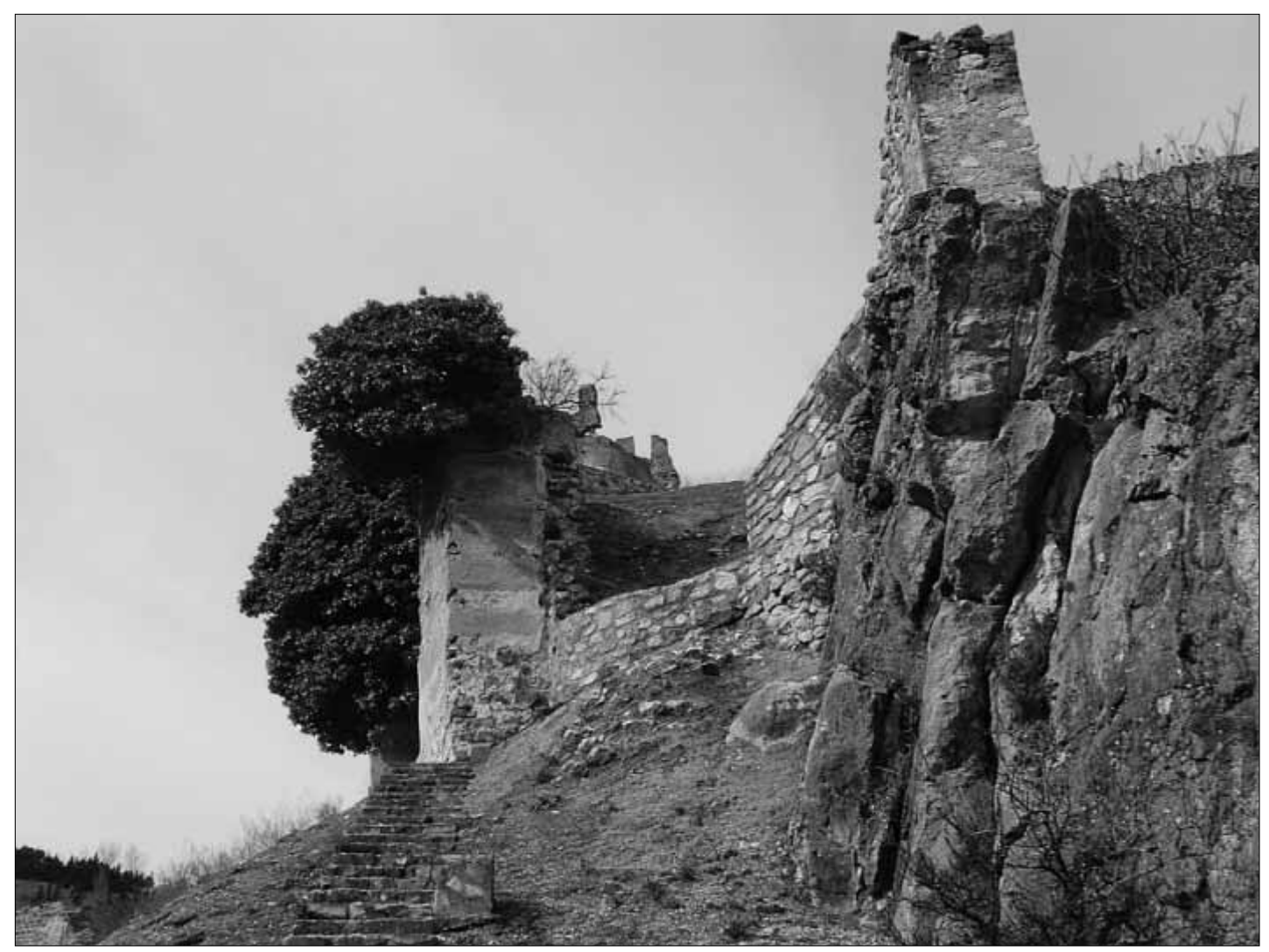

Lam. 63. Extremo Este de la muralla

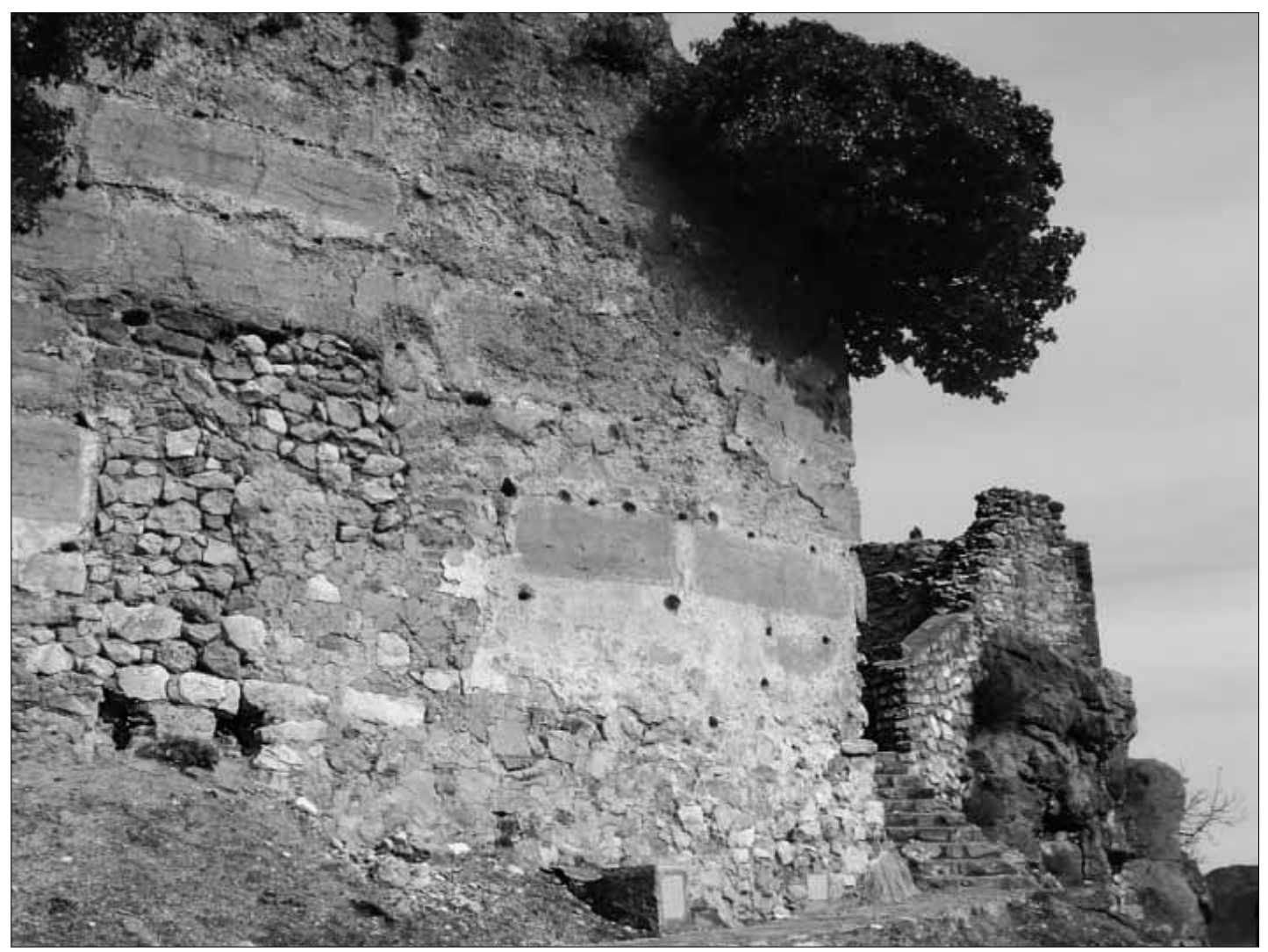

Lam. 64. Alteraciones en la muralla desde el Sur 


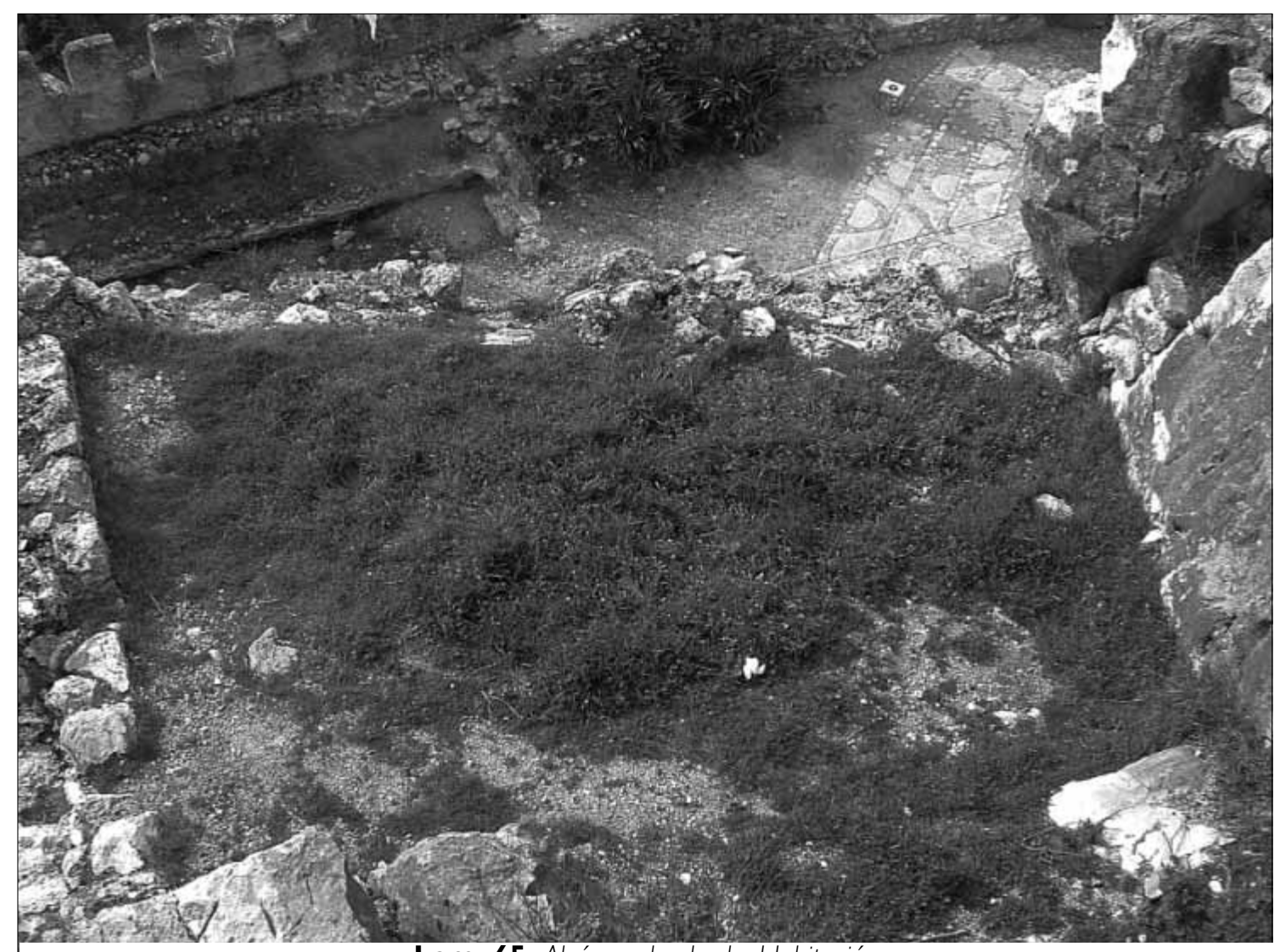

Lam. 65. Alcázar almohade. Habitación

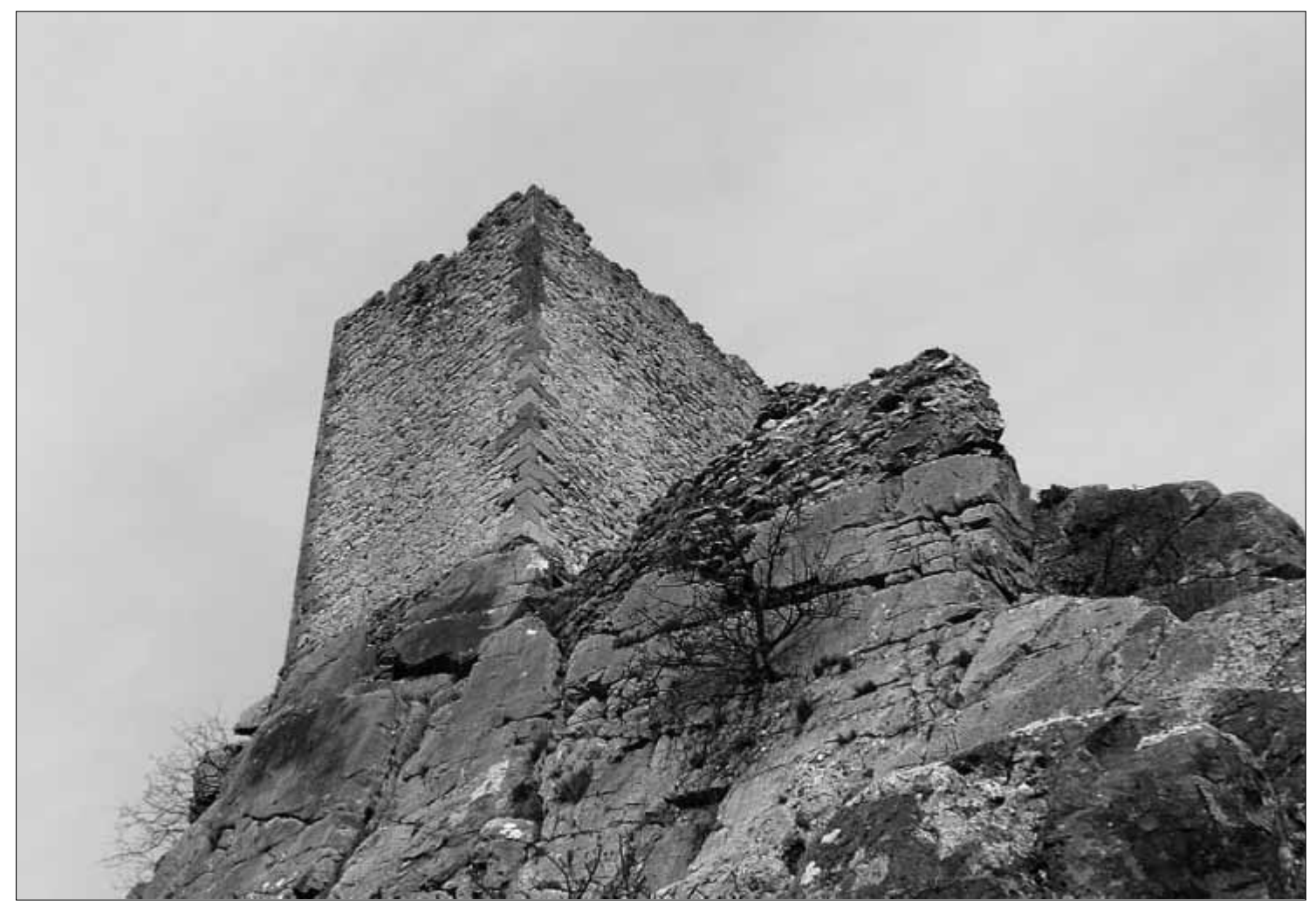

Lam. 66. Alcázar Almohade. Muro de la habitación desde el exterior 


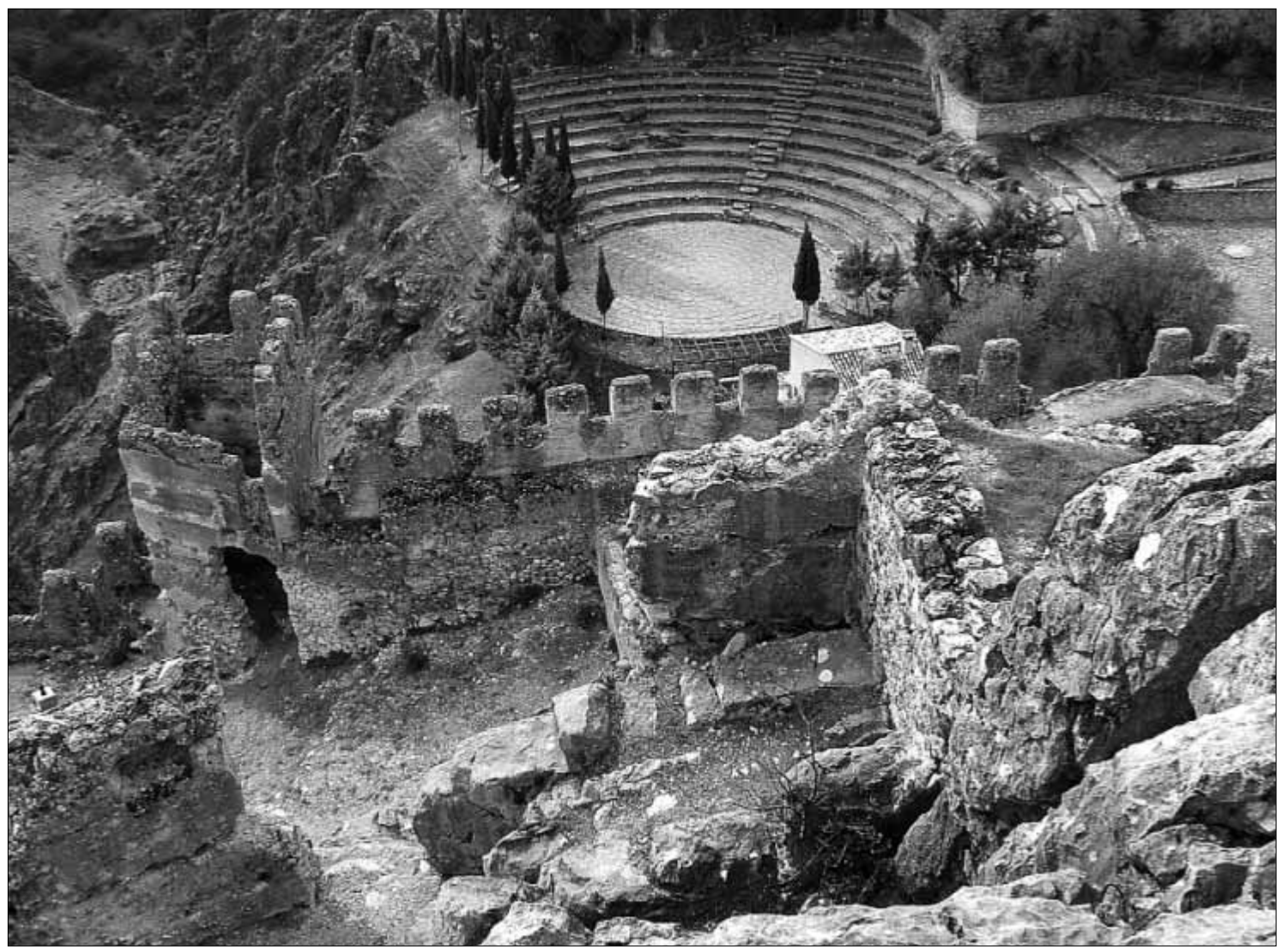

Lam. 67. Alcázar almohade. Recinto inferior

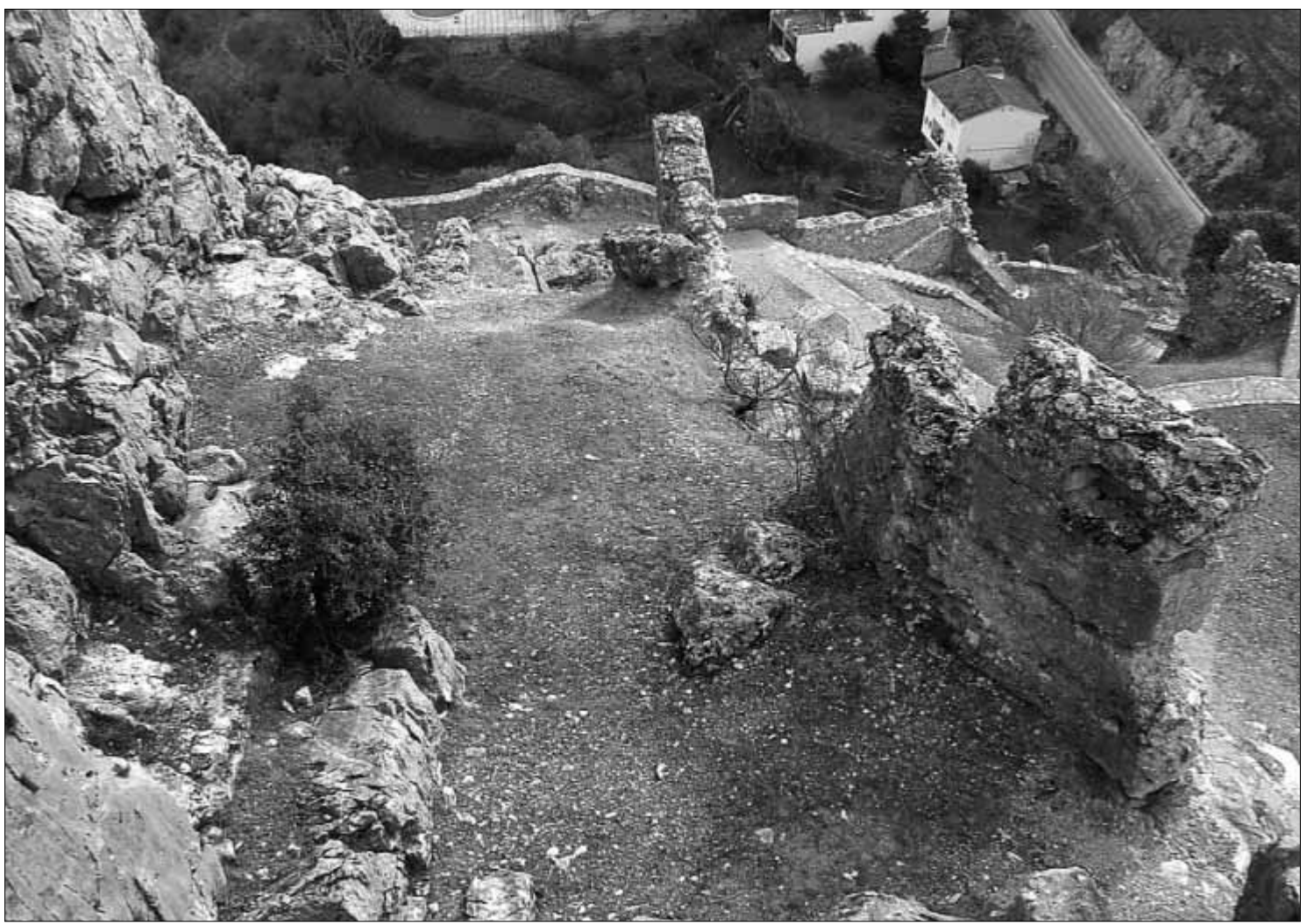

Lam. 68. Alcázar almohade. Recinto inferior 


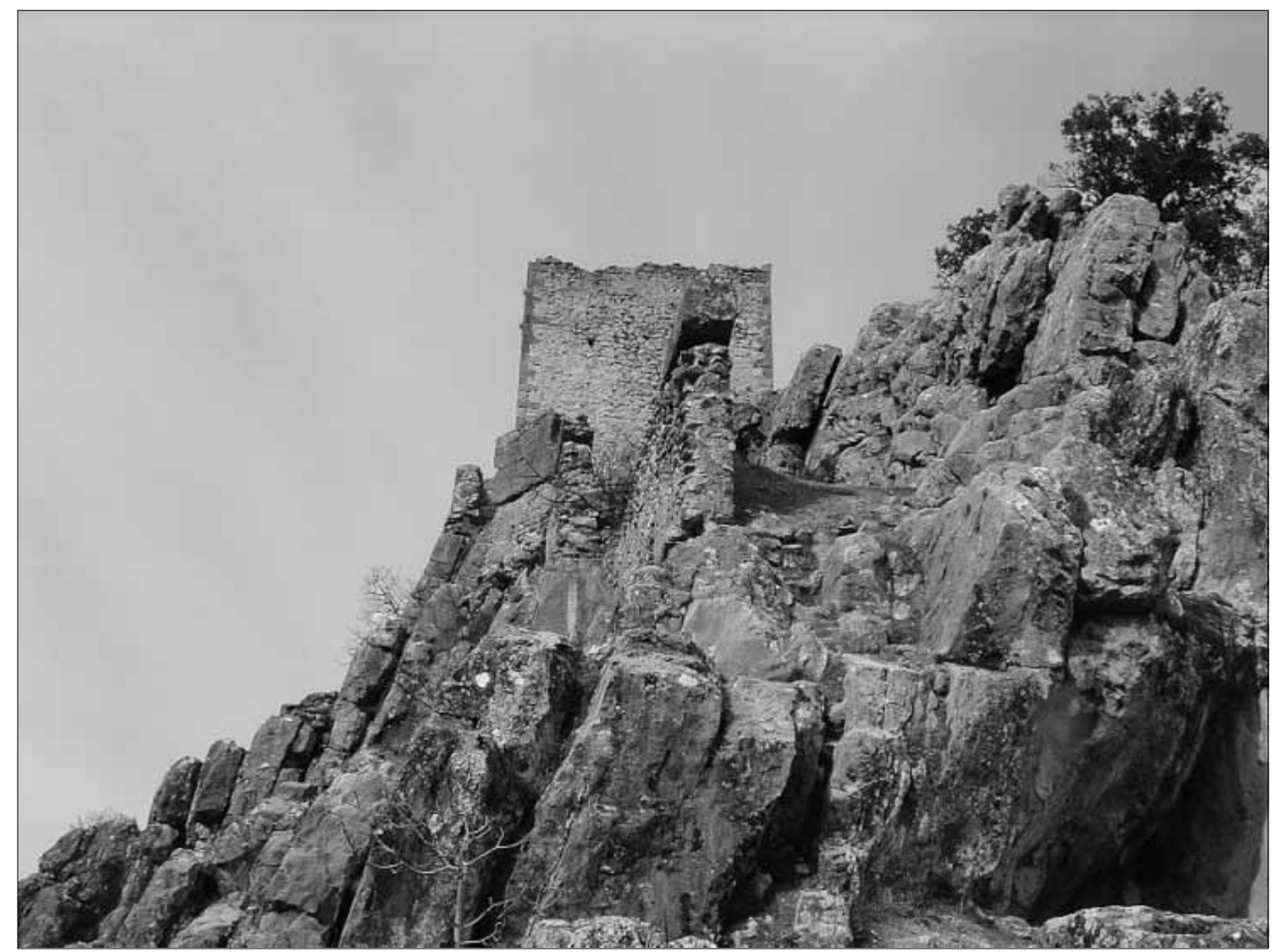

Lam. 69. Alcázar almohade. Recinto inferior

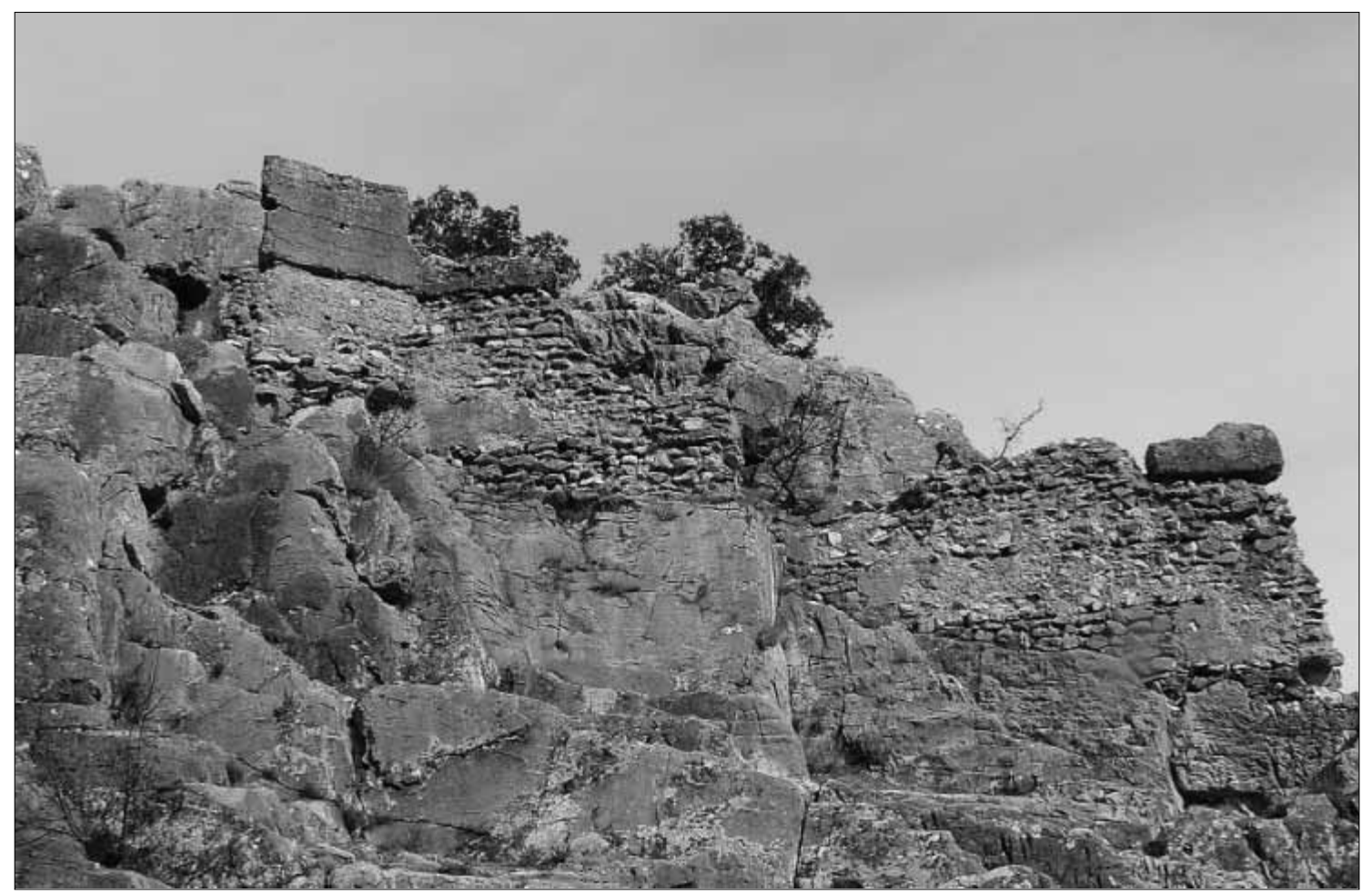

Lam. 70. Alcázar almohade. Recinto inferior 
Lam. 7I. Torre del picacho desde la población
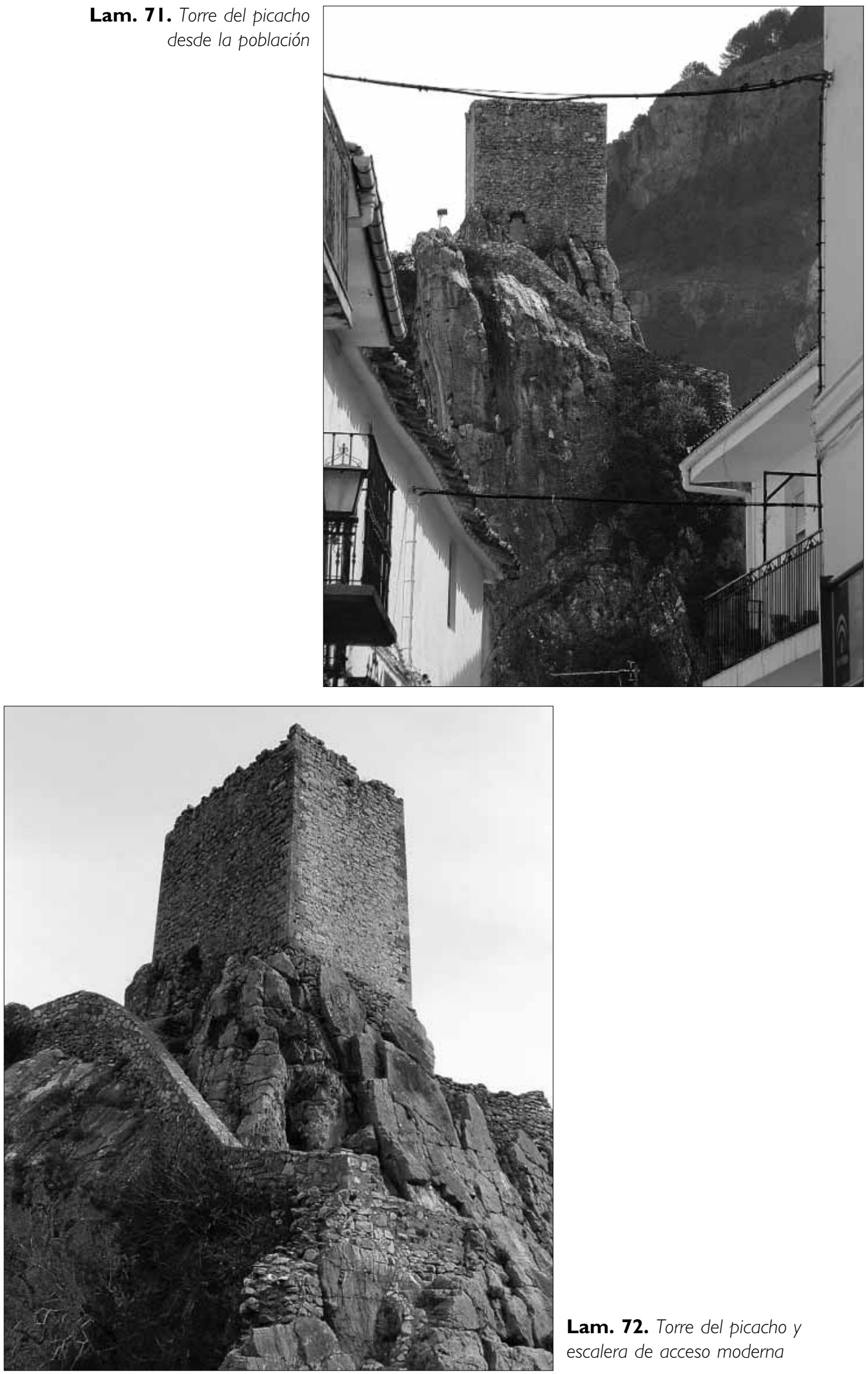

Lam. 72. Torre del picacho y escalera de acceso moderna 
Lam. 73. Torre del Picacho, interior y bóveda
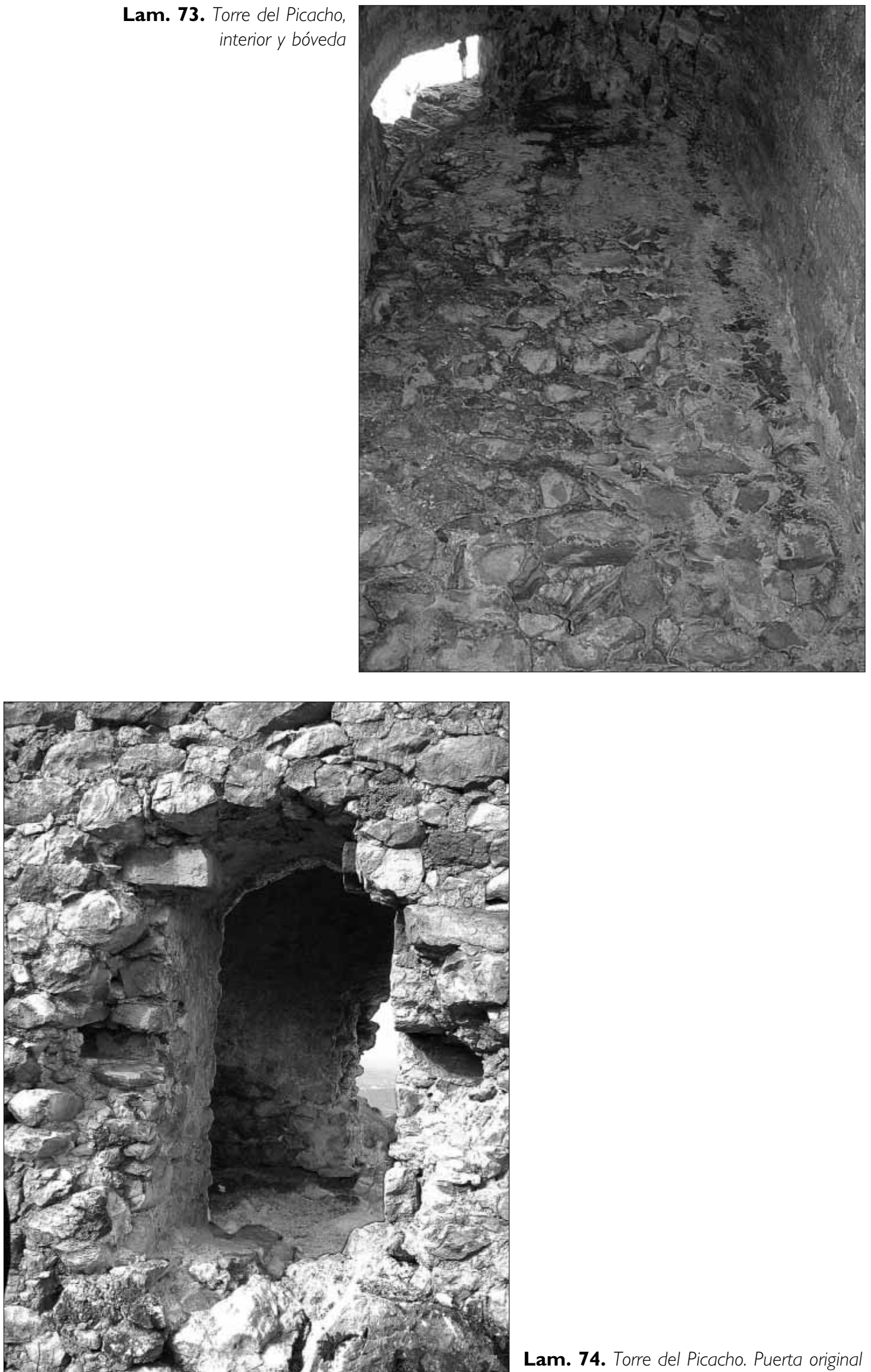

Lam. 74. Torre del Picacho. Puerta original 


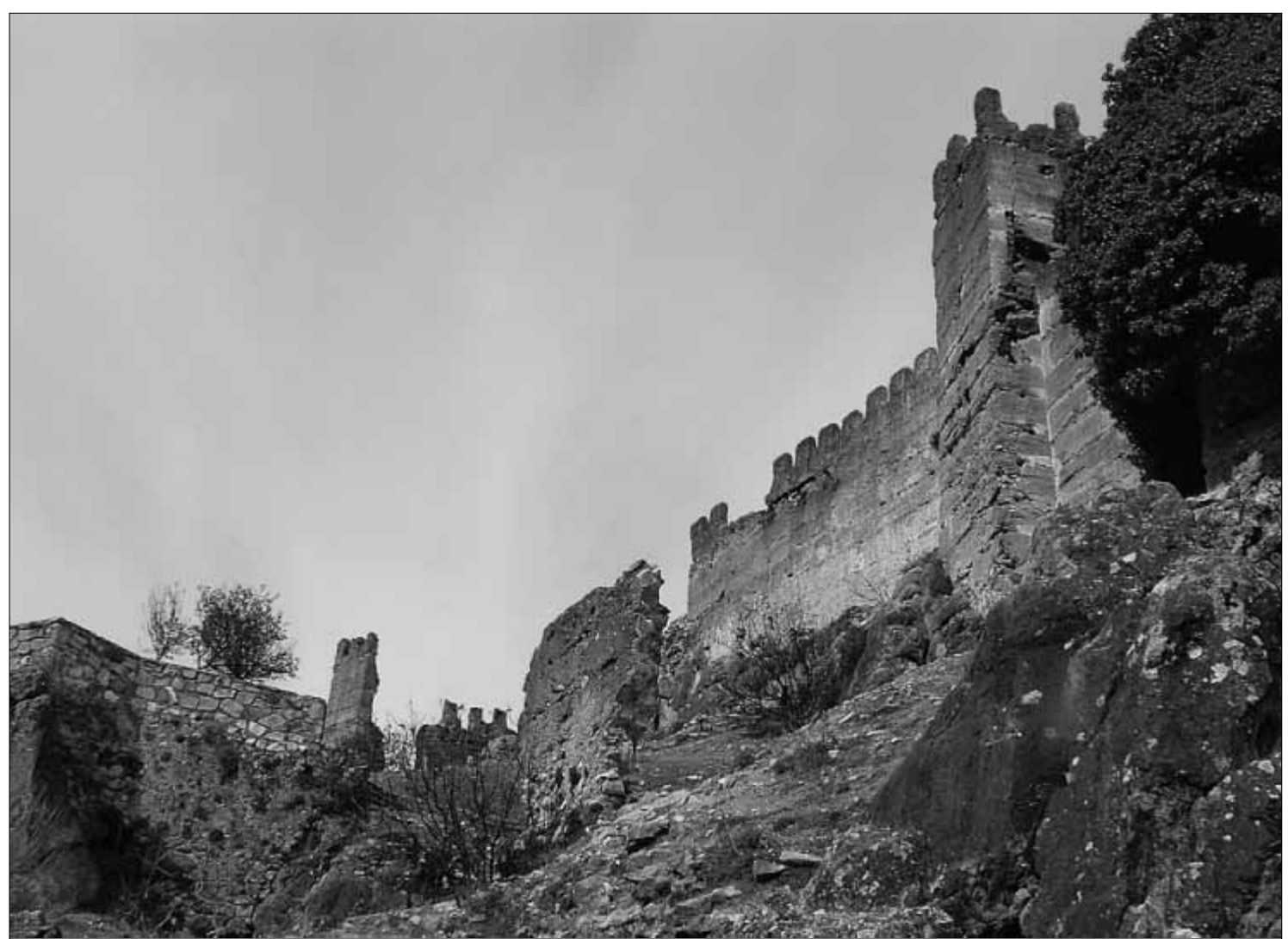

Lam. 75. Muro Sur desde el Sureste

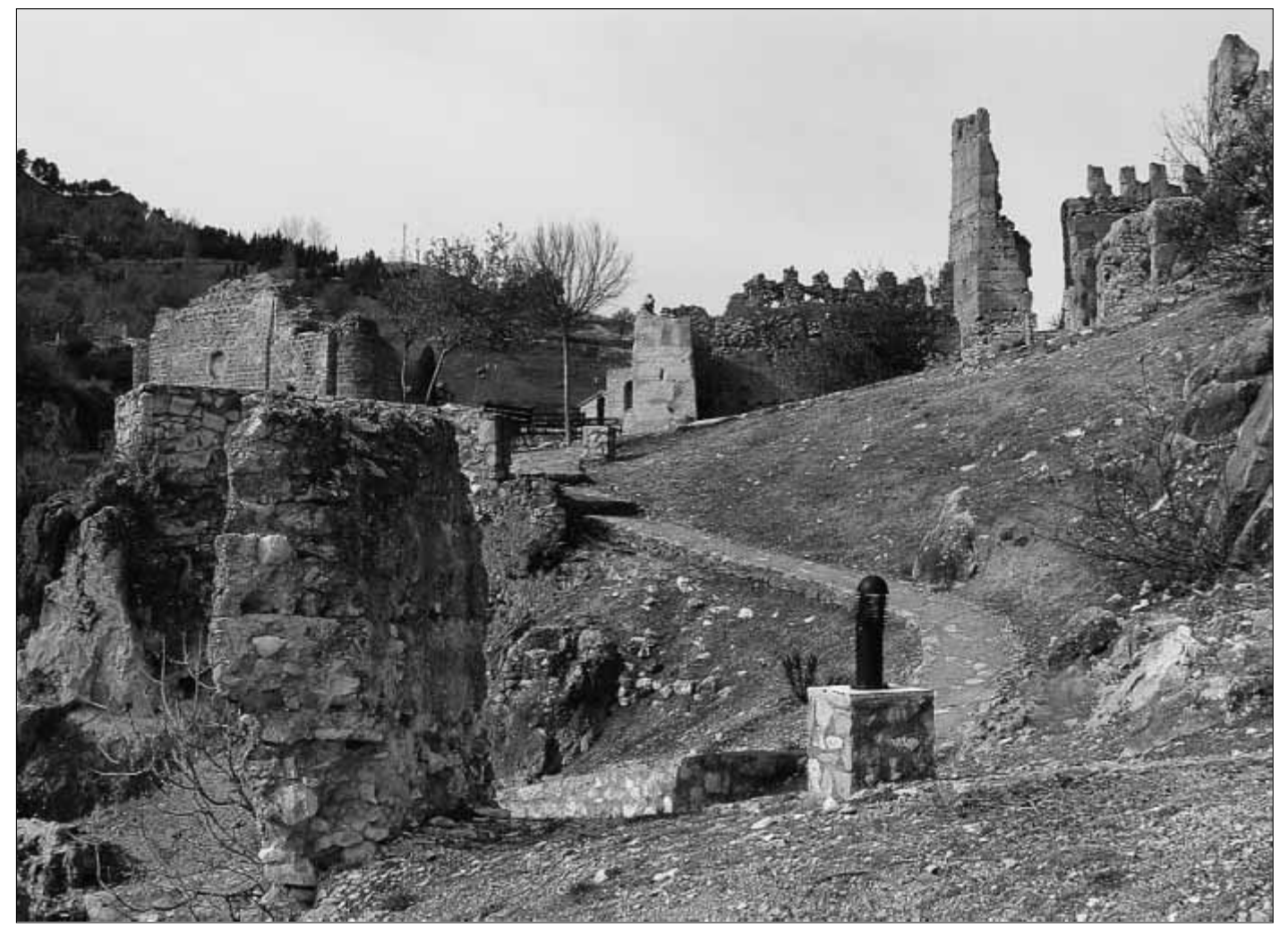

Lam. 76. Muro Sur. Detalle 
Lam. 77. Muro Sur junto a la Torre VI
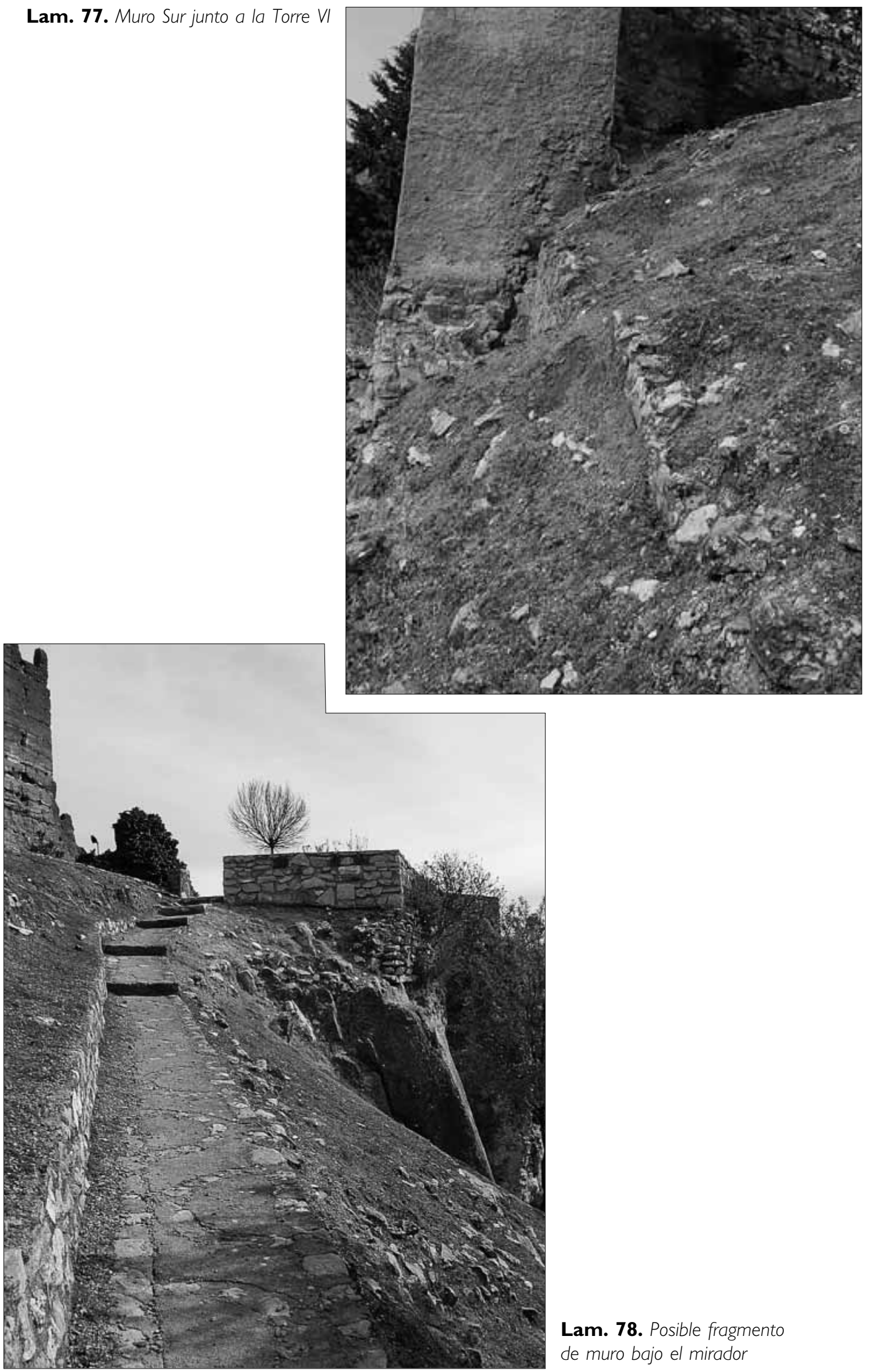

Lam. 78. Posible fragmento de muro bajo el mirador 


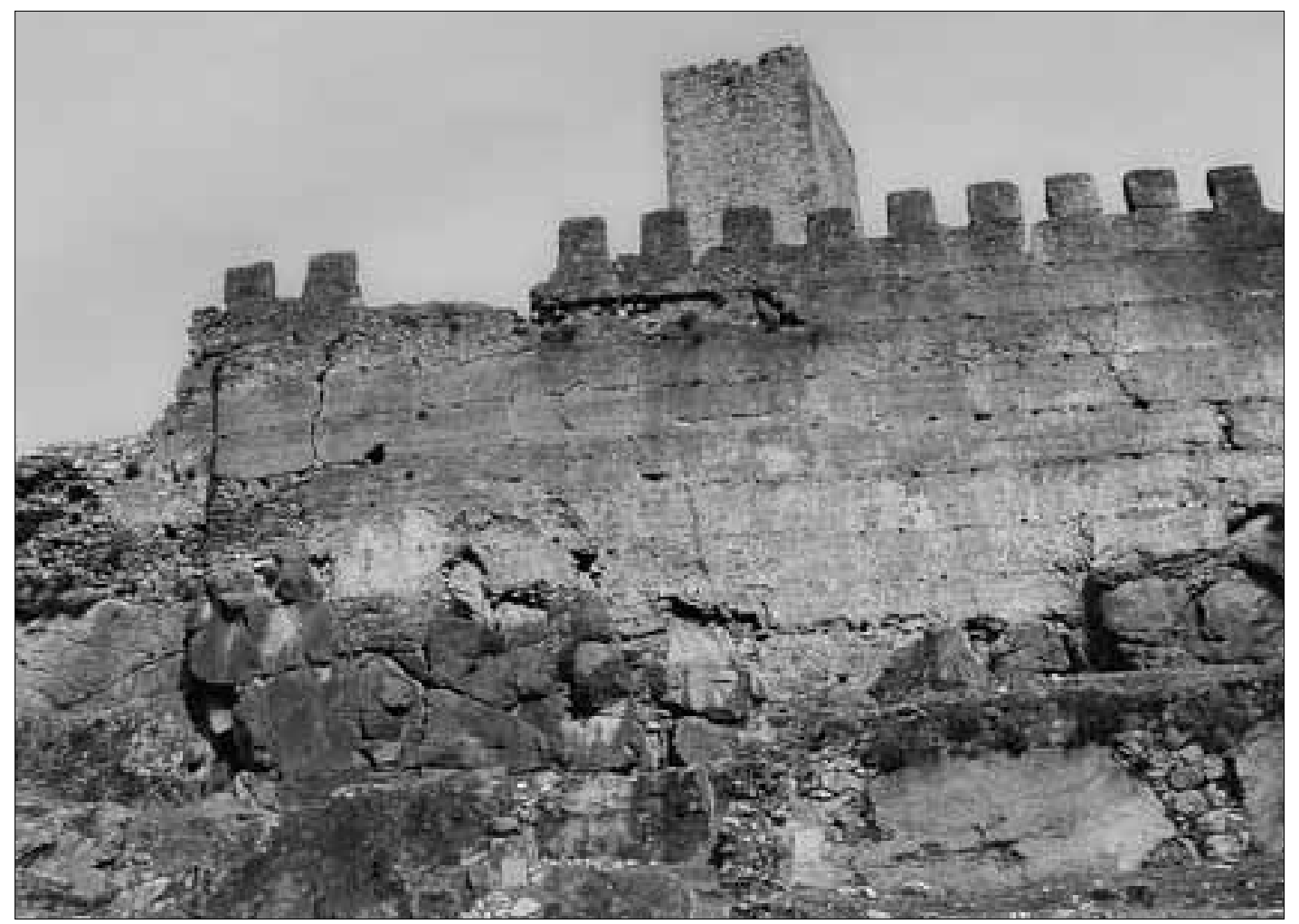

Lam. 79. Hipotética casa en el Recinto III. Vista general

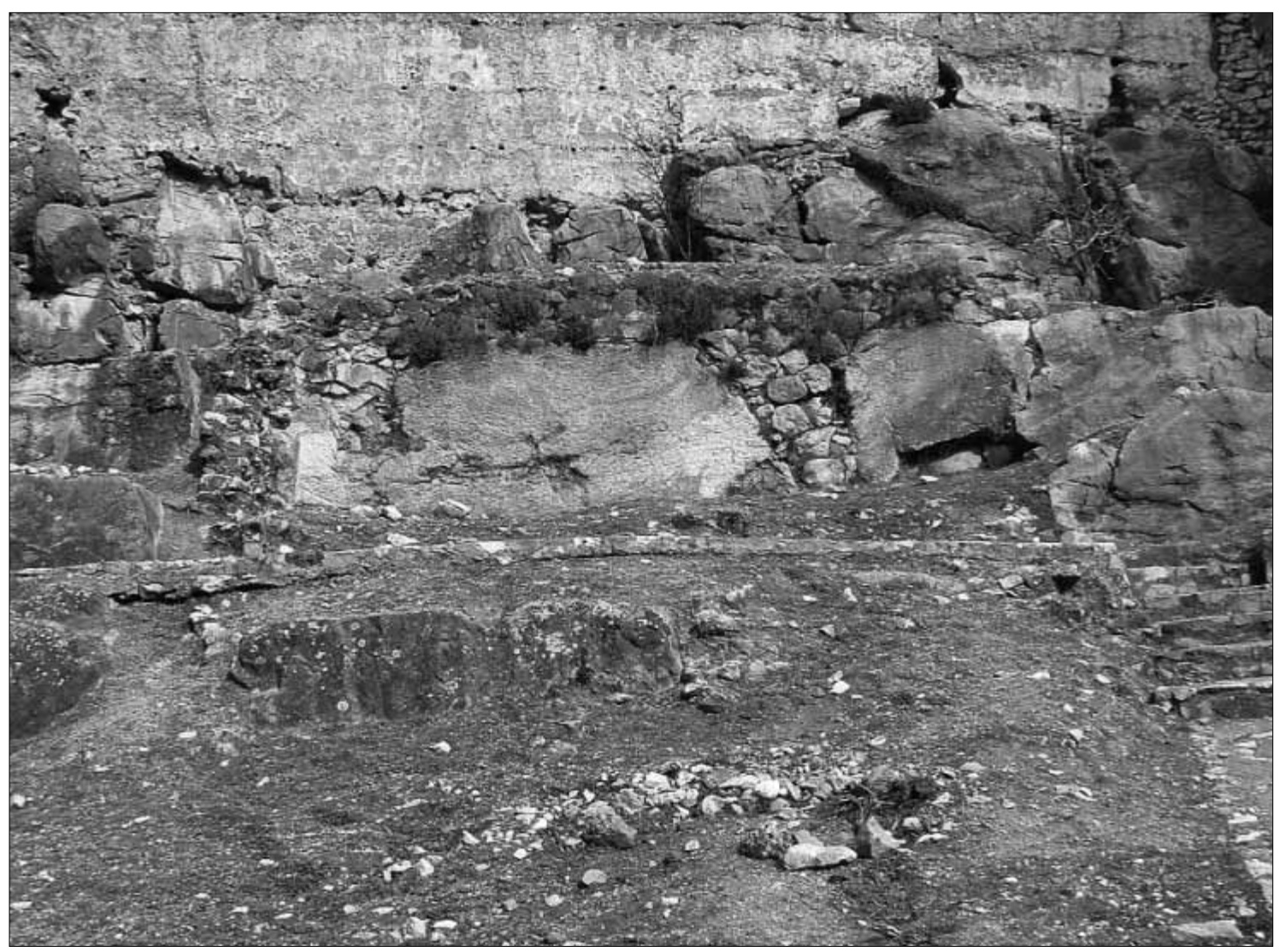

Lam. 80. Hipotética casa en el Recinto III. Detalle 